\title{
INFLUÊNCIA DO DESBASTE E DA ADUBAÇÃO NA QUALIDADE DA MADEIRA SERRADA DE Eucalyptus grandis Hill ex-Maiden
}

ISRAEL LUIZ DE LIMA

Tese apresentada à Escola Superior de Agricultura "Luiz de Queiroz", Universidade de São Paulo, para obtenção do título de Doutor em Recursos Florestais, com opção em: Tecnologia de Produtos Florestais.

\author{
PI RACI CABA \\ Estado de São Paulo - Brasil \\ Março - 2005
}




\title{
INFLUÊNCIA DO DESBASTE E DA ADUBAÇÃO NA QUALIDADE DA MADEIRA SERRADA DE Eucalyptus grandis Hill ex-Maiden
}

\author{
ISRAEL LUIZ DE LIMA \\ Engenheiro Florestal
}

Orientador: Prof. Dr. JOSÉ NIVALDO GARCIA

Tese apresentada à Escola Superior de Agricultura "Luiz de Queiroz", Universidade de São Paulo para obtenção do título de Doutor em Recursos Florestais, com opção em: Tecnologia de Produtos Florestais.

P I R A C I C A BA

Estado de São Paulo - Brasil

Março - 2005 
Dados Internacionais de Catalogação na Publicação (CIP) DIVISÃO DE BIBLIOTECA E DOCUMENTAÇÃO - ESALQ/USP

\section{Lima, Israel Luiz de}

Influência do desbaste e da adubação na qualidade da madeira serrada de Eucalyptus grandis Hill ex-Maiden / Israel Luiz de Lima. - - Piracicaba, 2005.

$137 \mathrm{p}$.

Tese (doutorado) - - Escola Superior de Agricultura Luiz de Queiroz, 2005. Bibliografia.

1. Desbaste 2. Eucalipto 3. Fertilizante 4. Madeira serrada 5. Manejo 6. Rachadura 7. Tecnologia da madeira I. Título

CDD 674.142 
A Deus

OFEREÇO.

Aos meus pais e aos meus irmãos,

DEDICO. 


\section{AGRADECIMENTOS}

Ao Prof. Dr. José Nivaldo Garcia, pela valiosa orientação, amizade e incentivos constantes que permitiram a realização deste trabalho.

Ao Prof. Dr. José Luiz Stape, pelas sugestões e contribuições apresentadas na amostragem e desenvolvimento do trabalho.

A pesquisadora Prof ${ }^{a}$. Dr ${ }^{a}$. Sônia Maria de Stefano Piedade, pelas assessorías recebidas durante o desenvolvimento dos procedimentos estatísticos utilizados neste trabalho.

Ao Prof. Dr. Geraldo Bortoleto Jr. pelas sugestões e contribuições apresentadas, no Exame Geral de Qualificação , o qual atuou como membro titular.

Aos Professores do Departamento de Ciências Florestais da ESALQ/USP, pelos ensinamentos recebidos.

Aos colegas de pós-graduação, pela agradável convivência durante o curso.

Aos Funcionários do Departamento de Ciências Florestais da ESALQ/USP, pela atenção e amizade, especialmente ao licenciado em Química Luis Eduardo Facco pela amizade, dedicação no apoio experimental.

Ao Eng. Ezer Dias de Oliveira Jr. , pela contribuição na coleta de dados. 
As empresas RIPASA S/A Celulose e Papel Ltda e CAF Florestal e a seus funcionários, pelo fornecimento do material de estudo e o inestimável apoio logístico que propiciou o pleno desenvolvimento do presente trabalho.

Ao IPEF (Instituto de Pesquisas e Estudos Florestais), pela bolsa de PósGraduação concedida.

Ao Instituto Florestal do Estado de São Paulo, pela concessão do afastamento temporário que possibilitou a conclusão do presente trabalho.

A todos que contribuíram de forma direta ou indireta, para a realização deste trabalho. 


\section{S U M Á R I O}

Página

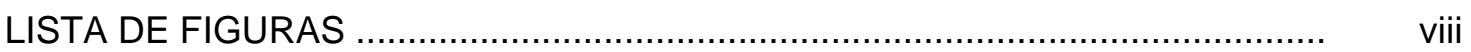

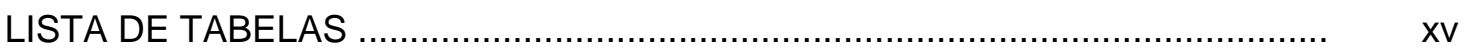

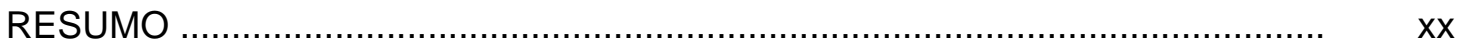

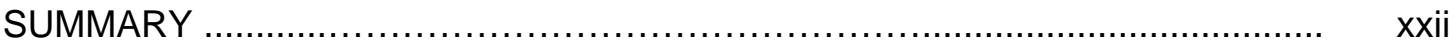

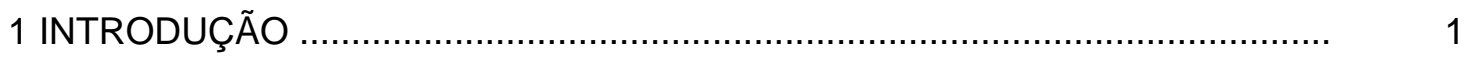

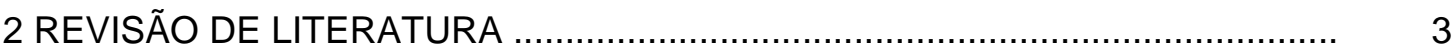

2.1 Potencial do uso da madeira serrada de eucalipto ........................................ 3

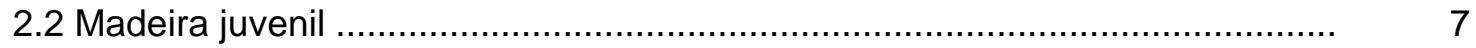

2.3 Tensão de crescimento .......................................................................... 12

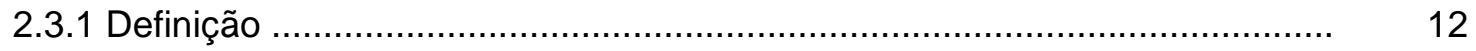

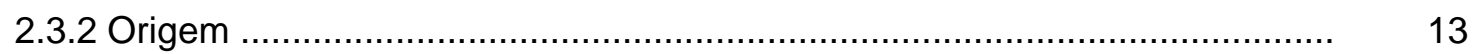

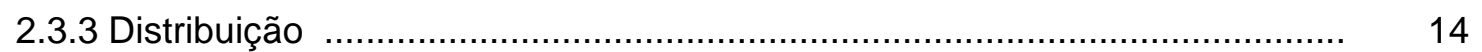

2.3.4 Efeitos da tensão de crescimento ................................................................ 16

2.3.5 Variabilidade dos efeitos da tensão de crescimento .................................... 19

2.3.6 Variação genética ................................................................................ 20

2.4 Influência de práticas silviculturais na qualidade madeira de eucalipto ............ 22

2.4.1 Influência de práticas silviculturais nas propriedades físicas e mecânica da madeira de eucalipto.......................................................................... 23

2.4.2 Influência de práticas silviculturais na tensão de crescimento ....................... 32

3 MATERIAL E MÉTODOS ............................................................................ 34

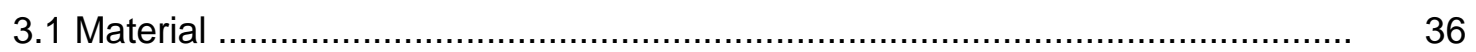

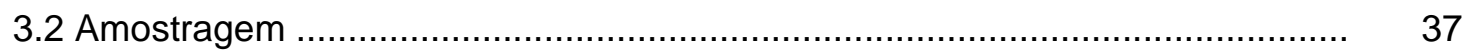

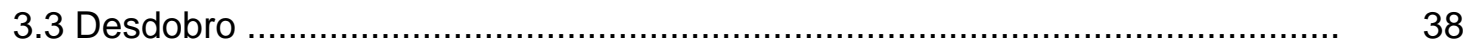

3.4 Obtenção de dados e ensaios realizados ................................................... 42 
3.4.1 Deslocamento da medula (DM) …......................................................... 42

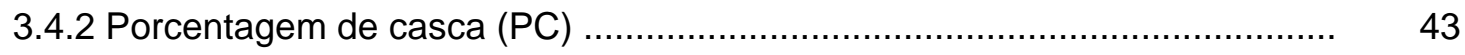

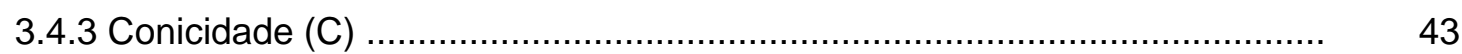

3.4.4 Índice de rachaduras de topo de tora (IRTT) .............................................. 44

3.4.5 Rachadura de extremidade de tábua serrada ............................................ 45

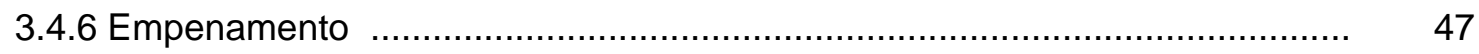

3.4.7 Módulo de elasticidade estrutural (MOEe) …........................................... 50

3.4.8 Rendimento em madeira serrada ................................................................... 54

3.4.9 Classificação de tábua seca ..................................................................... 56

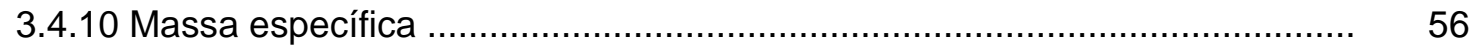

3.5 Análise estatística ................................................................................. 58

4 RESULTADOS E DICUSSÃO …............................................................. 62

4.1 Deslocamento da medula (DM) .................................................................. 62

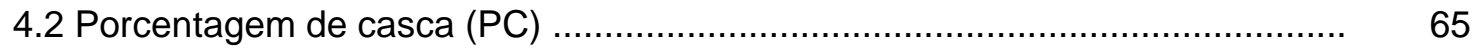

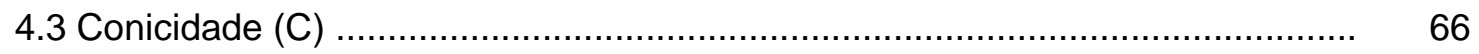

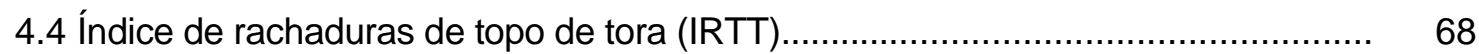

4.5 Índice de rachaduras de extremidade de tábua verde (IRPV) ........................... 70

4.6 Índice de rachaduras de extremidade de tábua seca (IRPS) ............................ 74

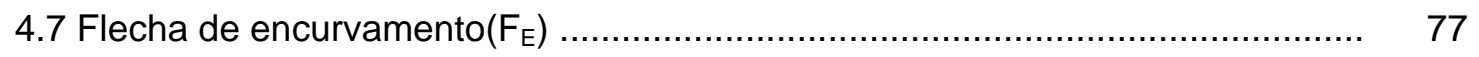

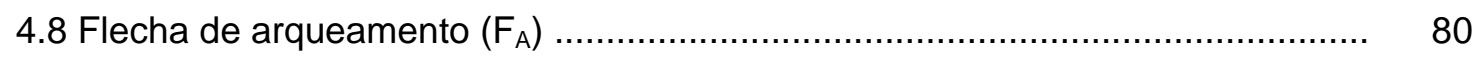

4.9 Módulo de Elasticidade em flexão estática (MOEe) …........................................ 86

4.10 Rendimento em madeira serrada …....................................................... 87

4.11 Classificação de tábuas serradas ............................................................ 89

4.12 Massa específica ...................................................................................... 92

4.13 Estudo de correlações entre as variáveis .................................................... 98

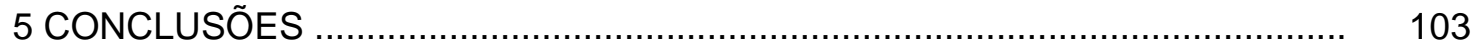

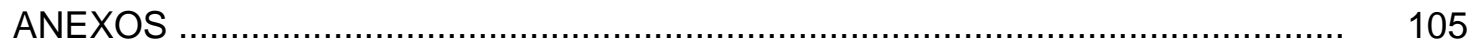

REFERÊNCIAS BIBLIOGRÁFICAS ............................................................ 125 


\section{LISTA DE FIGURAS}

Página

1 Perfil densitométrico da madeira de E. grandis, na direção medula-casca

2 Orientação das microfibrilas nas camadas $S_{1}, S_{2}$ e $S_{3}$ da parede celular típica de uma fibra

3 Representação gráfica da distribuição teórica das tensões de crescimento no sentido longitudinal (cor negra em tração e cinza em compressão), a diferentes níveis em árvores de diâmetro diferentes)

4 Distribuições de tensões de crescimento no sentido longitudinal ao longo do raio de uma árvore de $60 \mathrm{~cm}$ de diâmetro, segundo os modelos de Kubler (1959) e Garcia (1995)

5 Tipos de rachaduras de topo de tora

6 Rachadura de extremidade de tábuas serradas

7 Gráfico de densidade básica (DB) versus tipo de crescimento para, E. grandis, aos 8,5anos de idade

8 Gráfico de densidade básica versus distância da medula 
10 Seqüência de cortes para obtenção da prancha diametral isenta da rachadura longitudinal de medula das toras nas árvores

11 Esquema de desdobro comercial efetuado para liberação equilibrada de tensões

12 Cortes simultâneos de 2 costaneiras na serra de fita dupla, produzindo um semi-bloco (a) e Corte múltiplo do semi-bloco numa serra circular múltipla (b)

13 Variáveis que expressam o deslocamento da medula na seção transversal da tora

14 Geometria de uma tora cônica, mostrando o ângulo ( $\alpha$ ) formado entre a direção da fibra e o eixo da peça serrada, quando obtida por cortes paralelos à medula

15 Tábua verde com rachaduras de extremidades

16 Tábua seca com rachaduras de extremidades

17 Vista do encurvamento e da variável flecha de encurvamento $\left(F_{E}\right)$

18 Vista do arqueamento e da variável flecha de arqueamento $\left(F_{A}\right)$

19 Teste de deflexão de campo, não destrutivo, para determinação do MOE estrutural

20 Prancha central representando as posições radiais de retiradas dos corpos de prova para estudo da variabilidade radial posição radial

21 Representação do corpo de prova utilizado na determinação da massa específica da madeira 
22 Deslocamento da medula (DM) na tora 2 de $E$.grandis de 21 anos de idade ..

23 Deslocamento da medula (DM) na tora 3 de $E$.grandis de 21 anos de idade..

24 Porcentagem de casca (PC) na tora 2 de E.grandis de 21 anos de idade 65

25 Porcentagem de casca (PC) na tora 3 de E.grandis de 21 anos de idade 66

26 Conicidade $(\mathrm{C})$ na tora 2 de E.grandis de 21 anos de idade

27 Conicidade (C) na tora 3 de E.grandis de 21 anos de idade.

28 Índice de rachaduras de topo de tora (IRTT) de E.grandis de 21 anos de idade na tora 2

29 Índice de rachaduras de topo de tora (IRTT) de E.grandis de 21 anos de de idade na tora 3

30 Índice de rachaduras de extremidade de tábua verde (IRPV) de E. grandis de 21 anos de idade na posição $0 \%$ (a) na posição $50 \%$ (b) e na posição $100 \%$ (c) do raio da tora

31 Índice de rachaduras de extremidade de tábua verde (IRPV) de E.grandis de 21 anos de idade em função da intensidade de desbaste (a) e da adubação (b) 
32 Índice de rachaduras de extremidade de tábua seca (IRPS) de E. grandis de 21 anos de idade na posição $0 \%$ (a) na posição 50\% (b) e na posição $100 \%$ (c) do raio da tora

33 Índice de rachaduras de extremidade de tábua seca (IRPS) de E.grandis, de 21 anos de idade em função da intensidade de desbaste (a) e da adubação (b)

34 Flecha de encurvamento $\left(F_{E}\right)$ de $E$. grandis de 21 anos de idade na posição 0\% (a) na posição $50 \%$ (b) e na posição $100 \%$ (c) do raio da tora

35 Flecha de encurvamento $\left(F_{E}\right)$ em E.grandis de 21 anos de idade em função da intensidade de desbaste (a) e da adubação (b)

36 Flecha de arqueamento $\left(F_{A}\right)$ de $E$. grandis de 21 anos de idade na posição 0\% (a) na posição $50 \%$ (b) e na posição $100 \%$ (c) do raio da tora

37 Flecha de arqueamento $\left(F_{A}\right)$ de E.grandis de 21 anos de idade em função da intensidade de desbaste (a) e da adubação (b)

38 Relação entre a carga $(F)$ e o deslocamento (f) para a tábua central, (posição $0 \%$ do raio) da tora 2 pertencente à classe superior da intensidade de $37 \%$ de desbaste sem adubação, de E.grandis de 21 anos de idade 
39 Módulo de Elasticidade estrutural na flexão estática (MOEe) de E. grandis de 21 anos de idade na posição $0 \%$ (a) na posição $50 \%$ (b)e na posição $100 \%$ (c) do raio da tora

40 Módulo de Elasticidade estrutural na flexão estática (MOEe) de E.grandis de 21 anos de idade em função da intensidade de desbaste (a) e da adubação (b)

41 Rendimento em madeira serrada de E.grandis de 21 anos de idade na classe superior em função da intensidade de desbaste (a) da adubação (b)

42 Rendimento em madeira serrada de E.grandis de 21 anos de idade na classe média em função da intensidade de desbaste (a) da adubação (b)

43 Freqüência percentual de tábuas serradas secas por classe de qualidade em função da intensidade de desbaste de E.grandis de 21 anos de idade

44 Freqüência porcentual de tábuas serradas secas por classe de qualidade em função da adubação e classe de DAP de E.grandis de 21 anos de idade..

45 Freqüência porcentual de tábuas serradas secas por classe de qualidade em função da posição relativa do raio de E.grandis de 21 anos de idade

46 Massa específica à umidade de equilíbrio ao $\operatorname{ar}(\mathrm{ME})$ da madeira de $E$. grandis de 21 anos de idade na posição radial (0\%) 
47 Massa específica à umidade de equilíbrio ao ar (ME) da madeira de $E$. grandis de 21 anos de idade na posição radial (25\%) 94

48 Massa específica à umidade de equilíbrio ao ar (ME) da madeira de $E$. grandis de 21 anos de idade na posição radial (50\%)

49 Massa específica à umidade de equilíbrio ao ar (ME) da madeira de $E$. grandis de 21 anos de idade na posição radial (75\%)

50 Massa específica à umidade de equilíbrio ao ar (ME) da madeira de $E$. grandis de 21 anos de idade na posição radial (100)

51 Massa específica (ME) de E.grandis de 21 anos de idade em função da intensidade de desbaste (a) e da adubação (b)

52 Relação entre índice de rachaduras de extremidade de tábua seca (IRTS) e índice de rachaduras de topo de tora (IRTT) para E. grandis de 21 anos de idade

53 Relação entre conicidade $(C)$ e porcentagem de casca $(P C)$ para E. grandis de 21 anos de idade

54 Relação entre índice de rachaduras de extremidade de tábua verde (IRTV) e índice de rachaduras de topo de tora (IRTT) para E. grandis de 21 anos de idade

55 Relação entre rendimento em madeira serrada verde sem destopo (RVSD) e rendimento em madeira serrada seca com destopo (RS) para E. grandis de 21 anos de idade 
56 Relação entre rendimento em madeira serrada verde com destopo (RVCD) e rendimento em madeira serrada verde sem destopo (RVSD) para $E$. grandis

de 21 anos de idade

57 Relação entre índice de rachaduras de extremidade de tábua seca (IRTS) e índice de rachaduras de extremidade de tábua verde (IRTV) para E. grandis de 21 anos de $^{*}$ idade 101

58 Relação entre rendimento em madeira serrada seca com destopo (RS) e rendimento em madeira serrada verde com destopo (RVCD) para E. grandis de 21 anos de idade 


\section{LISTA DE TABELAS}

1 Comparação entre as propriedades físicas e mecânicas de E. grandis e de Algumas espécies tradicionalmente utilizadas para processamento mecânico da madeira

2 Tratamentos selecionados dentro de uma população experimental de $E$. grandis de 21 anos de idade

3 Forças aplicadas no meio do vão da tábua por influência do peso utilizado como carga em diferentes pontos da alavanca

4 Parâmetros adotados para a classificação da madeira serrada de E.grandis de 21 anos de idade

5 Componentes de variância da análise inteiramente casualizada no esquema fatorial $3 \times 2 \times 3$ para a variável da tora 1

6 Componentes de variância da análise inteiramente casualizada no esquema fatorial $3 \times 2 \times 2$ para as variáveis das tora 2 e 3

7 Variáveis do inventário realizado nas parcelas selecionadas dentro da população experimental de E. grandis de 21 anos

8 Análise de variância do deslocamento da medula (DM) da tora 2

9 Análise de variância do deslocamento da medula (DM) da tora 3 
10 Análise de variância da porcentagem de casca $(\mathrm{PC})$ da tora 2

11 Análise de variância da porcentagem de casca (PC)da tora 3

12 Análise de variância da conicidade (C) da tora 2

108

13 Analise de variância da conicidade (C) da tora 3

14 Análise de variância do índice de rachaduras de topo de tora (IRTT) da tora 2 ...

109

15 Análise de variância do índice de rachaduras de topo de tora (IRTT) da tora $3 \ldots$

16 Análise de variância do (IRTV) da posição radial (0\%) da tora 2

17 Análise de variância do (IRTV) da posição radial (50\%) da tora 2

18 Análise de variância do (IRTV) da posição radial (100\%) da tora 2

19 Análise de variância do (IRTV) da posição radial (0\%) da tora 3

20 Análise de variância do (IRTV) da posição radial (50\%) da tora 3

21 Análise de variância do (IRTV) da posição radial (100\%) da tora 3

22 Análise de variância do (IRTS) da posição radial (0\%) da tora 2

23 Análise de variância do (IRTS) da posição radial (50\%) da tora 2

24 Análise de variância do (IRTS) da posição radial (100\%) da tora 2 
26 Análise de variância do (IRTS) da posição radial (50\%) da tora 3

27 Análise de variância do (IRTS) da posição radial (100\%) da tora 3

28 Análise de variância da Flecha de encurvamento $\left(\mathrm{F}_{\mathrm{E}}\right)$ da posição radial $(0 \%)$ da tora 2

29 Análise de variância da Flecha de encurvamento $\left(\mathrm{F}_{\mathrm{E}}\right)$ da posição radial $(50 \%)$ da tora 2

30 Análise de variância da Flecha de encurvamento $\left(F_{E}\right)$ da posição radial $(100 \%)$ da tora 2

31 Análise de variância da Flecha de encurvamento $\left(F_{E}\right)$ da posição radial $(0 \%)$ da tora 3

32 Análise de variância da Flecha de encurvamento $\left(F_{E}\right)$ da posição radial $(50 \%)$ da tora 3

33 Análise de variância da Flecha de encurvamento $\left(F_{E}\right)$ da posição radial (100\%) da tora 3

34 Análise de variância da Flecha de arqueamento $\left(F_{A}\right)$ da posição radial (0\%) da tora 2

35 Análise de variância da Flecha de arqueamento $\left(F_{A}\right)$ da posição radial (50\%) da tora 2

36 Análise de variância da Flecha de arqueamento $\left(F_{A}\right)$ da posição radial (100\%) da tora 2

37 Análise de variância da Flecha de arqueamento $\left(F_{A}\right)$ da posição radial $(0 \%)$ 
da tora 3

38 Análise de variância da Flecha de arqueamento $\left(\mathrm{F}_{\mathrm{A}}\right)$ da posição radial $(50 \%)$ da tora 3

39 Análise de variância da Flecha de arqueamento $\left(F_{A}\right)$ da posição radial (100\%) da tora 3

40 Análise de variância do (MOEe) da posição radial (0\%) da tora 2

41 Análise de variância do (MOEe) da posição radial (50\%) da tora 2

42 Análise de variância do (MOEe) da posição radial (100\%) da tora 2

43 Análise de variância do (MOEe) da posição radial (0\%) da tora 3

44 Análise de variância do (MOEe) da posição radial (50\%) da tora 3

45 Análise de variância do (MOEe) da posição radial (100\%) da tora 3

46 Resultados do teste $\mathrm{F}$ da análise de variância do RVSD, RVCD e RS da tora 2

47 Resultados do teste $\mathrm{F}$ da análise de variância do RVSD, RVCD e RS da tora 3

48 Resultados do teste $\mathrm{F}$ da análise de variância da (ME) na posição radial (0\%) da tora 1

49 Resultados do teste $\mathrm{F}$ da análise de variância da (ME) na posição radial (25\%) da tora 1 
(50\%) da tora 1

51 Resultados do teste $\mathrm{F}$ da análise de variância da (ME) da posição radial (75\%) da tora 1

52 Resultados do teste $\mathrm{F}$ da análise de variância da (ME) da posição radial $(100 \%)$ da tora 1 


\section{INFLUÊNCIA DO DESBASTE E DA ADUBAÇÃO NA QUALIDADE DA MADEIRA SERRADA DE Eucalyptus grandis Hill ex-Maiden}

Autor: ISRAEL LUIZ DE LIMA

Orientador: Prof. Dr. JOSÉ NIVALDO GARCIA

\section{RESUMO}

O presente trabalho teve como objetivo geral estudar a influência do manejo florestal no rendimento e na qualidade tecnológica da madeira serrada de uma população plantada de Eucalyptus grandis, de 21 anos de idade, manejada pelo sistema de desbastes seletivos com aplicação de fertilizantes na época do início dos desbastes. Os fatores utilizados foram três intensidades de desbastes seletivos (37, 50 e 75\%), presença ou ausência de fertilizantes, três classes de diâmetro e três posições verticais ao longo da altura do fuste comercial.As influências dos fatores e de suas combinações nas tensões de crescimento das árvores foram avaliadas de forma indireta através das rachaduras de extremidade de tora, rachadura de extremidade de tábua úmidas e secas, encurvamento e arqueamento de tábua úmida e deslocamento da medula em relação à sua normal posição central. Foram avaliadas, também, porcentagem de casca e conicidade de toras, que são variáveis que interferem no rendimento em madeira serrada; massa específica da madeira à umidade de equilíbrio ao ar; módulo de elasticidade estrutural na flexão estática não destrutiva, determinado em tábuas secas de dimensões comerciais e um sistema de classificação de tábuas segundo diferentes classes de qualidade. O deslocamento da medula, conicidade, porcentagem de casca e o índice de rachaduras de topo de tora não sofreram nenhuma influência 
significativa dos fatores desbaste, adubação e classe de diâmetro. As rachaduras de extremidade de tábua serrada seca ou verde, encurvamento, arqueamento e o módulo de elasticidade estrutural sofreram influências dos fatores desbaste, adubação e classe de diâmetro em algumas situações específicas. $O$ índice de rachadura de tábuas serrada verde ou seca diminui da medula para a casca enquanto que o encurvamento de peça serrada e o módulo de elasticidade estrutural aumentam da medula para a casca. $\mathrm{O}$ arqueamento das tábuas não apresenta nenhuma tendência de variação ao longo do raio da tora. A metodologia não destrutiva utilizada para avaliação do módulo de elasticidade estrutural à flexão estática demonstrou-se ser simples, prática e eficiente.Na classificação das tábuas serradas foi constatado que a posição relativa da tábua no raio interfere nas classes de qualidade da madeira. A freqüência de tábuas de $1^{\text {a }}$ classe aumenta da medula para a casca enquanto que as tábuas de refugo diminuem da medula para casca. A massa específica da madeira à umidade de equilíbrio ao ar sofreu influência do fator adubo e aumenta significativamente da medula para a casca. A intensidade de $75 \%$ de desbaste propiciou, de maneira geral, maior homogeneidade de qualidade da madeira ao longo do raio. Observa-se boas relações positivas entre rachadura de tábua seca e rachadura de tábua verde, mas a melhor relação foi observada entre o rendimento em madeira serrada seca e o rendimento em madeira serrada verde com destopo. 


\title{
Influence of thinning and fertilization on Eucalyptus grandis (Hill ex-Maiden) sawn wood quality
}

\author{
Author: ISRAEL LUIZ DE LIMA \\ Adviser: Prof. Dr. JOSÉ NIVALDO GARCIA
}

\section{SUMMARY}

The study had the general objective of studying the influence of forest thinning on the some yield and technological quality indicators of sawn wood from a 21 year old grown Eucalyptus grandis stand managed by selective thinning with the use of fertilizers at 6 years old. The thinning intensities (37, 50 and $75 \%$ ), presence or absence of fertilizers, two diameter classes, two vertical positions along the stem commercial height and three longitudinal position along the tree radius were taken as the study factors. The influences of the factors treatments and their combinations on tree growth stresses were evaluate indirectly through log end splitting, green and dry sawn lumber end splitting, green sawn lumber bow and spring and pith displacement from it normal central position. The percentage of bark and log taper which are variables that interfere on the sawn wood yield was also evaluated. Structural modulus of elasticity at static bending determined in commercial dimensions dry sawn lumber and a grading system of sawn pieces were determined. Thinning and fertilization had no significant effect on pith displacement, log tapering, bark percentage and log end splitting index. Green and dry sawn lumber, bow, spring and structural modulus of elasticity were influenced by thinning, fertilization and diameter class in some specific situations. Green or dry sawn lumber end splitting index decreases from pith to bark although green sawn lumber bow and the structural modulus of elasticity increase toward the periphery of the tree. Green 
lumber spring presents no variation tendency along the log radius. The methodology of non-destructive testing used for structural modulus of elasticity evaluation at static bending had demonstrated to be simple, practical and efficient. It was observed during sawn lumber grading operation that the relative position of a piece in the tree radius interferes on its class grade. The frequency of first class lumber increases from pith to bark while the refused pieces number decreases toward the outer part of the tree. In general the $75 \%$ thinning intensity slightly promoted a better homogeneity of sawn wood quality along the tree radius. 


\section{INTRODUÇÃO}

As exportações brasileiras de produtos de base florestal vêm melhorando a cada ano. O volume total exportado em 2003, que inclui móveis, madeira, papel e celulose, resultou na receita de US\$ 5,6 bilhões. A exportação de madeira serrada chegou a US\$ 647,9 milhões e encontra-se em ascensão (Revista da Madeira, 2004).

Atualmente, verifica-se uma redução da oferta de madeira oriunda de florestas nativas, destinada ao processamento mecânico. Esse fato deve-se aos desmatamentos realizados sem um planejamento adequado, ausência de manejo sustentado, pressão ambientalista, custo elevado do transporte e distância dos centros produtores.

Eucalyptus e Pinus são os gêneros mais utilizados atualmente, no Brasil, para produção de madeira via reflorestamentos e destinam-se principalmente à produção de carvão, energia, celulose, painéis e serraria.

O gênero Eucalyptus apresenta grande potencial para processamento mecânico da madeira, por ser de rápido crescimento, possuir boa adaptação às nossas condições ambientais e por sua madeira apresentar boas propriedades físicas e mecânicas e ser de fácil trabalhabilidade, além de poder ser produzida a baixo custo. Há ainda no gênero uma grande variedade de cores agradáveis que contribui para destacar e valorizar o seu grande potencial de substituição de espécies nativas tradicionalmente utilizadas em certos usos.

Outro aspecto vantajoso da utilização de espécies de rápido crescimento, como os eucaliptos, para a produção madeireira refere-se à fixação ("seqüestro") de carbono (C), isto é, à imobilização de C na biomassa da floresta e, principalmente, no produto madeiro que tem, via de regra, longa duração. 
Sem nenhuma dúvida um dos grandes desafios da produção de madeira de reflorestamento é o de minimizar a formação de madeira juvenil, em árvores jovens, de rápido crescimento e de pequenas dimensões que, inevitavelmente, tendem a compor o mercado madeireiro num futuro bastante próximo.

De um modo geral, pode-se melhorar, modificar, controlar ou minimizar os fatores que afetam a quantidade e a qualidade da madeira, por meio de tratos silviculturais.

Entre os tratos silviculturais que possibilitam alterações nas condições e taxas de crescimento das árvores podemos destacar a aplicação de fertilizantes e os desbastes que são freqüentemente utilizados para aumentar-se a quantidade e qualidade da madeira produzida.

O objetivo do presente trabalho foi o de estudar a influência da fertilização e de diferentes intensidades de desbaste, no rendimento e na qualidade tecnológica da madeira serrada oriunda de uma população de Eucalyptus grandis de 21 anos de idade. 


\section{REVISÃO DE LITERATURA}

\subsection{Potencial do uso da madeira serrada de eucalipto}

O eucalipto tem sido usado como madeira serrada em vários países, tais como Austrália, África do Sul, Chile, Nova Zelândia, Uruguai e Argentina. No Brasil, o uso dessa espécie como madeira serrada é ainda bastante incipiente. Algumas das razões para isto são a falta de informações, defeitos apresentados pela madeira e disponibilidade de outras espécies florestais. Estudos realizados pelo IPT (Instituto de Pesquisa Tecnológica) e por outras instituições, têm demonstrado que a madeira serrada de eucaliptos (Eucalyptus grandis, Eucalyptus saligna e Eucalyptus urophylla) pode ter muitas aplicações, em substituições às espécies nativas, como por exemplo: móveis; estruturas para telhados, paletes, casas pré-fabricadas, componentes de edificações, cruzetas para postes de transmissão, passarelas para pedestres entre outras e com resultados excelentes (Ponce, 1994).

O gênero Eucalyptus possui espécies de crescimento rápido que oferecem vantagens competitivas significativas e versatilidade para o estabelecimento de projetos de alto rendimento, por várias razões: adaptam-se bem a diferentes ecossistemas; ocorrem em populações nativas ainda existentes e protegidas nas suas regiões de origem, sendo assim fontes de material genético; a maturação é precoce e tem boa forma; diferentes espécies podem ser cruzadas para produção de híbridos vigorosos e madeiras com novas características; é possível clonar híbridos e várias espécies; e podem produzir madeira para diversas finalidades, simultaneamente, por exemplo, fibra, energia, painéis e madeira serrada (Campinhos,2001).

Entre as espécies do gênero Eucalyptus destaca-se o E. grandis Hill ex Maiden que ocorre na Austrália, ao norte do estado de New South Wales, ao sul de Queensland (próximo à região costeira e na parte central), e ao norte de Queensland 
em áreas de altitude (300 a 900 m) em sua área de dispersão natural. A precipitação pluviométrica varia de 1.000 a 1.700 mm, predominantemente no verão, com estação seca não ultrapassando 3 meses, e geadas ocasionais. A temperatura média das máximas do mês mais quente está compreendida entre 29 a $32^{\circ} \mathrm{C}$ e a média das mínimas do mês mais frio, entre 5 a $6^{\circ} \mathrm{C}$ (Ferreira, 1979).

A madeira de $E$. grandis é leve, fácil de ser trabalhada, possui coloração castanha avermelhada clara, textura fina e grã direita, com gosto e cheiro indistintos, apresenta pouca resistência e limitada duração. É utilizada, intensivamente, na Austrália e na república sul-africana, como madeira de construção, quando oriunda de plantações de ciclo longo. A madeira produzida em ciclos curtos é utilizada para caixotaria. Normalmente, a madeira oriunda de árvores com rápido crescimento apresenta problemas de empenamento, contrações e rachaduras quando do desdobro. Plantações convenientemente manejadas podem produzir madeira excelente para serraria e laminação. É a principal fonte de matéria prima para celulose e papel do Estado de São Paulo ( Ferreira, 1979, Lamprech ,1990 e Oliveira, 1997).

Segundo Sella (2001), entre os motivos do crescente interesse para o gênero Eucalyptus, na utilização de madeira para processamento mecânico, pode-se destacar:

a) Pressões ambientalistas, principalmente internacionais, pela preservação das florestas nativas remanescentes;

b) Desenvolvimento de projetos industriais com a matéria prima produzida de forma sustentável, com localização estratégica, próxima aos maiores centros industriais de consumo do produto final e exportações;

c) O E. grandis, espécie mais cultivada no Brasil, apresenta boas características físico-mecânicas, versatilidade no seu uso, beleza e coloração natural com grande aceitação para utilização refinada em interiores.

No entanto, como madeira serrada, o gênero eucalipto apresenta algumas características que podem dificultar o seu uso. Essas dificuldades não são, todavia, maiores do que aquelas apresentadas pela maioria das madeiras. As principais características que, de alguma maneira, podem dificultar o seu processamento são rachaduras e empenamentos devidos à presença de tensões 
residuais elevadas nas toras, madeira juvenil, retração, colapso, nós, bolsas de resina e variabilidade em suas propriedades (Freitas \& Brito Neto, 1993; Ponce, 1994; Malan, 1995 e Viana, 1996).

De acordo com Waugh (1998), o gênero Eucalyptus é qualificado pela maioria dos processadores de madeira como sendo de difícil desdobro, em razão dos altos níveis de tensões de crescimento que, aliados às perdas durante a secagem, o tornam adequado apenas para a fabricação de produtos de baixa qualidade como embalagens. Por esta razão, a predisposição que toras ou peças têm de rachar ou a apresentar distorções durante o processo de secagem está entre os fatores considerados mais importantes na utilização de produtos sólidos e a sua redução pode promover ganhos técnicos e econômicos significativos para a indústria baseada neste gênero.

De acordo com Jankowsky (1995), a madeira de eucalipto é, de forma geral, de difícil secagem sendo um processo lento e com grande probabilidade de aparecimento de defeitos. Para que se possa obter sucesso na secagem é necessário conhecer as características da madeira e os equipamentos mais adequados, além dos processos envolvidos na retirada da umidade. Devido a sua estrutura anatômica desfavorável ao fluxo de fluidos líquidos, a fase inicial do processo de secagem da madeira deve ser cuidadosamente conduzida. Isso requer não só um programa de secagem, mas, também, que o secador esteja operando sem criar zonas diferenciadas em seu interior.

A madeira de eucalipto formada na região da medula apresenta qualidades tecnológicas muito variáveis, sendo freqüentemente qualificada como imprópria para transformações. Deve ser objeto dos produtores de madeira para processamento mecânico a obtenção de um material menos heterogêneo possível.

Rocha (2000), em um estudo sobre a viabilidade da utilização da madeira para processamento das espécies de E. grandis com 12 anos de idade sem desbaste e E. dunnii, com 16,5 anos com desbaste, conclui que a espécie E. grandis é mais adequada que o E. dunnii para a obtenção de madeira serrada. Quanto à viabilidade técnica da substituição das madeiras tradicionais por madeiras de $E$. grandis e E. dunnii, o autor conclui que o E. grandis e E. dunnii não devem ser utilizados em substituição às madeiras nativas tradicionais, principalmente, quando se deseja madeira em classes de qualidades superiores, já que não obtiveram resultados 
satisfatórios para tal, sendo então, necessárias novas técnicas de silvicultura e manejo para as florestas plantadas de Eucalyptus destinadas à produção de madeira serrada.

Cruz et al. (2003), em um estudo sobre variações de propriedades físicas e mecânicas da madeira de clones de híbridos de Eucalyptus, encontraram que tanto as propriedades físicas quanto as mecânicas apresentaram maiores variações na direção da medula para a casca do que da base para o topo das árvores, mostrando a importância do conhecimento das variações radiais nas toras, para classificação da madeira serrada e conseqüentemente homogeneização.

Na Tabela 1 é mostrada uma comparação entre E. grandis e algumas espécies tradicionalmente utilizadas no processamento mecânico da madeira, no que se refere às principais propriedades físicas e mecânicas. Nessa tabela, pode-se verificar que o E. grandis apresenta algumas propriedades com valores inconvenientes como, por exemplo, a alta retração volumétrica e o fator de retração. Entretanto, valores como esses têm sido normalmente obtidos de árvores provenientes de florestas onde não foi realizado um manejo adequado para produzir madeira para processamento mecânico e, além disso, verifica-se que muitas das propriedades da madeira de eucaliptos apresentam alta variabilidade onde seria possível selecionar espécies com valores mais adequados para uma determinada finalidade. 
Tabela 01. Comparação entre as propriedades físicas e mecânicas de E. grandis e de algumas espécies tradicionalmente utilizadas para processamento mecânico da madeira

\begin{tabular}{|c|c|c|c|c|c|}
\hline \multicolumn{6}{|c|}{ PROPRIEDADES FÍSICAS } \\
\hline & $\begin{array}{l}\text { Pinus } \\
\text { elliottii }\end{array}$ & $\begin{array}{c}\text { Swietenia } \\
\text { macrophylla }\end{array}$ & $\begin{array}{l}\text { Ocotea } \\
\text { porosa }\end{array}$ & $\begin{array}{l}\text { Amburana } \\
\text { cearensis }\end{array}$ & $\begin{array}{c}\text { Eucalyptus } \\
\text { grandis }\end{array}$ \\
\hline $\begin{array}{c}\text { Massa específica } \\
\text { (15\% de umidade) } \mathrm{g} / \mathrm{cm}^{3}\end{array}$ & 0,48 & 0,63 & 0,65 & 0,60 & 0,68 \\
\hline Retração volumétrica (\%) & 10,5 & 8,6 & 9,8 & 9,3 & 17,5 \\
\hline T/R (Fator de anisotropia) & 1,9 & 1,4 & 2,3 & 2,1 & 2,2 \\
\hline \multicolumn{6}{|c|}{ PROPRIEDADES MECÂNICAS } \\
\hline $\begin{array}{c}\text { Resistência à } \\
\text { compressão paralela às } \\
\text { fibras } \\
\text { (madeira verde) MPa }\end{array}$ & 19 & 39 & 40 & 38 & 34 \\
\hline $\begin{array}{c}\text { Resistência à } \\
\text { compressão paralela às } \\
\text { fibras } \\
\text { (umidade 15\%) } \mathrm{MPa}\end{array}$ & 31 & 54 & 51 & 43 & 48 \\
\hline $\begin{array}{c}\text { Cisalhamento } \\
\text { (madeira verde) } \mathrm{MPa}\end{array}$ & 6 & 11 & 10 & 10 & 10 \\
\hline $\begin{array}{c}\text { Módulo de elasticidade à } \\
\text { flexão estática } \\
\text { (madeira verde) MPa }\end{array}$ & 8.849 & 10.663 & 8.829 & 10.673 & 12.606 \\
\hline
\end{tabular}

Fonte: Costa (1996)

\subsection{Madeira juvenil}

Segundo Browning (1963), a madeira é um material heterogêneo que possui diferentes tipos de células adaptadas a desempenharem funções específicas. As variações nas composições químicas e anatômicas da madeira, bem como nas propriedades físicas e mecânicas são grandes entre espécies, ocorrendo variações também dentro de uma mesma espécie, principalmente em função da idade, dos 
fatores genéticos e ambientais, existindo, além disso, diferenças entre o cerne e alburno, madeira juvenil e adulta e, em escala microscópica, entre células individuais.

A madeira juvenil é formada pelo câmbio nos primeiros anos de crescimento do tronco e situa-se em volta da medula. Esse período de crescimento é chamado de juvenilidade. Nas toras de árvores muito jovens, quase toda a madeira é juvenil, enquanto que nas toras de idade mais avançada, somente uma porção muito pequena do centro o é. O período de juvenilidade varia conforme a espécie e pode ser afetado pelas condições ambientais. A madeira adulta é formada após o período de juvenilidade e, em geral, as células dessa madeira alcançam suas dimensões máximas e estas se mantêm mais ou menos constantes, exceto quando são influenciadas drasticamente pelas condições ambientais (Jankowsky, 1979, Zobel, 1981 e Hillis \& Brown, 1984).

A proporção de madeira juvenil existente em uma tora é uma característica que depende fundamentalmente da idade da árvore, bem como do ambiente e do manejo; entretanto, em uma mesma idade e em condições semelhantes de ambiente e de manejo, pode-se verificar que existe grande variabilidade neste aspecto (Hillis \& Brown, 1984 e Malan, 1995).

A duração do período juvenil, de 7 a 15 anos, varia de acordo com cada espécie e com o ambiente. Em uma árvore com 15 anos, esse período pode ocupar cerca de $85 \%$ do tronco e, dos 30 anos em diante, cerca de 10\%. As características das madeiras juvenil e adulta da mesma árvore diferem sensivelmente (Koga, 1988).

Kucera (1994), estudando a influência do espaçamento entre árvores de norway spruce (Picea abies), na formação de madeira juvenil, observou que o início de formação de madeira adulta, na base do tronco, ocorre quando o incremento corrente anual e a altura atingem o valor máximo, sendo que em espaçamento menor o início da madeira adulta deu-se entre 18 e 19 anos e para o espaçamento maior, entre 28 e 29 anos.

A grande diferença em termos de madeira juvenil em relação à madeira adulta está na magnitude das alterações anatômicas e físicas que ocorrem no sentido da medula para a casca do tronco. As características anatômicas envolvidas nas mudanças são: comprimento de fibra, ângulo fibrilar, proporções dos tipos de células, diâmetro celular, espessura da parede celular e teores de umidade. Outros fatores tais 
como massa específica, resistências e retrabilidade variam em conseqüência da variação de tais características anatômicas (Silva, 2000).

De maneira geral, de acordo com a literatura, para madeira de folhosas, algumas características da madeira juvenil são: menor comprimento dos elementos dos vasos, menor comprimento das fibras, menor diâmetro celular, parede celular mais fina, maiores ângulos fibrilares, maior proporção de fibras, menor proporção de vasos, maior teor relativo de hemicelulose, menor teor relativo de celulose, menor densidade, altos teores de madeira de reação, altos teores de lignina e anéis de crescimento mais largos.

A madeira juvenil apresenta, geralmente, fibras mais curtas e menor densidade que a madeira normal. Conseqüentemente possui propriedades físicas e mecânicas inferiores à madeira normal. A madeira juvenil ocorre tanto nas folhosas como nas coníferas, sendo que nas coníferas as diferenças entre madeira adulta e madeira juvenil são maiores que nas folhosas. O comprimento das fibras nas coníferas pode ser quatro vezes maior que na madeira adulta; ao passo que nas folhosas, as fibras podem aumentar até duas vezes mais que na madeira adulta. Nas folhosas, a madeira juvenil não é considerada um problema significativo, porém a qualidade da madeira é mais influenciada em sua fase juvenil do que na fase adulta (Jacob \& Balloni,1978 e Zobel, 1981).

De acordo com Jankowsky (1979), alguns autores têm afirmado que a madeira juvenil é formada somente quando existe um rápido crescimento inicial, mas o período em que ocorrem rápidos aumentos de densidade e no comprimento da fibra independe da proporção de crescimento, estando presente em todo tronco, a todos os níveis de altura. Isto quer dizer que, tanto para material de desenvolvimento lento como rápido na zona central do tronco, as dimensões das células estão mudando. Contudo, em árvores de crescimento lento, essa zona será pequena em volume, enquanto que nas plantas de rápido desenvolvimento ela será grande também em volume. Esta característica parece estar associada à velocidade com que ocorre a transição da fase juvenil para a fase adulta.

Para madeiras de eucalipto, segundo Hillis \& Brown (1984), os limites de formação de madeira juvenil ainda não estão claramente conhecidos, e poucas comparações têm sido feitas entre as propriedades da madeira próxima da medula com a madeira adulta. Ainda segundo esses autores, a densidade da madeira de 
árvores adultas é maior do que aquela de madeira juvenil, proveniente de árvores jovens. Também a presença de cerne quebradiço está associada à presença de madeira juvenil.

Em espécies com dimorfismo foliar acentuado, como E. citriodora, E. dunnii e E. globulus, é fácil perceber quando ocorre a mudança da fase juvenil para adulta. É notável a variação que existe entre as várias árvores do povoamento quando do início da mudança da fase. Algumas árvores mudam de fase já no primeiro ano, enquanto outras levam até seis anos para manifestar a transição da fase juvenil para a adulta. As árvores que mudam de fase mais rapidamente apresentam menor quantidade de madeira juvenil, pois iniciam a produção de madeira adulta mais cedo. Ao contrário, árvores que demoram a mudar de fase passam vários anos produzindo madeira juvenil, resultando em uma proporção maior de madeira juvenil (Oliveira, 1997).

De acordo com Zobel \& Jett (1995), a velocidade de mudança de fase é uma característica sob forte controle genético. Isso significa que a quantidade de madeira juvenil pode ser reduzida através da seleção. Outro aspecto citado por esses mesmos autores é que a qualidade da madeira juvenil também apresenta grande variação entre árvores e também pode ser melhorada geneticamente.

De acordo com Malan (1995), a qualidade da madeira varia de árvore para árvore, bem como dentro de troncos individuais. A variação no sentido radial é a fonte de variação mais importante, sendo que a sua extensão é determinada pela proporção de madeira juvenil e de suas características físicas, mecânicas, químicas e anatômicas ao longo do raio.

A densidade da madeira tende a aumentar com a idade devido ao aumento da espessura da parede celular e diminuição do lume das células, ou seja, à medida que diminui a proporção de madeira juvenil no tronco da árvore (Ferreira \& Kageyama, 1978 e Vital,1984).

Trugilho et al. (1997) observaram em eucaliptos que à medida que aumenta a idade ocorre aumento e uma estabilização na taxa de incremento da densidade básica, do comprimento da fibra e da espessura da parede celular, enquanto que o diâmetro do lume diminui e também se estabiliza a taxa de incremento. Isso significa que a elevação do grau do gradiente de variação dentro da zona juvenil diminui com o passar do tempo. 
Wilkes (1984) afirma que, em madeira de eucalipto, a taxa de crescimento tem pouca influência quanto à formação de madeira juvenil e esse tipo de madeira ocupa proporção semelhante ao diâmetro nas árvores de crescimento rápido e lento, sugerindo um grau de maturidade semelhante entre ambos os grupos de árvores.

A Figura 1 ilustra a variação da densidade aparente no sentido medulacasca na madeira de E. grandis, através da variação proveniente de árvores de aproximadamente 15 anos de idade. De acordo com Oliveira (1999) observa-se, na Figura 1, valores de densidade aparente a $12 \%$ de umidade, bastante inferiores aos da madeira adulta em boa parte do raio formado por madeira juvenil. Para o caso dessa madeira, vê-se que para um raio de aproximadamente $140 \mathrm{~mm}$, a porção de madeira juvenil corresponde a um raio de aproximadamente $90 \mathrm{~mm}$. Também na Figura 1, observa-se um acréscimo de densidade, da ordem de 50\% para madeira adulta, em relação à juvenil. Os menores valores de densidade da madeira juvenil irão refletir imediatamente nas propriedades de resistência da madeira.

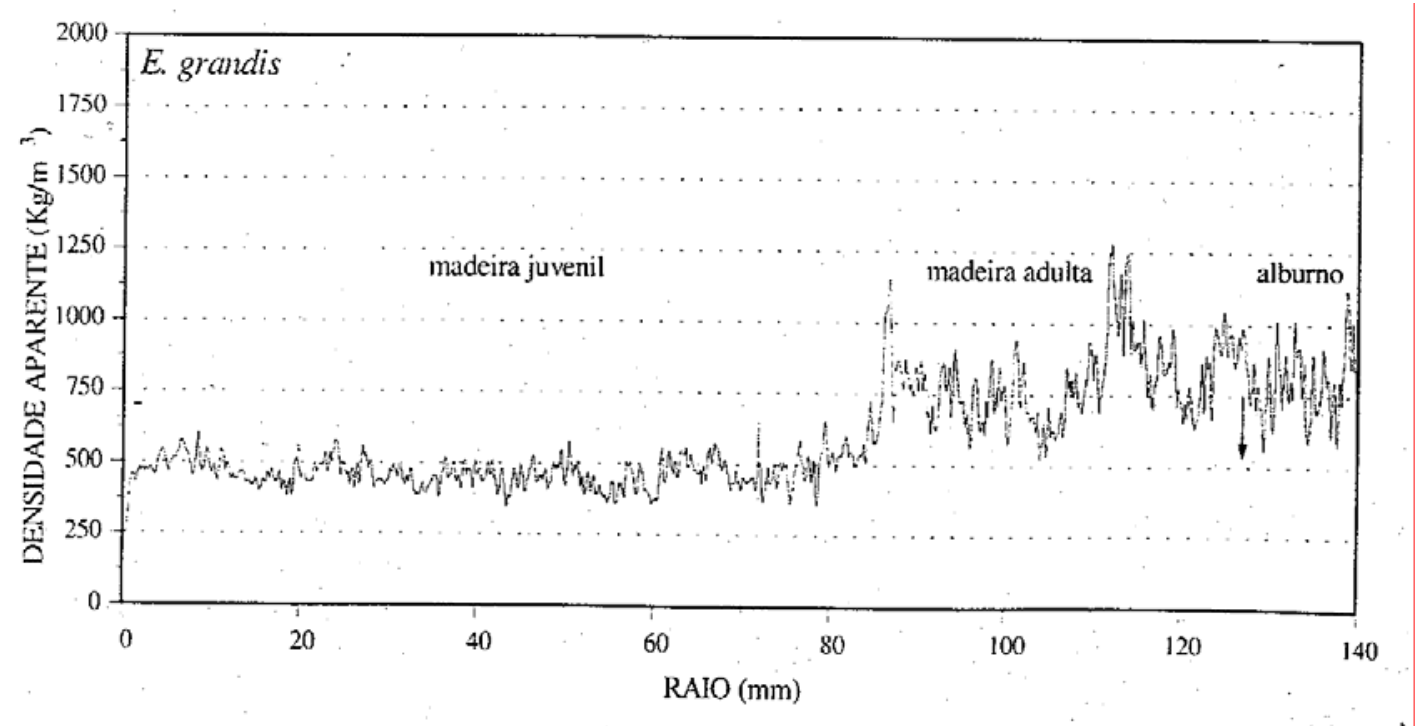

Figura 1 - Perfil densitométrico da madeira de E. grandis, na direção medulacasca

Fonte: OLIVEIRA (1999)

O lenho juvenil difere do lenho adulto por apresentar massa específica mais baixa, maior ângulo microfibrilar, traqueóides mais curtos, menor contração transversal, maior contração longitudinal, maior proporção de lenho de reação, menor 
porcentagem de lenho outonal, paredes celulares mais finas, maior conteúdo de lignina, menor conteúdo de celulose e menor resistência mecânica. As madeiras juvenil e adulta também influenciam na massa específica. Essas diferenças podem ser atribuídas à constituição genética, à idade, à fisiologia e à taxa de crescimento da árvore. Algumas características são indesejáveis para um determinado fim de utilização da madeira, portanto, a quantidade de lenho juvenil deve ser observada com cuidado. Muitos fatores, incluindo tratos silviculturais, podem afetar positiva ou negativamente a quantidade de lenho juvenil (Lewark, 1986).

Segundo Oliveira (1997), observa-se nas plantações de eucalipto uma passagem progressiva da madeira do estado juvenil para o adulto, de origem morfogenética, dependendo das condições de crescimento locais e da idade das árvores.

As propriedades mecânicas são requisitos básicos para a utilização da madeira como material de construção, principalmente no uso estrutural. A madeira de eucalipto atende às mais diferentes exigências quanto às propriedades mecânicas. Um dos aspectos que deve ser levado em consideração com relação às propriedades de resistências da madeira de eucalipto é a grande variabilidade destas propriedades ao longo do raio ou na direção medula-casca do tronco. Essa variabilidade está associada à formação de madeira juvenil que se caracteriza por apresentar resistência muito inferior àquela da madeira adulta (Oliveira, 1999).

\subsection{Tensão de crescimento}

\subsubsection{Definição}

No processamento mecânico da madeira de espécies de eucaliptos de rápido crescimento, a ocorrência de rachaduras e empenamentos é a principal causa dos baixos rendimentos encontrados na produção de madeira serrada. Esses defeitos são originários de elevadas tensões de crescimento nas árvores.

As tensões de crescimento existentes na madeira são definidas como forças que se desenvolvem no interior dos troncos das árvores vivas (Dinwoodie, 1966). 
As tensões de crescimento são características intrínsecas ao crescimento natural das árvores e podem ocorrer tanto em folhosas como em coníferas (Jacobs,1945). Elas ocorrem nas árvores antes da derrubada, atuando como uma forma de dar-Ihes estabilidade ajudando a manter o equilíbrio das árvores (Van Wik, 1978).

De acordo com Opie et al. (1984), as causas das altas tensões de crescimento nas árvores não são bem conhecidas, mas há suspeitas de que estejam relacionadas a fatores genéticos, idades, dimensões da tora, taxa de crescimento e inclinação do fuste.

Lisboa (1993) afirma que as tensões de crescimento têm efeitos benéficos para as árvores vivas, constituindo-se, entretanto, em graves dificuldades para o processamento da madeira, quando cortes transversais e longitudinais resultem em empenamentos e rachas.

\subsubsection{Origem}

As tensões de crescimento originam-se na região cambial dos troncos das árvores, durante a maturação das paredes das células, ou seja, durante o desenvolvimento da parede secundária das fibras na camada $S_{2}$ (Figura 2). Essas células tendem a contrair-se longitudinalmente e, simultaneamente, a expandirem-se lateralmente. Desde que essas células são partes integrantes dos tecidos das árvores, elas são quase que inteiramente impedidas de sofrerem essas alterações dimensionais (Boyd, 1950 e Wilhelmy \& Kubler, 1973).

De acordo com Wikins (1986), existem várias hipóteses para explicar a origem das tensões de crescimento, porém, somente duas têm sido mais aceitas. Uma primeira explicação é que a deposição da lignina na fase de diferenciação celular resulta num inchamento da parede celular (Watanabe, 1965 e Boyd, 1972). Uma segunda explicação, segundo Kubler (1987), é que o encurtamento das células periféricas resulta da contração dos cristais de celulose das microfibrilas da camada $S_{2}$. Porém, tanto para a primeira quanto para a segunda hipótese, se o ângulo de inclinação das microfibrilas na camada $S_{2}$ for menor que $40^{\circ}$ ocorrerá um encurtamento das células, se for maior irá ocorrer um alongamento das células. 


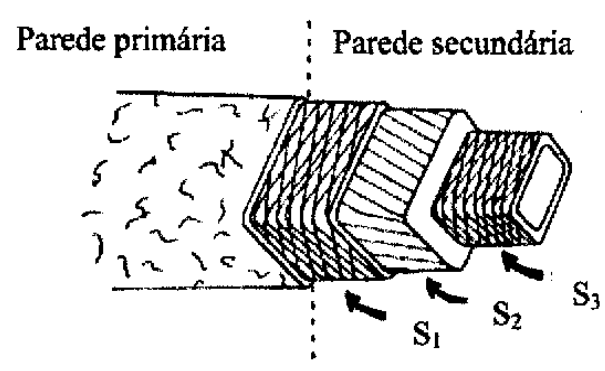

Figura 2 - Orientação das microfibrilas nas camadas $S_{1}, S_{2}$ e $S_{3}$ da parede celular típica de uma fibra

Fonte: Wilkins (1986)

\subsubsection{Distribuição}

As tensões de crescimento ocorrem nas direções longitudinal, tangencial e radial. As tensões radiais aparecem em reação às tensões tangencias, enquanto que as tensões longitudinais são devidas ao encurtamento das fibras na periferia da árvore (tensão de tração) e ao alongamento das fibras em direção à medula (tensão de compressão). Caso ocorra, o rompimento do equilíbrio natural existente dentro da árvore resultará na liberação das tensões de crescimento (Boyd, 1950, Dinwoodie, 1966 e Kubler, 1987).

Segundo Wilkins (1986), as tensões de crescimento longitudinais são as mais severas e variáveis. A distribuição das tensões de crescimento longitudinais varia de uma tração máxima na periferia da árvore até um valor máximo de compressão, na medula. A transição entre tração e compressão se dá por volta de $2 / 3$ de raio da tora, medido a partir da medula (Figuras 3 e 4) (Jacobs, 1945 e Garcia, 1992).

Segundo Okuyama (1997), as tensões de crescimento são criadas sucessivamente durante o crescimento secundário. Uma certa tensão elástica é acumulada nas paredes das células durante o período de crescimento, embora exista um relaxamento de tensões. Tanto o acúmulo quanto o relaxamento, são devidos às propriedades visco-elásticas das paredes das células. 


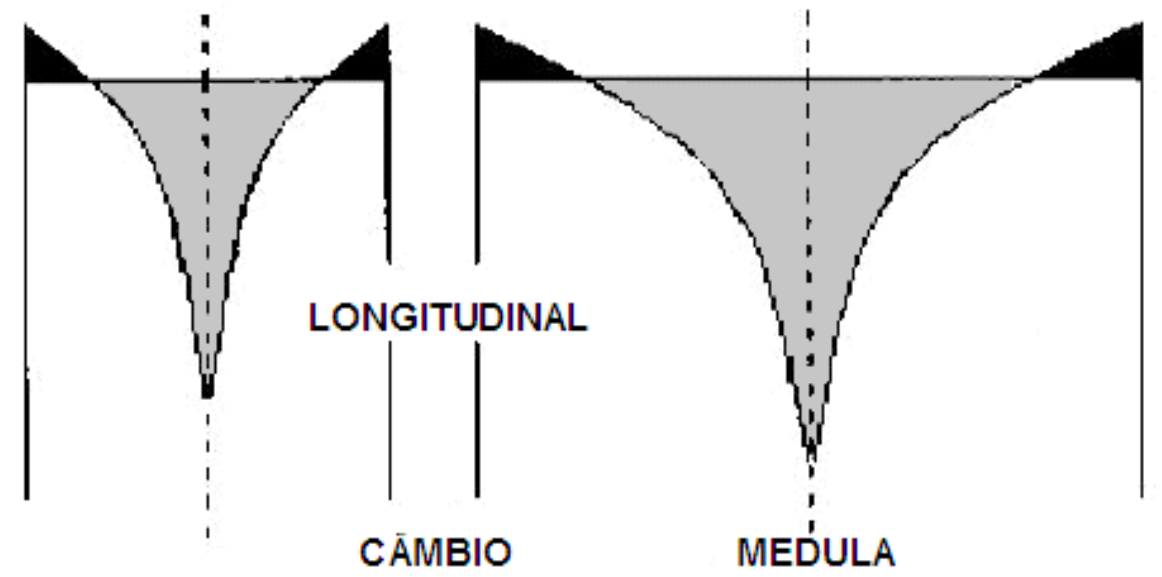

Figura 3 - Representação gráfica da distribuição teórica das tensões de crescimento no sentido longitudinal (cor negra em tração e cor cinza em compressão), a diferentes níveis em árvores de diâmetro diferentes

Fonte: Kubler (1987)

Pela Figura 3 é possível observar que em árvores de diâmetro maior ocorre um gradiente menor de tensão.

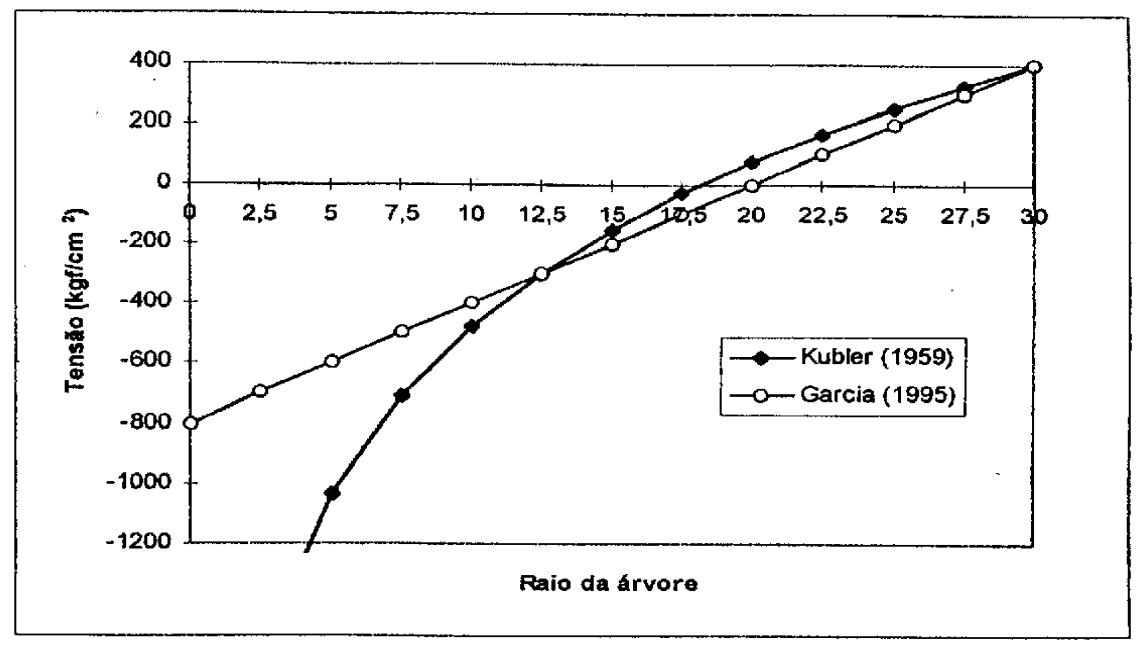

Figura 4 - Distribuições de tensões de crescimento no sentido longitudinal ao longo do raio de uma árvore de $60 \mathrm{~cm}$ de diâmetro, segundo os modelos de Kubler (1959) e Garcia (1995)

Fonte: Garcia (1995) 


\subsubsection{Efeitos da tensão de crescimento}

\section{a) Rachaduras de topo de toras}

Garcia (1995), relata que as tensões de crescimento são aliviadas parcialmente quando as árvores são derrubadas e seccionadas em toras, mas esse alívio é limitado a uma pequena distância das novas extremidades. O seccionamento causa, principalmente, a redistribuição e a transformação das tensões longitudinais em tensões transversais que são as verdadeiras responsáveis pelo aparecimento das rachaduras. Após o abate e o seccionamento em toras, a região próxima à casca tende a contrair-se longitudinalmente enquanto a região central da tora, sob compressão, tende a expandir-se. Dessa maneira, as faces das extremidades das toras tendem à forma convexa e as rachaduras começam a se manifestar.

Segundo Hillis \& Brown (1984), a maioria das rachaduras de topo de tora devem ocorrer durante uma semana. Entretanto, rachaduras adicionais podem ocorrer durante o desdobro, quando há encurvamento longitudinal das peças devido às tensões residuais ao longo da tora. Essas rachaduras ou fendas podem ser intensas e estas distorções podem ser acentuadas durante a secagem. Esses defeitos podem ocorrer principalmente em espécies de eucaliptos de crescimento rápido.

Segundo Bariska (1990), existem 5 tipos de rachaduras que podem degradar a qualidade da madeira. Uma devida ao desbalanço entre tensões atuantes e resistentes, outra devido ao efeito da derrubada, outra de topo de tora, outra de colapso e a última oriunda do processo de secagem. Somente as rachaduras de desequilíbrio e as de topo são resultantes das tensões de crescimento. As rachaduras devidas ao desbalanço entre tensões atuantes e resistentes podem ocorrer em árvores ainda em pé e as demais aparecem após o seccionamento das toras. As tensões de crescimento são distintas das tensões de secagem, mas podem estar associadas (Chafe, 1979).

De acordo com Garcia (1995), no caso de tensões de crescimento elevadas, a seção transversal de uma árvore recém cortada tem o seu diâmetro aumentado e adquire a forma de calota. Tal fato quase sempre vem acompanhado por rachaduras de extremidade, as quais têm sido propostas como indicadores de seleção de árvores para serraria. 
Segundo Lima et al. (2002), o índice de rachadura de topo de tora pode ser considerado uma propriedade muito importante e muito útil na seleção de árvores de eucaliptos para uso em serraria, principalmente para seleção de árvores com baixa intensidade de rachaduras na madeira serrada.

De acordo com Schacht et al. (1998), o índice de rachadura de topo pode ser facilmente obtido, sendo recomendada sua utilização até mesmo no campo, para descartar a tora para serraria.

A Figura 5 mostra os tipos mais comuns de rachaduras de topo de tora.

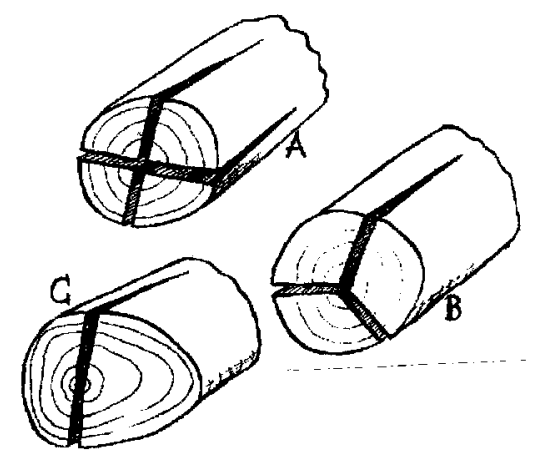

Figura 5 - Tipos de rachaduras de topo de tora : $A=X ; B=Y$ e $C=1$ Fonte: Mattheck et al. (1991)

\section{b) Rachaduras de tábuas serradas}

As tensões de crescimento causam defeitos que forçam a redução das dimensões das peças obtidas, principalmente o comprimento (Villiers, 1973). A Figura 6 mostra um exemplo de uma tábua serrada com rachaduras nas suas extremidades. 


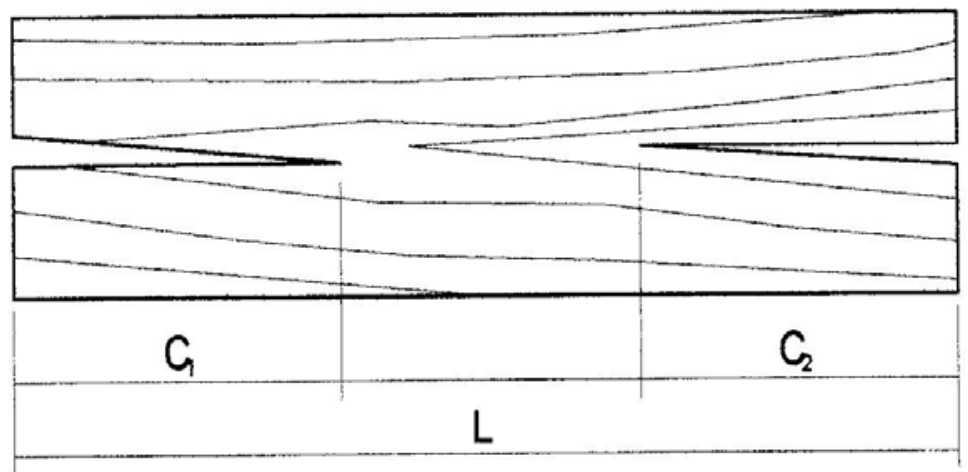

Figura 6 - Rachadura de extremidade de tábuas serradas, onde L é o comprimento da tábua e $\mathrm{C}_{1}$ e $\mathrm{C}_{2}$ são comprimento das rachaduras

Fonte: Barchet (2001)

Trugilho et al. (2003), em um estudo sobre tensão de crescimento de $E$. urophylla, observaram que a deformação residual longitudinal é mais acentuada nas tábuas de origem mais externa às toras, indicando a influência do gradiente de tensão.

\section{c) Empenamento}

O empenamento é uma distorção da peça de madeira em relação aos planos originais de suas superfícies e pode ocorrer na madeira durante o desdobro e secagem, na forma de encurvamento e arqueamento (Ponce, 1994).

O desdobro pode provocar o encurvamento das peças em virtude das tensões de crescimento, ou seja, durante o desdobro há uma tendência das peças de se curvarem de modo que as extremidades se distanciam do centro da tora enquanto que o arqueamento pode ocorrer durante o desdobro devido a um deslocamento muito acentuado da medula ou então um erro de simetria na operação do desdobro (Garcia, 1992).

Segundo Garcia (1995), a tensão de crescimento pode ser avaliada através da deformação de crescimento medida na periferia da árvore, porém, de acordo com a literatura a deformação é ainda de difícil, imprecisa e de demorada obtenção. O desdobro provoca encurvamento e arqueamento da peça resultando em uma flecha que também pode constituir-se num importante indicador de seleção e que, pelo menos por enquanto, é a variável mais fácil e segura para avaliarem-se as conseqüências da deformação de crescimento, para um determinado processo de desdobro. 
As rachaduras oriundas das tensões de crescimento, usualmente, se iniciam imediatamente após o seccionamento da tora e, normalmente, atingem o seu máximo depois de um período de 3 dias. As rachaduras devem aumentar acentuadamente durante o resto da semana, por influência de outros tipos de tensões. Rachaduras adicionais e encurvamento longitudinal das peças serradas podem ocorrer durante o desdobro, devido às tensões residuais ao longo da tora. Essas rachaduras podem ser intensas e as distorções podem ser acentuadas durante a secagem (Malan, 1979, Hillis \& Brown,1984 e Bariska, 1990).

\section{d) Cerne quebradiço}

A tensão de compressão na parte interna da árvore pode ser tão alta que pode ultrapassar a resistência da madeira à ruptura, ocasionando fraturas de compressão nas regiões centrais dos fustes (Ponce, 1994).

Segundo Nicholson (1973), essas fraturas são conhecidas como cerne quebradiço resultante, então, da excessiva tensão de compressão que leva a madeira à ruptura por exceder sua resistência intrínseca.

Segundo Chafe (1979), conforme se dá o crescimento da árvore em diâmetro, ocorre um aumento da força de compressão que, eventualmente, pode ultrapassar a resistência à compressão paralela da madeira, resultando em falhas de compressão.

O cerne quebradiço é normalmente de difícil visualização nas toras, mas pode ser detectado pela facilidade de serrar toras, pelo aspecto felpudo, por fibras quebradas na superfície de corte transversal ou ainda pela coloração mais pálida do que a da madeira normal (Hillis \& Brown, 1984).

\subsubsection{Variabilidade dos efeitos da tensão de crescimento}

Os índices que refletem o nível de tensão de crescimento apresentam três padrões de variação com a altura da árvore. Uma das tendências é a de diminuir com a altura (Chafe, 1985, Purnell, 1988, Gaiotto, 1993, Schacht et al., 1998 e Del Menezzi, 1999), outra é a de aumentar até o meio da árvore e a partir desse ponto diminuir (Yao, 1979, Malan, 1984 e Lima et al., 2000a) e, a última, de aumentar com a altura (Chafe, 1981, Miranda \& Nahuz 1999, Trugilho, 2002 e Scanavaca \& Garcia, 2003). 
Devido à ocorrência da variação do nível de tensão de crescimento com a altura da árvore é de se esperar que haja variação medula-casca.

Del Menezzi (1999) observou uma tendência de aumento da intensidade do encurvamento e uma diminuição da rachadura, no sentido medula-casca, para $E$. grandis e E. cloeziana.

Chafe (1985) não encontrou correlação significativa entre tensão de crescimento e o diâmetro de $E$. nitens em árvore em pé, porém, para o $E$. regnans ocorreu correlação altamente significativa e positiva. Ocorreu, também, correlação para diâmetros de árvores abatidas de E. nitens.

Scanavaca \& Garcia (2003) não encontraram correlação entre diâmetro e as rachaduras nas extremidades das toras ou das tábuas serradas de E. urophylla, sendo assim, não houve correlações do diâmetro com as tensões de crescimento.

\subsubsection{Variação genética}

Shacht \& Garcia (1997), estudando variações entre e intraclones das rachaduras de topo em $E$. urophylla, concluíram que as rachaduras iniciais até o $4^{\circ}$ dia, após a toragem, devem ser devidas ao efeito da interação das rachaduras de colapso com as rachaduras de tensões de crescimento, visto que rachaduras de secagem por retração começam a se manifestar, normalmente, após o $4^{\circ}$ dia, enquanto que as de colapso podem já começar a ocorrer 20 minutos após exposição da seção transversal às condições ambientais. Isso também foi constatado por Barnacle (1971) e Bariska (1990).

Segundo Nicholson (1973), a intensidade da tensão de crescimento longitudinal medida na periferia da árvore apresenta uma tendência de variar, independentemente da taxa de crescimento e fatores ambientais.

Fernandes (1982) estudou as tensões de crescimento em progênie de E. urophylla e detectou variações grandes na intensidade de rachaduras de extremidades de pranchas centrais, sendo que as variações dentro das progênies foram maiores que entre progênies.

Fernandes et al. (1989) não encontraram variação significativa nos níveis de tensões de crescimento, medida através do índice de rachadura, entre 5 
procedências de $E$. grandis, e também observaram que não existe associação significativa entre as dimensões das fibras e os índices de rachaduras.

Schacht et al. (1998) concluíram que as rachaduras e os empenamentos de toras e de peças serradas são altamente herdáveis em E. urophylla e, portanto, constituem importantes indicadores tecnológicos sobre os quais devem basear-se os programas de melhoramento de árvores para serraria.

Segundo Lima et al. (2000a) e Malan (2000) as rachaduras de topo de toras têm pouca relação com rachaduras de tábuas. Isto demonstra que as rachaduras de topo não são controladas somente pelo nível de tensão de crescimento, mas também por outros fatores como, por exemplo: diferenças nas forças de cisalhamento, presença de grã entrecruzada e alívio desequilibrado de tensões que provocam concentrações de tensões durante o desdobro. Os pesquisadores devem ter, então, o cuidado de não utilizarem somente o baixo valor do índice de rachaduras de topo de tora como o único critério para identificar árvores com baixo nível de tensão de crescimento, em programas de melhoramento. Da mesma forma, é importante evitar avaliar as rachaduras ao nível do solo, pois, a natureza e a severidade das mesmas nesse nível, são fortemente influenciadas pelo maior grau de grã torcida que geralmente ocorre nessa parte do tronco.

Assis (2000) encontrou variações genéticas significativas entre procedências para a propensão às rachaduras de topo em toras e tábuas, em E.grandis e E. pilularis, bem como entre clones de E.grandis, E. saligna e E. grandis $\mathrm{x}$ E. urophylla. Os valores das estimativas de herdabilidade foram altos, mostrando a possibilidade de se conseguir melhorar geneticamente essa característica.

Trugilho et al. (2002), em um estudo de avaliação da magnitude da tensão de tração longitudinal em árvores de 11 clones de Eucalyptus, observaram que o efeito do clone foi altamente significativo, indicando a existência de uma grande variação entre os materiais avaliados, tanto para deformação longitudinal residual como para tensão de crescimento longitudinal.

Santos (2002), em um estudo numa população de progênies de polinização aberta de E. grandis, observou níveis de variabilidade favoráveis para melhoramento genético das características rachaduras de extremidades de toras e encurvamento de tábuas. 


\subsection{Influência de práticas silviculturais na qualidade da madeira de eucalipto}

Qualidade da madeira é o conjunto de características físicas, mecânicas, químicas e anatômicas que conferem a aptidão à madeira para determinado uso final. Somente com o conhecimento das características e da variabilidade da madeira é possível a elaboração de classes de qualidade de utilizações confiáveis (Jorge \& Pereira, 1998).

Segundo vários autores, tais como Busnardo et al. (1983), Teixeira et al. (1993), Oliveira (1997), Garcia (1998) e Cruz et al. (2003), a densidade da madeira é a mais importante propriedade na definição da qualidade, em decorrência da mesma estar relacionada às características químicas, físicas, mecânicas e anatômicas da madeira. A densidade básica da madeira é um dos principais fatores utilizados na classificação de madeiras estruturais e na seleção de material de alta qualidade a ser usado para fins em que a resistência seja imprescindível. Isso é devido ao alto grau de correlação existente entre a densidade e a resistência mecânica encontrada em todas as espécies produtoras de madeira.

A formação da madeira é um processo biológico que ocorre dentro da árvore viva, enquanto a qualidade da madeira é uma avaliação arbitrária de uma peça isolada de madeira, de uma parte da árvore ou de um derivado de madeira. Conseqüentemente, a qualidade da madeira somente pode ser alterada através do processo de formação dessa madeira. Até certo ponto pode-se modificar, controlar, minimizar ou melhorar os fatores relacionados à qualidade da madeira, através de tratamentos silviculturais e por seleção e melhoramento genético (Zobel, 1981).

Dentre os principais fatores que afetam as características da madeira pode-se citar o sítio, as operações silviculturais (espaçamento, fertilização, desbaste, desrama), melhoramento genético, colheita, conversão e métodos adequados de processamento. A madeira só poderá ser usada de maneira eficiente e efetiva com o conhecimento de seus atributos e características.

No manejo florestal interessa saber até que ponto pode-se controlar a qualidade da madeira. Para isso é necessário certo conhecimento das propriedades que determinam a qualidade da madeira e até que ponto as mesmas são influenciadas 
pelas características genéticas e pelas modificações do ambiente (espaçamento, proporção de copa viva e a taxa de crescimento).

Dentre esses tratamentos silviculturais o espaçamento e o desbaste são os que controlam a competição entre árvores, sendo assim podem influenciar os diversos parâmetros que compõem a qualidade da madeira.

\subsubsection{Influência de práticas silviculturais nas propriedades físicas e mecânicas da madeira de eucalipto}

\section{a) desbaste e espaçamento}

O manejo de floresta de eucalipto para produção de madeira para serraria envolve práticas silviculturais diferentes daquelas utilizadas para produzir madeira para outros fins como celulose, papel, energia e painéis. Dentre as práticas silviculturais destacam-se os desbastes que têm por objetivo estimular o crescimento das árvores remanescentes e aumentar a produção de árvores de melhor qualidade. Entende-se como melhor qualidade, árvores de maior dimensão, aumentando o rendimento nas serrarias e também as suas propriedades físicas e mecânicas, além de apresentar redução de defeitos (Couto, 1995).

Shonau \& Coetzee (1989) recomendam para população de eucaliptos que os primeiros desbastes devem ser precoces e severos, suficientes para eliminar árvores dominadas e de forma ruim. Os desbastes intermediários, depois dos 12 anos, podem ser mais leves que os primeiros, para evitar a produção de ramos laterais e de altas proporções de madeira de baixa qualidade.

De acordo com Couto (1995), as árvores remanescentes após a realização de desbastes, tendem a transferir a energia produzida para o crescimento para a adaptação à nova situação ambiental. Com isso os crescimentos iniciais logo após os desbastes são lentos. Os desbastes, portanto, devem ser pouco intensos e mais freqüentes. Entretanto a intensidade e a freqüência devem ser economicamente viáveis.

Segundo Stape (1996), o eucalipto apresenta grande potencial para produção de madeira de maiores dimensões para desdobro. A capacidade do eucalipto em ocupar o sítio, após o desbaste, possibilita a utilização de sistemas de manejo com poucos desbastes e de intensidades de moderada a pesada, desde que se preservem 
as árvores da classe dominante, através da aplicação de desbaste seletivo por baixo, associado com a utilização da fertilização.

Malan (1979) estudou a variação das propriedades da madeira de $E$. grandis em função da taxa de crescimento e concluiu que o aumento da produção de madeira através de medidas silviculturais não ocasionou nenhuma influência sobre as propriedades da madeira.

Zobel \& Jett (1995), citando vários trabalhos, comentam que a taxa de crescimento não apresenta correlação com a densidade da madeira de eucalipto.

A prática de atividades silviculturais intensas, como o controle do espaçamento, entre outras, afeta a qualidade da madeira em decorrência do seu efeito nos padrões de crescimento das árvores (Kellison et al., 1983).

De acordo com Harris (1981) tanto em coníferas quanto em folhosas o crescimento mais rápido da população pode ocasionar a diminuição do comprimento da fibra, da densidade da madeira e da resistência, além de aumentar o gradiente na direção medula-casca.

Migliorini (1986), em um estudo com a madeira de E. grandis, encontrou diferenças significativas entre a densidade básica de três diferentes níveis de produtividade selecionados no povoamento. Os resultados mostraram que a densidade básica diminui com o potencial de crescimento da floresta. Rezende et al. (1998) encontraram resultado semelhante.

Land et al. (1983) afirmaram que em sítios onde se tem rápido crescimento há uma redução da densidade básica em relação às taxas de crescimento menores, porém, o aumento do volume por unidade de área nos sítios mais produtivos compensaria a perda em densidade, havendo maior colheita de matéria seca por hectare. Os mesmos autores constataram, ainda, que as madeiras de árvores que cresceram mais livremente começam a produzir madeira adulta precocemente, alcançando níveis máximos de densidade mais cedo, resultando em um tronco com grande proporção de madeira adulta, de densidade relativamente uniforme. Além disso, a densidade média ponderada aumentou com o aumento da intensidade de desbaste.

Bamber et al. (1982) compararam duas populações de E. grandis aos 33 meses de idade, sendo uma com crescimento normal e outra com crescimento rápido, influenciado pela combinação de tratamentos silviculturais. Observaram que para a 
densidade básica da madeira, no crescimento normal, o valor foi de $0,42 \mathrm{~g} \mathrm{~cm}^{-3}$ e no crescimento rápido a densidade básica foi de $0,46 \mathrm{~g} \mathrm{~cm}^{-3}$.

Segundo Malan (1991), a taxa de crescimento causa efeitos mínimos nas propriedades básicas da madeira em árvores de E. grandis de mesma idade. $\mathrm{Na}$ Figura 7 está representado esse resultado. Entretanto o crescimento inicial rápido poderá maximizar a zona de madeira juvenil podendo causar um efeito significativo nas propriedades da madeira (Malan \& Hoon, 1992).

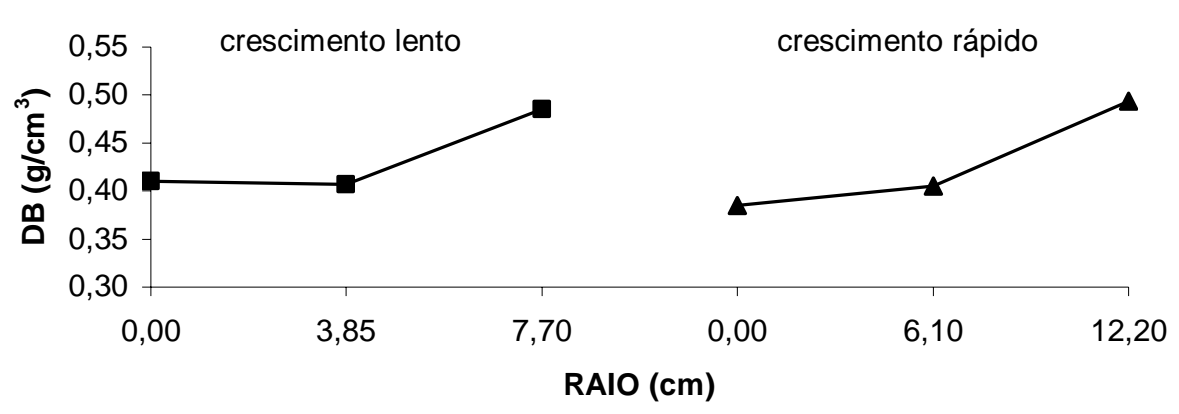

Figura 7 - Gráfico de densidade básica (DB) versus tipo de crescimento para, E. grandis aos 8,5 anos de idade

Fonte: Malan, 1991

O aumento em densidade e comprimento de fibra no sentido da medula para a casca, obtido através de crescimento lento, pode resultar em uma madeira de melhor qualidade. Isso pode ser conseguido com a redução da taxa de crescimento inicial através do controle da densidade populacional inicial e retardando a programação de possíveis desbastes, o que resultaria em uma menor proporção de madeira juvenil em favor de um aumento posterior da densidade. O crescimento rápido obtido em idade mais avançada através de operações silviculturais tenderá a reduzir a densidade perto da periferia como também produzir uma madeira com pouco ou reduzido gradiente de densidade na direção da medula para casca (Hans et al.,1972).

Malan \& Hoon (1992) estudaram o efeito do desbaste em uma população de $E$. grandis, na qual foram testadas diferentes séries de intensidades de desbastes. Os autores concluíram que as madeiras de árvores que cresceram mais livremente começam a produzir madeira adulta precocemente, alcançando níveis 
máximos de densidade mais cedo, resultando em um tronco com grande proporção de madeira adulta, de densidade relativamente uniforme. Além disso, a densidade média ponderada elevou-se com o aumento da intensidade de desbaste. Esse resultado é muito importante, visto que as práticas silviculturais aceleradoras do crescimento não têm um efeito pronunciado nas propriedades básicas da madeira e a falta de uniformidade das madeiras é um dos problemas mais sérios para a qualidade da madeira de espécies comerciais. Na Figura 8 está representado esse resultado, demonstrando ser possível conseguir uma madeira mais homogênea através da prática de desbastes ou outras práticas silviculturais que controlam a competição entre árvores.

Segundo Malan (1995), a prática de desbastes causa efeito no desenvolvimento da copa e na taxa de crescimento das árvores, podendo causar um efeito significativo na formação da madeira. Isso pode resultar num aumento da área de madeira juvenil, resultando uma madeira de baixa densidade, fibras curtas além de alta retração longitudinal sob secagem e ainda um alto teor de lignina. Para Oliveira (1999), somente a partir de DAP (diâmetro a altura do peito, 1,30m) de $30 \mathrm{~cm}$, aproximadamente, é que se começa a obter madeira de densidade básica mais uniforme.

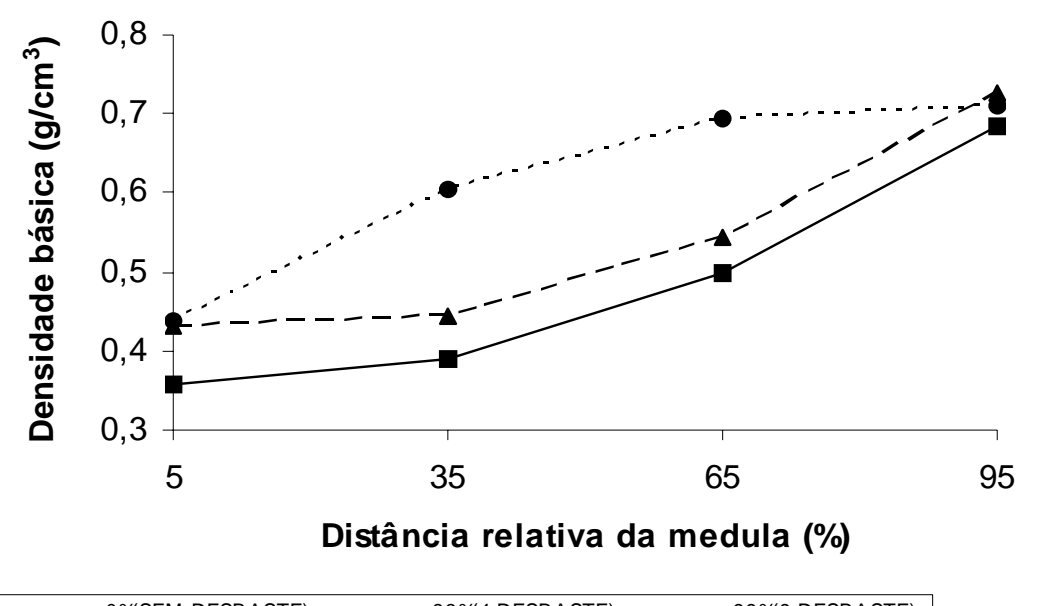

$\longrightarrow-0 \%($ SEM DESBASTE) $-\rightarrow--83 \%(4$ DESBASTE) $\cdots \cdots \bullet-\cdot-99 \%$ (9 DESBASTE)

Figura 8 - Gráfico de densidade básica versus distância da medula Fonte: Malan \& Hoon 1992 


\section{b) Fertilização}

No Brasil, embora a fertilização para plantios florestais resulte em ganhos de produtividade, pouca atenção tem sido dada aos possíveis efeitos que ela possa ter sobre a qualidade da madeira produzida. São poucas as informações a respeito do efeito da fertilização nas propriedades físicas, mecânicas, químicas e anatômicas das madeiras do gênero Eucalyptus (Jacob \& Balloni, 1978 e Andrade et al. 1994).

Segundo Larson (1967), a fertilização é a ferramenta mais comum e, talvez, de ação mais efetiva de que se dispõe para melhorar a qualidade do sítio e, com isso, aumentar a taxa de crescimento, o que também é destacado por Mello et al. (1970). A quantidade, o tipo e a época de aplicação dos fertilizantes podem vir a ocasionar alterações na qualidade da madeira, sendo que estas mudanças dependem da espécie florestal e da fertilidade do solo.

Segundo Donald \& Schutz (1977), para população de E. grandis, pode ser conseguido um aumento do crescimento em diâmetro através da fertilização, sem prejuízo da qualidade da madeira.

Em um estudo da interação de clones com a fertilização em E. saligna, para a característica densidade básica, Kikuti \& Namikawa (1990) concluíram que não houve efeito da fertilização.

Lima et al. (2000b), em estudo de variação de densidade e propriedades mecânicas da madeira de clones de Eucalyptus em 4 sítios diferentes, concluíram que ocorreram diferenças entre sítios e posição da tora na árvore.

Raymond \& Muneri (2000), em um estudo de aplicação de N e P em E. globulus em 4 locais diferentes, concluíram que não existe relação entre mudanças em propriedades de madeira e crescimento de árvore. Foram encontradas mudanças significativas em propriedades de madeira na ausência de mudanças em tamanho de árvore. Reciprocamente, aumentos significativos em tamanho de árvore devido ao fertilizante aplicado nem sempre foram acompanhados por mudanças em propriedades de madeira. Os efeitos do fertilizante aplicado em crescimento e propriedades de madeira eram dependentes do local e relacionados à chuva. Parece não haver nenhuma resposta clara à pergunta de se a adição de fertilizante resultará em madeira de baixa qualidade. O estudo sugere que a adição de fertilizante pode ser prejudicial a algumas propriedades da madeira em locais mais secos, mas podem não ter nenhum 
efeito principal em locais mais úmidos. Porém, a presença ou ausência de uma resposta de crescimento para o fertilizante aplicado não proverá nenhuma orientação sobre efeitos potenciais na qualidade da madeira.

De acordo com Larson (1969), a fertilização em árvores jovens, além de aumentar a área de madeira juvenil, pode atrasar a transição para a madeira adulta.

Garcia (1998), em um estudo sobre a importância de algumas características sobre a diversidade genética de clones de eucalipto em duas classes de produtividade, encontrou maiores valores de densidade básica, na classe de maior produtividade. A densidade básica foi a característica de maior importância na diversidade, destacando-se, porém, que os estudos devem considerar tanto as características de qualidade como as de crescimento, com o objetivo de obter-se melhor qualidade da matéria-prima associada à maior produtividade.

Quanto à época de aplicação de fertilizantes, normalmente a adubação feita durante o plantio das mudas não interfere na qualidade da madeira das árvores adultas. Porém, essas árvores tendem a produzir maior proporção de lenho juvenil (IPEF, 1976).

Zobel (1992) afirma que a fertilização de folhosas é mais comum, porém, a literatura é bastante contraditória a respeito dos efeitos dessa fertilização sobre a qualidade da madeira. A aplicação de nitrogênio diminui o tamanho das células, espessura da parede e peso específico, assim como nas coníferas, mas há muitas exceções, especialmente em espécies com poros difusos como os eucaliptos.

Vital (1990) também destaca, citando vários autores, a existência de resultados conflitantes sobre o efeito da fertilização na densidade da madeira, havendo a redução, aumento e a não-alteração em propriedades com a adubação, mas enfatiza que, se houver diminuição, o peso de madeira produzido por hectare será maior devido ao grande crescimento volumétrico.

De acordo com Higgs \& Rudman (1973), a densidade da madeira do $E$. regnans foi diminuída após a adubação com NPK em média $25 \mathrm{Kg} \cdot \mathrm{m}^{` 3}$.

Segundo Bamber et al. (1969), para E. grandis, a densidade da madeira sofreu pouca influência da taxa de crescimento.

Valeri et al. (1990), estudando a variação da densidade básica da madeira de E. grandis com a aplicação de calcário e fósforo, concluíram que a 
densidade básica não foi afetada pela aplicação do calcário, mas diminuiu com a aplicação de $200 \mathrm{Kg} \cdot \mathrm{ha}^{-1}$ de fósforo.

Andrade et al. (1994), estudando o efeito da fertilização na qualidade da madeira de E. grandis, aos seis anos de idade observaram que para densidade não houve diferenças significativas, porém ocorreu uma ligeira diminuição em relação às árvores não adubadas. A produção de massa foi afetada pela fertilização, havendo um acréscimo significativo desse parâmetro, em decorrência do aumento da produção volumétrica, visto que a densidade não foi afetada significativamente.

Vigneron et al. (1995) estudaram o efeito da fertilização em clones de híbrido Eucalyptus sobre a densidade básica da madeira e observaram que a fertilização aumentou a densidade básica.

Em árvores de crescimento lento, devido a alguma deficiência do solo, a aplicação de fertilizantes pode ocasionar aumento na densidade da madeira. Em árvores de crescimento médio pode haver redução de até $5 \%$ e em árvores de crescimento rápido não há efeito da adubação na densidade da madeira (Klem, 1968).

Mello (1968) estudou o efeito da aplicação de NPK e calcário sobre a qualidade da madeira de $E$. saligna e verificou que a densidade básica, a espessura e o comprimento das fibras não foram afetados pela aplicação dos macronutrientes primários, com exceção feita à aplicação de calcário (2 t. ha ${ }^{-1}$ ) que reduziu significativamente o comprimento das fibras. Em concordância, Andrade et al. (1994) constataram reduções significativas no comprimento das fibras e aumento no teor de extrativos da madeira de E. grandis devido à aplicação de calcário calcítico (2 t. ha $\left.{ }^{-1}\right)$; os mesmos autores, ainda, verificaram que a aplicação de gesso e fosfato reduziu a presença de extrativos na madeira.

Segundo Malavolta (1980) o cálcio tem função estrutural sendo encontrado em abundância na lamela média das fibras, e é responsável pelo aumento da rigidez da parede celular, dificultando o aumento do volume celular.

Vital (1990) destaca que o efeito de intervenções silviculturais tais como fertilização mineral é secundário, sendo decorrente de um maior crescimento da copa, de uma maior eficiência para realização da fotossíntese e conseqüente alteração no padrão de crescimento.

Diversas propriedades da madeira não respondem de forma homogênea à adubação mineral. Isso é devido às variações naturais das características genéticas 
e das diferentes condições ambientais a que estão sujeitas as espécies produtoras de madeira (Vital, 1990).

Sgarbi et al. (2000) verificaram que a deficiência de enxofre reduziu significativamente a densidade básica da madeira juvenil de E. grandis $x$ E. urophylla.

Zobel (1992) afirma que a aplicação de fertilizantes em pequenas e contínuas doses em povoamento florestal, em geral não afeta as características da madeira, sendo que grandes e poucas doses surtem maior efeito na qualidade da madeira, além disso, a aplicação de fertilizantes pode provocar alterações na estrutura anatômica da madeira e a constituição química da parede celular, além de alterações nas propriedades físicas e mecânicas.

Segundo Silveira (2000), a maioria dos estudos mostra que a fertilização promove ganhos de produtividade, porém pouco se conhece sobre os seus efeitos na qualidade química, física, mecânica e anatômica da madeira do Eucalyptus. Em quase todos os estudos já realizados o objetivo foi verificar o efeito da aplicação conjunta de NPK ou de fertilizantes nitrogenados, sem a preocupação de determinar os efeitos isolados ou das interações entre os nutrientes sobre a qualidade da madeira. Portanto, não se tem uma avaliação concreta da influência dos nutrientes na formação e nas características físicas, mecânicas, anatômicas e químicas da madeira.

Segundo Barrichelo \& Shimoyama (1994), a formação da madeira e suas características são dependentes da atividade cambial e da diferenciação dos xilemas, os quais são controlados pela produção de hormônios nas gemas apicais e pelo transporte de carboidratos das folhas para o câmbio. Deficiências e desequilíbrios nutricionais reduzem a biomassa foliar das árvores e, conseqüentemente, a eficiência fotossintética e a atividade das gemas apicais, proporcionando um menor suprimento de carboidratos e hormônios para a região cambial.

Dunisch et al. (1998) observaram que o conteúdo de $\mathrm{K}$ e Ca, durante a formação da madeira juvenil e adulta de Picea abies, afetou a formação da madeira juvenil. Durante a fase de elongação das células ocorreu um incremento do conteúdo de $\mathrm{K}$ do simplasto. $\mathrm{Na}$ fase de formação da parede celular aumentou o conteúdo de cálcio durante a diferenciação das células. Entretanto, o conteúdo de cálcio da parede celular decresceu durante a sua lignificação. Os autores concluíram que o potássio é fundamental para a elongação e diferenciação dos traqueídeos, enquanto que o cálcio 
é essencial para a síntese da parede celular na fase secundária do desenvolvimento e no processo de lignificação.

Segundo Megraw (1985), às vezes, não se verifica nenhum efeito da fertilização sobre a densidade porque os povoamentos são adubados muito jovens. Se o nitrogênio é aplicado quando a copa ainda está sendo formada, seu aumento ou vigor tem pouco efeito sobre a madeira. Somente após a copa formada é que sua expansão tem efeito nas características das células do tronco.

Silveira (2000) avaliou materiais genéticos buscando identificar sua eficiência na absorção de potássio e também analisou o efeito que este nutriente proporciona para a qualidade da madeira, de quatro progênies de E. grandis. As progênies tiveram comportamentos diferenciados para a densidade básica do lenho conforme se variou a dose de potássio na solução nutritiva. As maiores doses de potássio na solução proporcionaram aumento no comprimento e na largura das fibras dos genótipos.

Bouchardet (2002), estudando o efeito da aplicação de diferentes doses de boro nas características físicas e anatômicas da madeira juvenil de dois clones de E. grandis aos 24 meses de idade, concluiu que as doses de boro não tiveram efeito significativo sobre a densidade básica e as características anatômicas da madeira.

\section{c) Combinação de tratamento silviculturais}

Uma combinação bem ajustada entre desbaste e fertilização pode influenciar positivamente na qualidade e quantidade de madeira produzida de eucaliptos (Messina, 1992).

Berger et al. (2000) estudaram o efeito do espaçamento $(3 \times 2,3 \times 3$ e 3 x 4m) e da adubação (400 e $800 \mathrm{Kg} \cdot \mathrm{ha}^{-1}$ de NPK) sobre a Densidade Básica (DB), Módulo de Elasticidade (MOE) e Módulo de Ruptura (MOR) em uma população de um clone de E. saligna, aos 10 anos de idade. Concluíram que os fatores adubação e espaçamento tiveram efeitos significativos sobre a variável densidade básica, sendo que a maior dose de adubo e o maior espaçamento proporcionaram um aumento significativo dessa característica. Nos estudos de resistência à flexão estática, MOE e o MOR foram significativamente influenciados pelo espaçamento, adubação e posição da tora. A maior dose de adubo e o maior espaçamento proporcionaram os maiores 
valores médios de MOE e MOR, diferindo significativamente da menor dose de adubo $\left(400 \mathrm{Kg} \mathrm{ha}^{-1}\right)$ e dos menores espaçamentos ( $3 \times 2$ e $\left.3 \times 3 \mathrm{~m}\right)$.

Haselein et al. (2002) avaliaram o efeito do espaçamento e da fertilização em algumas propriedades físicas e mecânicas da madeira úmida de $E$. saligna. Os autores concluíram que o espaçamento e a dose de adubo afetam tanto a densidade quanto o MOR e o MOE à flexão estática da madeira verde, sendo que quanto maiores o espaçamento e a dose de adubos, maiores foram os valores dessas propriedades.

Higgs $(1969)^{1}$, citado por Wilkes \& Abbott (1983), mostra que a utilização de ambos, desbaste e fertilização, para E. regnans, aumentaram a taxa de crescimento das árvores, entretanto, diminuíram o comprimento da fibra.

Wilkins \& Horne (1991), trabalhando com uma população de E. grandis, de 9,5 anos de idade, estudaram o efeito de vários tratamentos silviculturais, sobre a densidade básica da madeira. Os autores verificaram que no tratamento onde ocorreu desbaste, fertilização e sulcamento, foram obtidos os maiores valores da densidade básica e, também, foi alterada a distribuição dos valores na árvore.

Wilkins \& Kitahara (1991) observaram que a fertilização mais desbaste aumentaram o valor da densidade básica quando comparado com a testemunha, para duas populações de $E$. grandis de 12,5 anos de idade.

\subsubsection{Influência de práticas silviculturais na tensão de crescimento}

Normalmente, desbastes em populações de eucalipto proporcionam madeira de excelente qualidade, porém, March \& Burger (1967) recomendam desbastes conservadores durante a primeira metade da vida útil das populações e um aumento na intensidade, suficiente para manter constante a taxa de crescimento, pois alterações bruscas na taxa de crescimento podem aumentar as rachaduras de topo (Kubler, 1987).

Malan (1988), estudando características de crescimento em E. grandis, na África do Sul, supõe que práticas silviculturais podem não ser um instrumento para

\footnotetext{
${ }^{1}$ Higgs, M. L. - Ph. D. Thesis, Australian National University, Canberra (1969).
} 
reduzir o nível de tensões de crescimento em árvores, pois os fatores genéticos podem estar envolvidos.

Ponce (1994) afirma que existe uma tendência de se atribuir às grandes taxas de crescimento a causa das tensões de crescimento e suas conseqüências nos eucaliptos. Todavia, não está provado que taxas maiores de crescimento induzem maiores níveis de tensões de crescimento. Deve-se entender então que tensão de crescimento não se trata de tensão de velocidade de crescimento.

Ferrand (1983), estudando o efeito dos desbastes no nível de deformação de crescimento em $E$. delegatensis e $E$. nitens, verificou que desbastes moderados não influenciaram o nível de deformação de crescimento. Entretanto, desbastes intensos e precoces reduziram o nível de deformação de crescimento. O nível de deformação de crescimento parece ser fortemente relacionado com a competição entre árvores. Isso pode ser verificado comparando-se a área basal do povoamento e o nível de deformação de crescimento.

Enquanto as intensidades de desbastes não provocarem reorientação das copas das árvores, elas poderão diminuir o nível de tensão de crescimento. Entretanto, quando as intensidades de desbaste forem muito rigorosas, fato que pode provocar novas orientações das copas das árvores, então o nível de tensão de crescimento pode ser aumentado (Kubler, 1987).

Wilkins \& Kitahara (1991) avaliaram os efeitos de desbastes em E.grandis no nível de deformações periféricas de crescimento e concluíram que houve um aumento na taxa de crescimento aliado a uma diminuição no nível de deformações periféricas de crescimento.

Wilson (1985) observou, seis semanas após o corte de obtenção das toras, um aumento da intensidade de rachaduras de topo de toras com o aumento do diâmetro para o E. macarthurii e E. elata e presumiu que isso foi devido ao aumento da proporção de madeira juvenil em relação à madeira adulta, uma vez que nessas espécies o lenho juvenil é mais suscetível ao colapso.

Shield (1995) considera que com o aumento do diâmetro da tora, seja através de desbastes ou da extensão da rotação, diminui o efeito da tensão de crescimento sobre as peças serradas. Entretanto, segundo o autor, isso é atribuído a uma diminuição do gradiente de tensão com o aumento do diâmetro e não a diminuição propriamente dita da intensidade da tensão. 
Malan \& Hoon (1992) analisaram um povoamento de E. grandis de 34 anos de idade, em diferentes séries de desbastes sucessivos. Concluíram que os desbastes gradativos não tiveram uma tendência sistemática de reduzir ou aumentar os níveis de tensões de crescimento.

Zobel (1992) destaca que qualquer alteração do padrão de crescimento de uma árvore, resultante ou não de intervenções silviculturais, pode causar variações na qualidade da madeira, sendo que não é possível prever em que sentido essas variações ocorrerão. $O$ autor sustenta que a adoção de um espaçamento maior no plantio evita mudanças abruptas nas condições de luminosidade, umidade e competição entre árvores, evitando alterações súbitas na qualidade da madeira. O mesmo foi observado por Wilkins \& Kitahara (1991) que verificaram a existência de uma forte correlação entre as deformações de crescimento com o aumento do grau de competição entre árvores.

As árvores que são plantadas em espaçamento mais amplo normalmente crescem mais rapidamente do que aquelas plantadas em espaçamento mais estreito. Entretanto, em determinada idade, elas terão maior tendência ao forquilhamento devido à ação dos ventos, maior conicidade, maior tortuosidade, ramos mais grossos e copas mais extensas que as árvores de plantios mais densos. Também existe a possibilidade dessas árvores favorecerem a formação de maior proporção de lenho de reação (Couto et al. ,1977 e Daniel et al., 1979).

Miranda \& Nahuz (1999), em um estudo sobre a influência do espaçamento sobre os índices de rachamento após o desdobro e após a secagem de E. saligna, concluíram que o espaçamento influenciou esses índices. Porém, não foi possível estabelecer a relação entre o espaçamento e rachamento das tábuas após o desdobro e após a secagem.

Segundo Malan (1984), na África do Sul, em geral, para populações de eucaliptos em sítio de melhor qualidade ocorre um aumento da rachadura e em sítio de pior qualidade ocorre uma diminuição de rachadura na madeira.

Garcia \& Lima (2000), em um estudo da variação da tensão de crescimento em uma população de E. grandis de 18 anos de idade, manejada através de desbastes sucessivos, concluíram que os índices de rachaduras de extremidades de tora sofreram uma pequena influência da intensidade de desbaste. A influência dos 
desbastes também, não apresentou uma tendência marcante, sendo em geral benéficos para essa variável.

Poda severa aplicada em E. grandis aos 10 anos e avaliada em seguida causou aumento das rachaduras de topo, devido à nova orientação das copas das árvores (Luckhoff, 1967); entretanto não tiveram nenhum efeito significativo em árvores colhidas 10 anos após a poda, pois com o passar do tempo, as árvores tendem a se estabilizarem e as tensões de crescimento também se estabilizam ( Bredenkamp et al., 1980). 


\section{MATERIAL E MÉTODOS}

\section{1 Material}

O material utilizado nesta pesquisa foi obtido de uma população experimental de Eucalyptus grandis Hill ex-Maiden, de 21 anos de idade, procedência Botucatu (origem Coff's Harbour), com nível de Melhoramento de P.S.C. (Pomar de Semente Clonal), segundo (Stape \& Martini,1991), localizada no município de Lençóis Paulista/SP e pertencente à Ripasa S/A Celulose e Papel. O solo local é classificado com latossolo vermelho amarelo, de textura média e o clima é do tipo CWa, segundo a classificação de Koppen.

O ensaio, composto de 22 parcelas de $900 \mathrm{~m}^{2}$, cada uma representando um tratamento diferente, foi plantado em 16/12/1982 em espaçamento de $(3,0 \times 1,5) \mathrm{m}$, totalizando 2.222 árvores/ha. Inicialmente foram aplicados $2.222 \mathrm{~kg} / \mathrm{ha}$ de NPK 6:30:6 distribuídos nos sulcos de plantio. Em 1987 foram iniciados desbastes do tipo seletivo, nas intensidades de 37, 50 e 75\%. Após o desbaste foi feita uma adubação com 1000 kg de NPK 12:06:12 e 100 kg de Lama-cal por hectare, distribuídos nas entrelinhas de apenas 11 das parcelas, caracterizando, portanto, tratamentos com e sem adubo. Em seguida à adubação foi efetuada uma gradagem leve para incorporar o adubo ao solo. Após o último dos três desbastes que ocorreu aos 8,5 anos, o experimento foi mantido sem alteração até o início do presente estudo.

A Tabela 2 mostra os tratamentos da população experimental que foram selecionados para serem estudados. 
Tabela 2. Tratamentos selecionados dentro de uma população experimental de $E$. grandis de 21 anos de idade

\begin{tabular}{ccccccc}
\hline Parcela & $\begin{array}{c}\text { Adubação } \\
\text { aos } \\
\mathbf{5} \text { anos }\end{array}$ & $\begin{array}{c}\mathbf{( \% )} \\
\text { Desbaste }\end{array}$ & $\begin{array}{c}\text { Idade no } \\
\mathbf{1}^{\mathbf{0}} \\
\text { desbaste }\end{array}$ & $\begin{array}{c}\text { Idade no } \\
\mathbf{2}^{\mathbf{0}}\end{array}$ & $\begin{array}{c}\text { Idade no } \\
\mathbf{3}^{\circ}\end{array}$ & $\begin{array}{c}\mathbf{N}^{\mathbf{0}} \text { de } \\
\text { árvores /ha }\end{array}$ \\
\hline 1 & N: não & $37 \%$ & 5 & 6,5 & 8,5 & 549 \\
2 & S: $\operatorname{sim}$ & $37 \%$ & 5 & 6,5 & 8,5 & 521 \\
3 & $\mathrm{~N}$ & $50 \%$ & 5 & 7,5 & - & 535 \\
4 & $\mathrm{~S}$ & $50 \%$ & 5 & 7,5 & - & 556 \\
5 & $\mathrm{~N}$ & $75 \%$ & 5 & - & - & 535 \\
6 & $\mathrm{~S}$ & $75 \%$ & 5 & - & - & 535 \\
\hline
\end{tabular}

\subsection{Amostragem}

Inicialmente realizou-se um inventário do experimento e a partir da distribuição diamétrica obtida, foram eleitas 3 classes de DAPs para o estudo, sendo:

Classe inferior: composta de árvores com DAP entre 20 e $25 \mathrm{~cm}$;

Classe mediana: composta de árvores com DAP entre 25 e $30 \mathrm{~cm}$;

Classe superior composta de árvores com DAP entre 30 e $3^{\star} 5 \mathrm{~cm}$.

Dentro de cada uma das parcelas foram tomadas 12 árvores, sendo 4 em cada uma das classes definidas, totalizando 72 árvores, que foram devidamente identificadas no campo.

Foram retiradas 3 toras de cada uma das árvores selecionadas, sendo a tora 1 , de 1,70 m de comprimento, retirada na base da árvore e as outras duas (tora 2 e tora 3 ), subseqüentes e de $3 \mathrm{~m}$ de comprimento, sendo que a tora 2 foi retirada da altura de $1,70 \mathrm{~m}$ e a tora 3 da altura de $6,4 \mathrm{~m}$, conforme mostra a Figura 9.

As toras foram adequadamente identificadas e posteriormente foi feita mensuração do comprimento e dos diâmetros, com e sem casca, de cada uma das toras. 
A tora 1 , da base da árvore, foi utilizada para o estudo da massa específica à umidade de equilíbrio ao ar, enquanto que as toras 2 e 3 foram utilizadas para avaliações dos defeitos oriundos da tensão de crescimento, classificação e qualidade mecânica da madeira serrada.

As toras 1 foram tomadas em todas as 3 classes de DAPs, enquanto que as toras 2 e 3 foram tomadas somente nas classes superior e média porque as toras da classe inferior não poderiam ser serradas em função de limitações dos equipamentos.

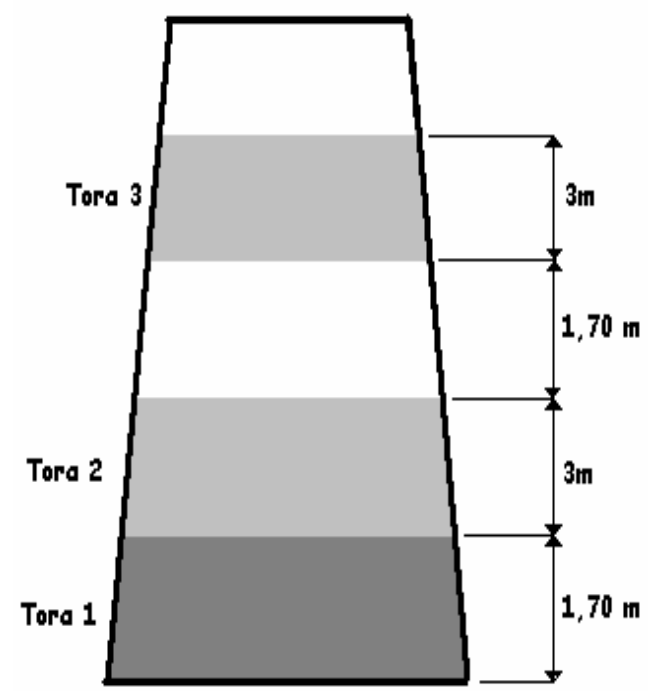

Figura 9 - Posições das toras amostradas dentro da árvore

\subsection{Desdobro}

\section{a) Desdobro das toras 1}

As toras 1 foram transportadas para a serraria da ESALQ/USP e desdobradas numa serra de fita simples, segundo o esquema mostrado na Figura 10, de tal forma a produzir uma prancha diametral passivel de fornecer corpos de prova representativos da posições $0,25,50,75$ e 100\% do raio da árvore, necessário ao estudo da variação medula-casca de uma forma bem completa. Essa técnica de desdobro foi adotada para evitar-se a rachadura que, normalmente, ocorre ao longo da medula da prancha diametral, por influência das tensões residuais remanescentes na tora. O primeiro corte teve o papel importante de transformar a energia de deformação, 
que provocaria a rachadura, em energia de deformação, que provocou deslocamentos transversais e conseqüentemente flexão das duas peças produzidas por esse corte.

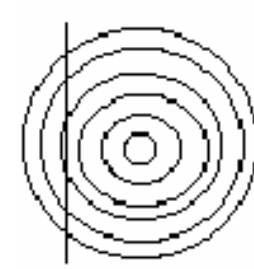

$1 *$ Corte

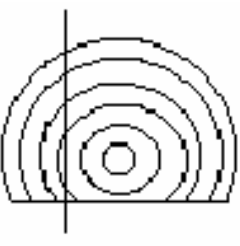

$2^{\bullet}$ Corte

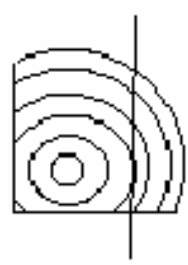

$3^{\bullet}$ Corte

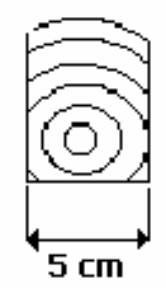

Prancha diametral

assimétrica

Figura 10 - Seqüência de cortes para obtenção da prancha diametral isenta da rachadura longitudinal de medula

\section{b) Desdobro das toras 2 e 3}

O desdobro das toras 2 e 3 foi realizado na serraria comercial da CAF em Martinho Campos/MG, segundo a estratégia de desdobro esquematizada na Figura 11, adotado pela empresa na produção de peças serradas de dimensões comerciais. Essa serraria foi escolhida para esta pesquisa porque a mesma processa comercialmente toras de eucalipto e tem grande experiência nessa atividade.

Essa operação foi efetuada dentro de 1 semana da derrubada das árvores no campo.

Para a realização do desdobro foi utilizada uma serra de fita dupla mostrada na Figura 12 (a), seguida de uma serra circular múltipla mostrada na Figura $12(b)$.

A espessura da tábua ( $h$ ) foi fixada em $2,5 \mathrm{~cm}$ e a largura variou de $10 \mathrm{a}$ $20 \mathrm{~cm}$ em função do diâmetro da tora.

Todas as peças serradas foram cuidadosamente identificadas e estratificadas por tora tendo-se o cuidado de mapear a suas posições espaciais no volume da tora de onde foram retiradas. 
As tábuas foram então separadas e medidas de acordo com sua posição relativa na tora e também na posição horizontal, ou seja, variação medula -casca.

Com o objetivo de estudar a variação medula-casca, foi utilizado 3 pontos de amostragem ao longo do raio da tora, ou seja, 0,50 e $100 \%$ do raio. As toras produziram de 3 a 5 tábuas, devido a esse fato, adotou-se o seguinte critério para a avaliação dos 3 pontos: nas produções ímpares utiliza-se a peça do meio e as duas laterais, nas produções pares utiliza-se a média das duas centrais e duas laterais.

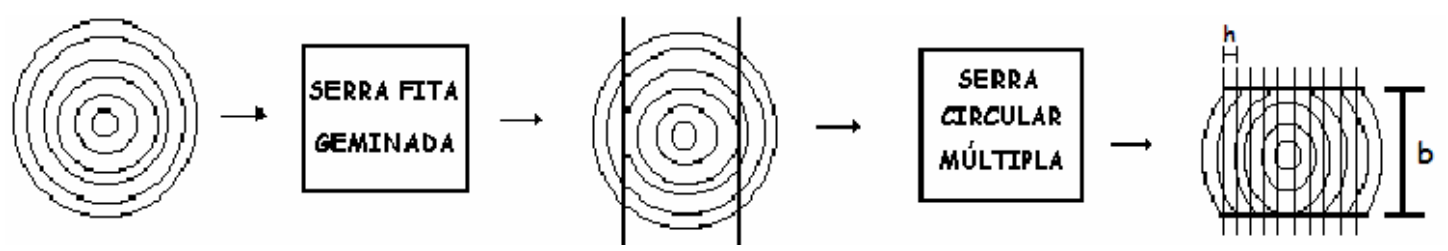

Figura 11 - Esquema de desdobro comercial efetuado para liberação equilibrada de tensões 


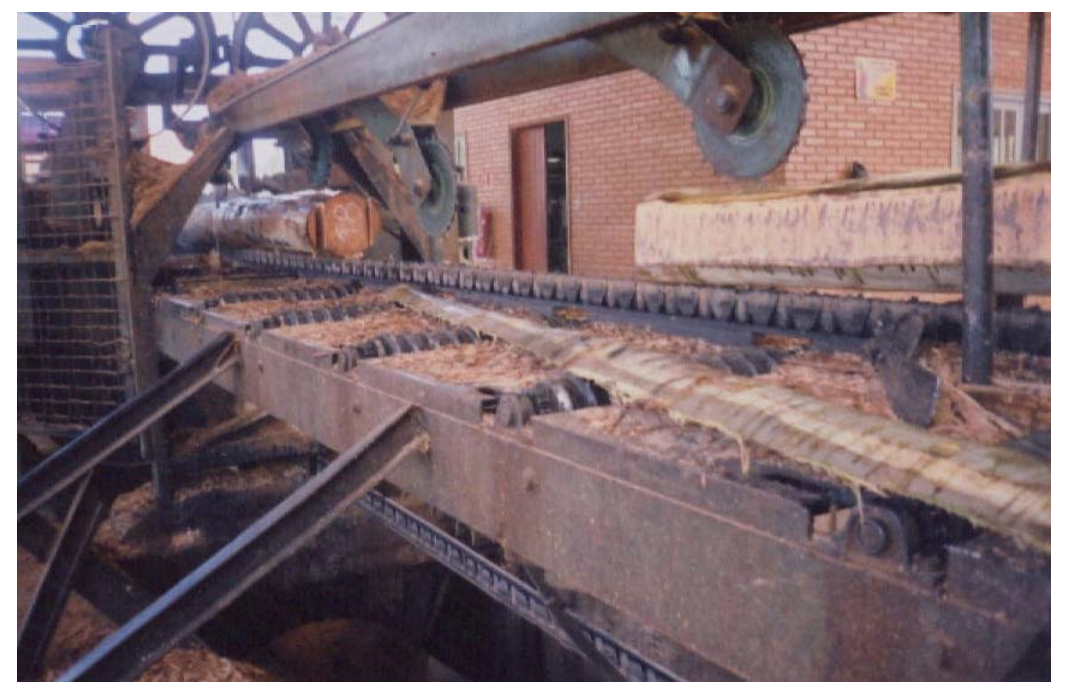

(a)

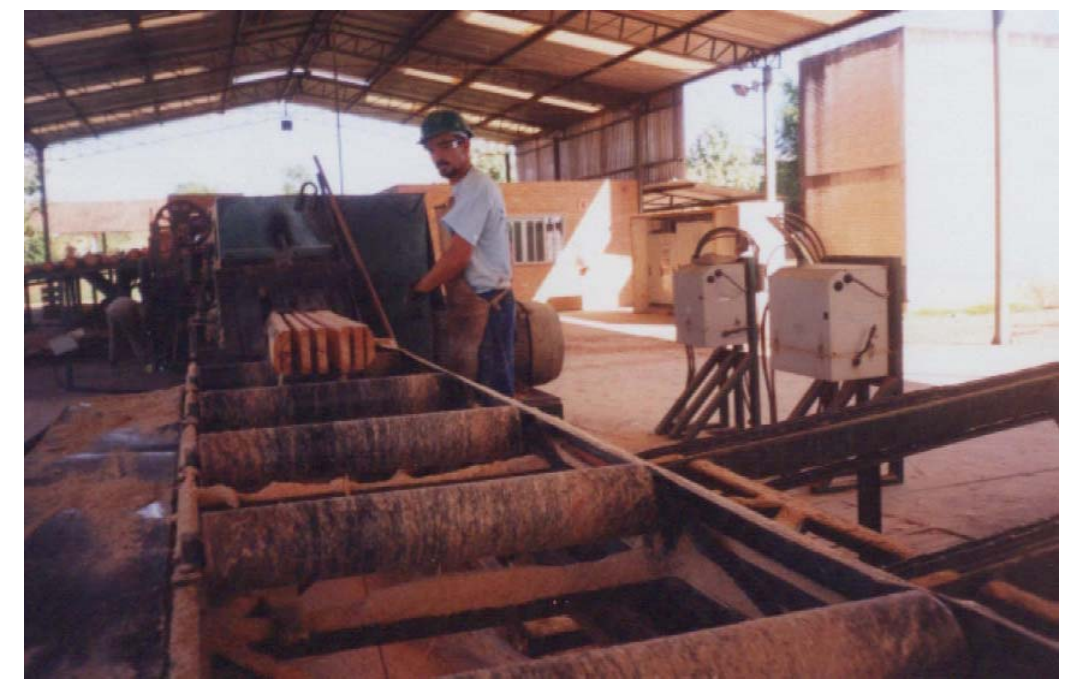

(b)

Figura 12 - Cortes simultâneos de 2 costaneiras na serra de fita dupla, produzindo um semi-bloco (a) e cortes múltiplos do semi-bloco numa serra circular múltipla (b) 


\subsection{Obtenção de dados e ensaios realizados}

\subsubsection{Deslocamento da medula (DM)}

O deslocamento da medula foi calculado, através da eq. 1 , cujas variáveis foram obtidas segundo o procedimento esquematizado na Figura 13, para cada uma das extremidades da tora. Tomou-se como variável de estudo, a média por tora, ou seja, a média dos dois valores obtidos em cada tora.

$$
D M=R_{\text {maior }}-R_{\text {médio }}
$$

Onde:

$\mathrm{DM}=$ deslocamento da medula $(\mathrm{cm})$;

$R_{\text {maior }}=$ valor da maior distância entre a medula e a periferia da tora $(\mathrm{cm})$;

$\mathrm{R}_{\text {médio }}=$ valor médio obtido dos raios maior, menor, perpendicular 1(Rp1) e perpendicular $2(\mathrm{Rp} 2)(\mathrm{cm})$.

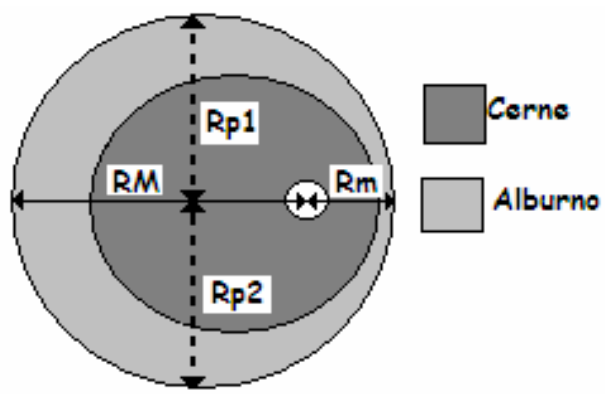

Figura 13 - Variáveis que expressam o deslocamento da medula na seção transversal da tora 


\subsubsection{Porcentagem de casca (PC)}

A porcentagem de casca foi obtida pela eq. 2, a partir das áreas das secções transversais calculadas com os respectivos diâmetros, com casca e sem casca, de cada tora.

$$
P C=\left(\frac{A c C-A s c}{A c C}\right) 100
$$

Onde:

$$
\begin{aligned}
& P C=\text { porcentagem de casca }(\%) ; \\
& A_{c c}=D c c^{2}+d_{c c^{2}} \\
& A_{s c}=D s c^{2}+d_{s c}^{2} ; \\
& D c c=\text { diâmetro com casca obtido na extremidade mais grossa }(\mathrm{cm}) ; \\
& \text { dsc }=\text { diâmetro com casca obtido na extremidade mais fina }(\mathrm{cm}) .
\end{aligned}
$$

\subsubsection{Conicidade (C)}

A conicidade de cada tora foi calculada utilizando-se a eq. (3).

$$
C=\left(\frac{D-d}{L}\right)
$$

Onde:

$$
\begin{aligned}
& C=\text { conicidade da tora }(\mathrm{cm} / \mathrm{m}) ; \\
& D=\text { diâmetro da extremidade mais grossa }(\mathrm{cm}) ; \\
& d=\text { diâmetro da extremidade mais fina }(\mathrm{cm}) ; \\
& L=\text { comprimento da tora }(\mathrm{m}) .
\end{aligned}
$$


A Figura 14, obtida de Garcia (1992) mostra as variáveis de cálculo da conicidade e, principalmente o efeito dessa variável na orientação da fibra na peça serrada.

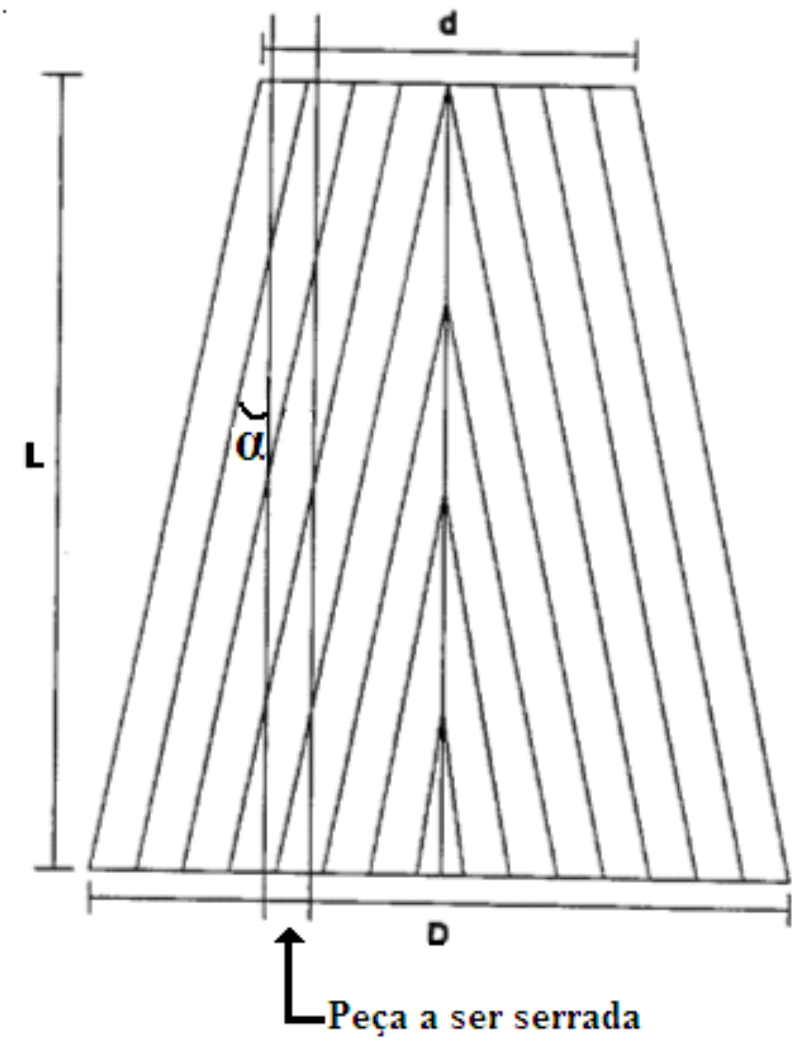

Figura 14 - Geometria de uma tora cônica, mostrando o ângulo ( $\alpha$ ) formado entre a direção da fibra e o eixo da peça serrada, quando obtida por cortes paralelos à medula

Fonte: Garcia (1992)

\subsection{4 Índice de rachadura de topo de tora (IRTT)}

Antes do desdobro foi determinado um IRTT para cada extremidade da tora, segundo a metodologia criada por Lima et al. (2002), expressa pela eq. (4). Foi 
considerado, para análise, apenas o índice médio da tora, ou seja, a média dos valores obtidos para cada extremidade da tora.

$$
I R T T=200\left(\frac{\sum_{i=1}^{n} a_{i} C_{i}}{\pi D^{2}}\right)
$$

Onde:

IRTT = índice de rachadura de topo de tora (\%);

$\mathrm{a}_{\mathrm{i}}=$ abertura máxima da i-ésima rachadura $(\mathrm{cm})$;

$\mathrm{C}_{\mathrm{i}}=$ comprimento da mesma rachadura $(\mathrm{cm})$;

$\mathrm{D}=$ diâmetro médio da seção transversal considerada na tora $(\mathrm{cm})$.

\subsubsection{Rachadura de extremidade de tábua serrada}

Nas tábuas resultantes do desdobro determinaram-se os índices de rachadura de extremidade de tábua serrada no estado verde e no estado seco.

\section{a) Índice de rachaduras de extremidade de tábua serrada verde (IRTV)}

Esse índice representa a média, na tora, dos comprimentos acumulados das rachaduras das duas extremidades de cada uma das tábuas serradas no estado verde e foi calculado pela eq. (5).

$$
I R T V=\frac{\sum_{i=1}^{n}\left(C_{1}+C_{2}\right)_{i}}{n}
$$

Onde:

IRTV = Índice de rachaduras de extremidade de tábua serrada verde $(\mathrm{cm})$; 
$\mathrm{C}_{1}$ e $\mathrm{C}_{2}=$ comprimento das rachaduras respectivas das extremidades 1 e 2 da tábua no estado verde $(\mathrm{cm})$, conforme Figura 15;

$\mathrm{n}=\mathrm{n}^{\circ}$ de tábua serradas obtidas da tora.

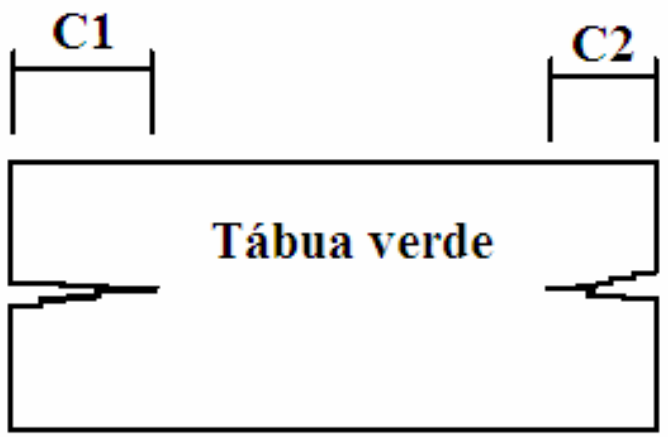

Figura 15 - Tábua verde com rachaduras de extremidades

b) Índice de rachaduras de extremidade de tábua serrada seca (IRTS)

As tábuas serradas no estado verde passaram por um processo de secagem em uma estufa solar, por um período de 28 dias. Após esse período de secagem, foi avaliado o IRTS que representa a média, na tora, dos comprimentos acumulados das rachaduras das duas extremidades de cada uma das tábuas serradas no estado seco e foi calculado pela eq. (6).

$$
\text { IRTS }=\frac{\sum_{i=1}^{n}\left(C_{1}+C_{2}\right)_{i}}{n}
$$

Onde:

IRTS = Índice de rachaduras de extremidade de tábua serrada seca $(\mathrm{cm})$;

$\mathrm{C}_{1}$ e $\mathrm{C}_{2}=$ comprimento das rachaduras respectivas das extremidades $1 \mathrm{e}$ 2 da tábua no estado seco $(\mathrm{cm})$, conforme Figura 16;

$\mathrm{n}=\mathrm{n} \times$ de tábuas serradas obtidas da tora. 


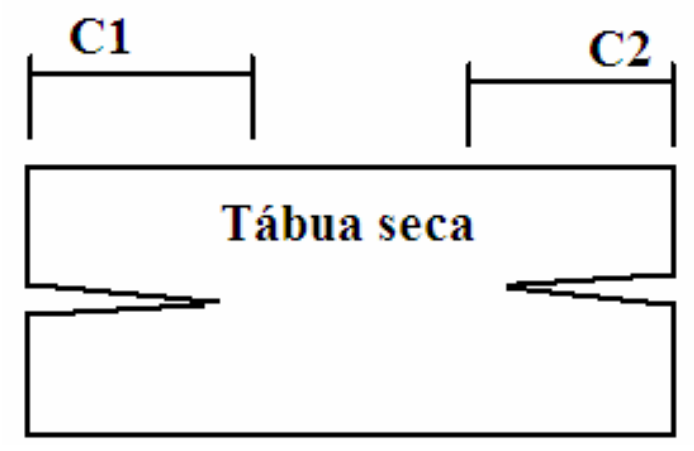

Figura 16 - Tábua seca com rachaduras de extremidades

\subsubsection{Empenamentos}

Empenamento é, de uma forma geral, o nome que se dá ao estado deformado de uma peça que sofreu flexão. A ABNT(1986) adotou, em função do que já vinha ocorrendo na prática das serrarias, os termos encurvamento e arqueamento como os designadores de dois tipos particulares de empenamentos. O encurvamento é utilizado para indicar o estado deformado de uma peça que sofreu flexão como conseqüência dos deslocamentos diferenciados que os pontos da peça sofreram numa direção perpendicular às faces serradas. O arqueamento indica o estado deformado da peça que ocorreu pelo deslocamentos de seus pontos na direção perpendicular às bordas. Observam-se, portanto, uma concavidade da face na peça encurvada e uma concavidade da borda da peça arqueada.

No presente trabalho, foram criadas as variáveis flecha de encurvamento e flecha de arqueamento para servir de indicadores quantitativos do encurvamento e do arqueamento, respectivamente. Essas variáveis foram medidas em cada tábua e no estado verde. 


\section{a) Flecha de Encurvamento $\left(F_{E}\right)$}

Do ponto de vista da engenharia das estruturas, o encurvamento surge pelo giro das seções transversais da peça em torno do seu eixo de menor inércia. No caso particular do presente estudo esse defeito surge em função da liberação das tensões residuais que existiam distribuídas ao longo da espessura da peça.

$\mathrm{Na}$ obtenção da flecha de encurvamento utilizou-se, como instrumento auxiliar, uma linha fina, que bem esticada, simulava uma reta de referência da peça serrada suposta indeformada. Essa linha era colocada junto à face côncava da peça de tal forma a ligar um ponto de uma extremidade ao ponto correspondente da outra extremidade e, dessa forma, a linha representava o plano da face indeformada da peça. A flecha de encurvamento, considerada como a distância da face deformada da peça ao plano virtual indeformado foi então medida, como mostra a Figura 17, na metade do comprimento da peça.

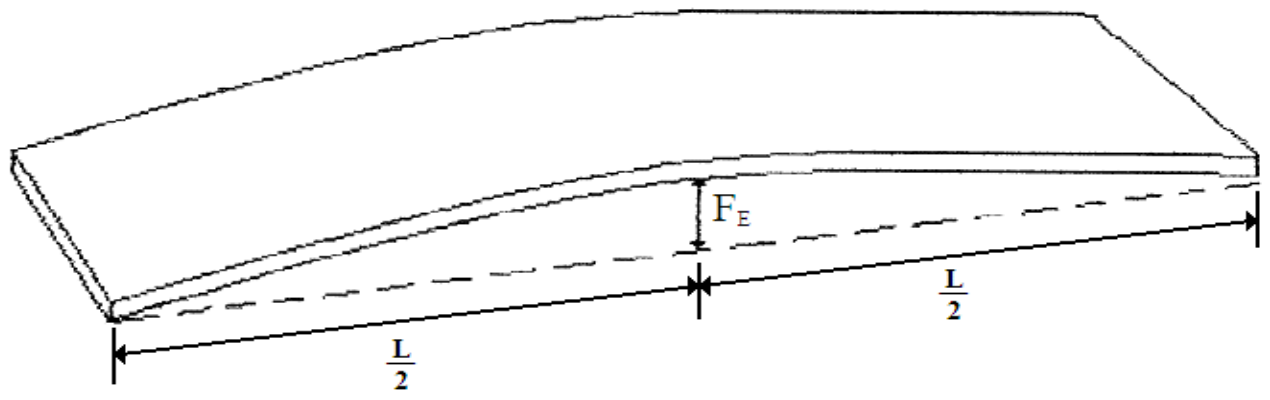

Figura 17 - Vista do encurvamento e da variável flecha de encurvamento $\left(\mathbf{F}_{\mathrm{E}}\right)$

O valor lido da flecha de encurvamento foi ajustado com base na proposição de Garcia (1992) que constatou que a relação entre o comprimento da tábua e o valor da flecha de encurvamento tem relação direta, mas não proporcional. A 
flecha varia com o quadrado da proporção de aumento ou decréscimo do comprimento da tábua.

Dessa maneira as flechas de encurvamento medidas no comprimento real das tábuas foram todas corrigidas para o comprimento padrão de $3 \mathrm{~m}$, através da eq. (7).

$$
F_{E}=F_{E m}\left(\frac{L_{p}}{L}\right)^{2}
$$

Onde:

$$
\begin{aligned}
& F_{E}=\begin{array}{l}
\text { flecha de encurvamento da tábua, ajustada para um comprimento } \\
\text { padrão } L, \text { tomado como sendo de } 3 \mathrm{~m}(\mathrm{~cm}) ;
\end{array} \\
& \mathrm{F}_{\mathrm{Em}}=\text { flecha de encurvamento medida na tábua }(\mathrm{cm}) ; \\
& \mathrm{L}=\text { comprimento real da tábua }(\mathrm{m}) .
\end{aligned}
$$

\section{b) Flecha de arqueamento $\left(F_{A}\right)$}

O encurvamento surge pelo giro das seções transversais da peça em torno do seu eixo de maior inércia e, analogamente ao encurvamento, esse defeito surge em função da liberação das tensões residuais que existiam distribuídas ao longo da largura da peça.

$\mathrm{O}$ arqueamento foi obtido de maneira similar ao encurvamento, como mostra a Figura 18, sendo dado pela distância da borda deformada à borda virtual indeformada, medida na metade do comprimento da peça serrada.

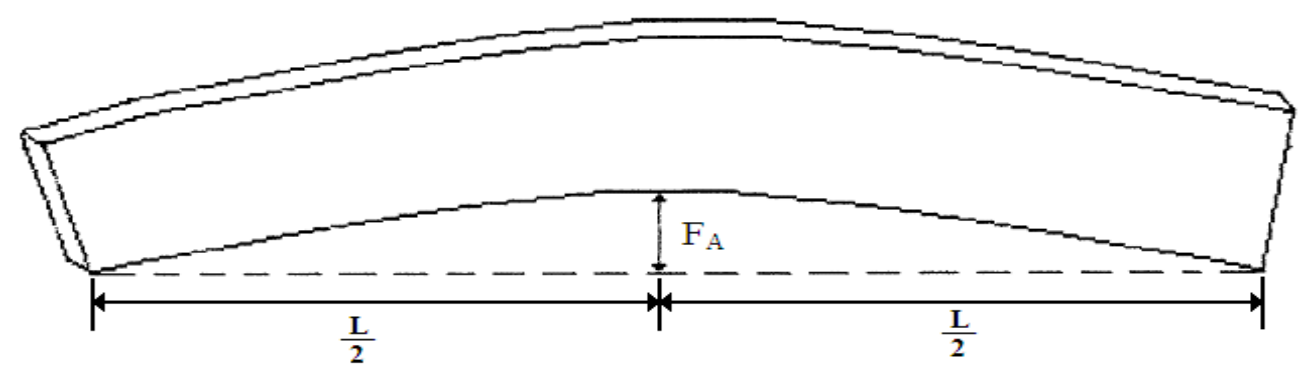

Figura 18 - Vista do arqueamento e da variável flecha de arqueamento( $\left.F_{A}\right)$ 
O arqueamento também foi ajustado para um comprimento padrão, através da eq. (8), similar à eq. (7).

$$
F_{A}=F_{A m}\left(\frac{L_{p}}{L}\right)^{2}
$$

Onde:

$\mathrm{F}_{\mathrm{A}}=$ flecha de arqueamento da tábua, ajustada para um comprimento padrão $L p$, tomado como sendo de $3 m(\mathrm{~cm})$;

$\mathrm{F}_{\mathrm{Am}}=$ flecha de arqueamento medida na tábua $(\mathrm{cm})$;

$L=$ comprimento real da tábua $(m)$.

\subsubsection{Módulo de elasticidade estrutural (MOEe)}

Essa variável foi obtida em ensaios não destrutivos de flexão estática desenvolvidos segundo uma metodologia elaborada para qualificar tábuas de dimensões estruturais ou comerciais na própria indústria, num canteiro de obra em que se utilize madeira serrada ou no campo. Para a aplicação da metodologia foi montada, no pátio da serraria onde as tábuas foram produzidas, uma máquina de ensaio manual, mostrada de forma esquemática na Figura 19, utilizando-se do seguinte material: dois cavaletes de madeira para apoio das tábuas, uma estrutura de metal, uma régua de madeira (alavanca) de 2,5 m de comprimento, graduada de 20 em 20 centímetros, dois pesos fixos de $2 \mathrm{~kg}$, três cutelos de metal utilizados nos apoios e na aplicação da força de flexão e um relógio comparador digital eletrônico com resolução de 0,01mm.

A parte principal da prensa era a alavanca articulada na estrutura vertical metálica e que transferia cargas de flexão para a peça sob ensaio por influência dos pesos que eram colocados em pontos definidos ao longo do seu 
comprimento. A peça a ser ensaiada era apoiada nos dois cavaletes posicionados equidistantemente da estrutura de aplicação de carga e alinhados segundo uma direção de 90 graus com a direção da alavanca. Dessa forma, aplicava-se a carga de flexão no centro do vão da peça sob ensaio e tomava-se, no relógio comparador, o valor do deslocamento vertical sofrido pelo ponto central da peça. O peso P1 (2 Kg + um peso fictício que produzia o mesmo momento do peso próprio da alavanca), mantido a uma distância fixa da articulação, foi utilizado para estabilizar o conjunto aplicador/receptor da carga, para evitarem-se perturbações quando o peso P2 era deslocado de um ponto para outro ao longo da alavanca. As forças aplicadas sucessivamente no meio do vão da tábua sob ensaio, calculadas pela eq. (9) estão mostradas na Tabela 3.

$$
F=\frac{P_{2}(d)+P_{1}\left(d_{1}+d_{2}\right)}{d_{1}}
$$

Onde:

F= força aplicada na tábua;

$P 1=$ peso fixo;

P2= peso móvel;

d = distância do ponto de aplicação da força variável;

d1 = distância do eixo da alavanca até o corpo de prova;

d2 = distância do corpo de prova até a força peso fixa. 

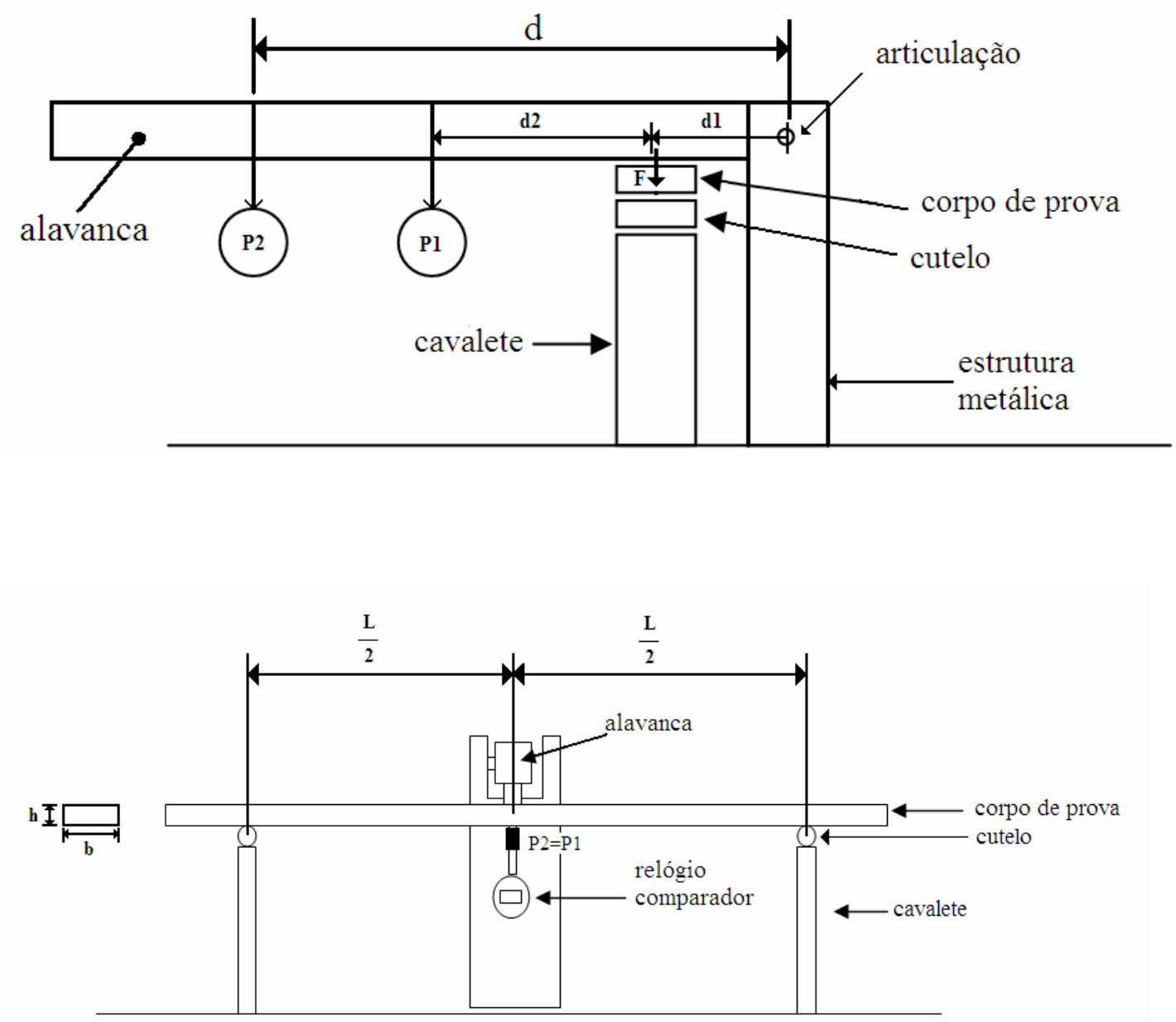

Figura 19 - Teste de flexão campo, não destrutivo, para determinação do MOE estrutural 
Tabela 3. Forças aplicadas no meio do vão da tábua por influência do peso utilizado como carga em diferentes pontos da alavanca

\begin{tabular}{|c|c|}
\hline Distância (d) do peso à articulação (cm) & Força aplicada na tábua (N) \\
\hline 0 & 0 \\
\hline 20 & 59,40 \\
\hline 40 & 79,70 \\
\hline 60 & 100,94 \\
\hline 80 & 121,54 \\
\hline 100 & 142,14 \\
\hline
\end{tabular}

O módulo de elasticidade estrutural na flexão estática foi calculado, através da eq. (10), para cada uma das tábuas obtidas no desdobro das toras 2 e 3 .

Onde:

$$
\text { MOEe }=\left(\frac{B L^{3}}{4 b h^{3}}\right) k \quad(10) \quad F=A+B f
$$

MOEe: módulo de elasticidade estrutural na flexão estática (MPa);

B: coeficiente angular da reta da eq. (11) obtida do diagrama carga-deformação;

A: coeficiente linear da reta;

F: Força aplicada peso aplicado aplicada (N);

f: fecha $(\mathrm{cm})$;

$L$ = vão livre da peça $(290 \mathrm{~cm})$;

$b$ = base da seção transversal, dada pela largura da tábua entre 10 e $20 \mathrm{~cm}$;

$h=$ altura da seção transversal, dada pela espessura da tábua, fixada em $2,5 \mathrm{~cm}$; $\mathrm{k}=0,01=$ fator de transformação de unidades. 


\subsubsection{Rendimento em madeira serrada}

Essa variável foi incorporado ao estudo porque é muito fácil de ser obtida e mostra claramente os pontos fracos do material ou do processo de desdobro. O rendimento sofre influência do diâmetro da tora, mas esse problema foi contornado porque todos os tratamentos foram representados por toras de diâmetros aproximadamente iguais. Foi obtido um valor para cada tora.

Visando identificar pontos críticos do processo, foram avaliados 3 tipos de rendimento de tal forma a se produzir uma base de dados para avaliar-se a relação custo / benefício da estratégia de se agregar valor à madeira serrada.

\section{a) Rendimento em madeira serrada verde sem destopo (RVSD)}

O rendimento em madeira serrada verde, sem destopo, foi obtido pela eq. (12), que expressa a relação entre o volume total das tábuas obtidas de cada tora e o volume dessa tora.

$$
R V S D=\left(\frac{\sum_{i=1}^{n} V T S D_{i}}{V T}\right) 100
$$

Onde:

$$
\begin{aligned}
& \text { RVSD = Rendimento em madeira serrada verde, sem destopo (\%); } \\
& \text { VTSDi= Volume da i-ésima tábua não destopada }\left(\mathrm{m}^{3}\right) ; \\
& \text { VT = Volume da tora }\left(\mathrm{m}^{3}\right) ; \\
& \mathrm{n}=\text { número de tábuas obtidas da tora. }
\end{aligned}
$$




\section{b) Rendimento em madeira serrada verde com destopo (RVCD)}

O rendimento em madeira serrada verde, com destopo, foi calculado pela eq. (13), de maneira similar ao anterior, utilizando-se o comprimento útil da tábua para o cálculo do volume de madeira serrada verde com destopo. O comprimento útil de cada tábua foi obtido descontando-se o IRTV do comprimento real da tábua.

$$
R V C D=\left(\frac{\sum V T C D}{V T}\right)
$$

Onde:

$$
\begin{aligned}
& \text { RVCD = Rendimento em madeira serra verde }, \text { com destopo }(\%) ; \\
& \text { VTCDi= Volumes a i-ésima tábua considerada destopada }\left(\mathrm{m}^{3}\right) ;
\end{aligned}
$$

c) Rendimento em madeira serrada seca isenta de rachaduras de extremidade (RS)

O rendimento em madeira serrada seca isenta de rachaduras de extremidades foi obtido pela eq. (14), sendo considerado como comprimento útil da peça seca, aquele, isento também das rachaduras de extremidades que surgem ou se propagam durante a secagem. Dessa forma, foi descontado o IRTS (que representa a soma do IRTV com comprimento das rachaduras ocorridas durante a secagem) do comprimento real da tábua para obtenção do comprimento útil da peça seca.

$$
R S=\left(\frac{\sum_{i=1}^{n} V T S_{i}}{V T}\right) 100
$$


Onde:

$$
\begin{aligned}
& \text { RS = } \text { Rendimento em madeira serrada seca isenta de rachaduras de } \\
& \text { extremidades }(\%) ; \\
& \text { VTSi }=\text { Volume da i-ésima tábua re-destopada depois da secagem }\left(\mathrm{m}^{3}\right) .
\end{aligned}
$$

\subsubsection{Classificação de tábua seca}

Realizou-se uma classificação das tábua secas, de acordo com a norma adotada pela empresa CAF. Na Tabela 4 estão os parâmetros adotados para a classificação.

Tabela 4. Parâmetros adotados para classificação da madeira serrada E. grandis de 21 anos de idade

\begin{tabular}{ll}
\hline \multicolumn{1}{c}{ QUALIDADE } & \multicolumn{1}{c}{ CRITÉRIO DE CLASSIFICAÇÃO } \\
\hline $\mathbf{1}^{\text {a }}$ Classe & Ausência de nós e rachaduras de topo de até $10 \mathrm{~cm} ;$ \\
$\mathbf{2}^{\text {a }}$ Classe & Presença de até um nó e rachaduras de topo de até $20 \mathrm{~cm} ;$ \\
$\mathbf{3}^{\text {a } \text { Classe }}$ & Presença de até dois nós e rachaduras de topo de até $30 \mathrm{~cm} ;$ \\
Refugo & Presença de mais de dois nós e rachaduras de topo com mais de 30 \\
& $\mathrm{~cm} ;$
\end{tabular}

Fonte: CAF

\subsubsection{Massa específica (ME)}

De cada prancha central oriunda das toras 1 , ainda no estado verde, foram retiradas 4 peças de $43 \mathrm{~cm}$ de comprimento e de cada uma dessas peças foram obtidos 2 ou 3 sarrafos de $(4 \times 4 \times 43) \mathrm{cm}$, como mostra a Figura 20 . Esse número variável de sarrafos por peça foi adotado para que fosse possível a obtenção de 2 sarrafos em cada uma das posições radiais de estudo, principalmente, no caso das pranchas de pequena largura obtidas das árvores da classe inferior. 


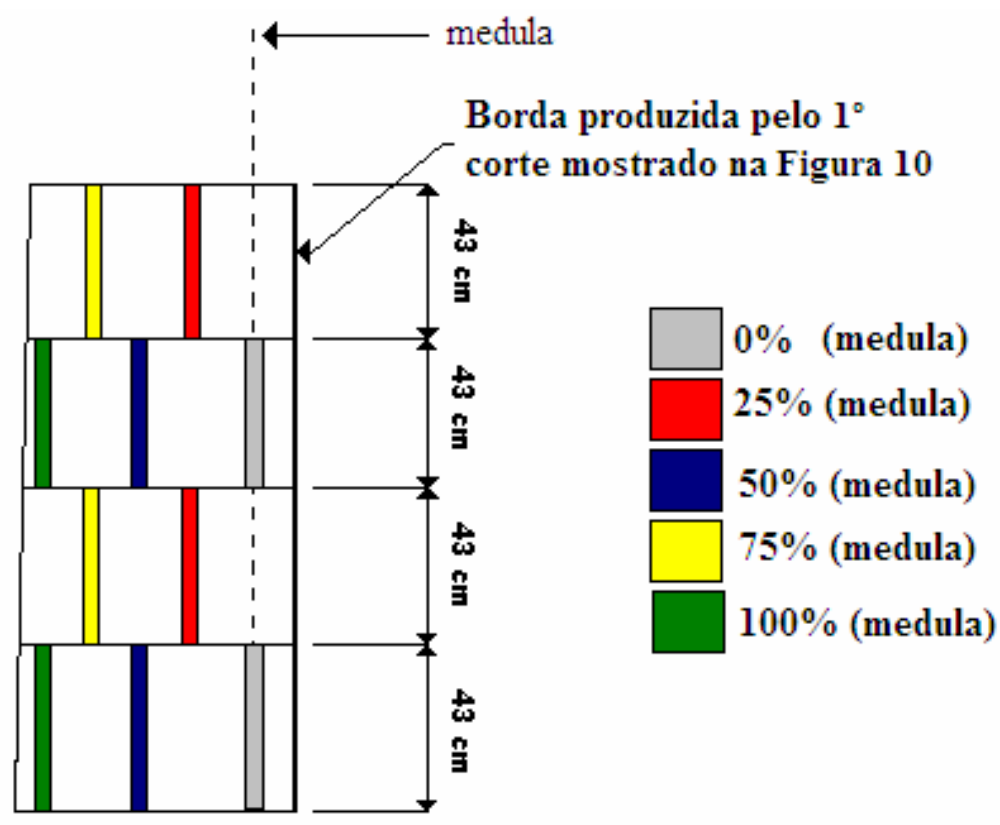

Figura 20 - Prancha central representando as posições radias de retirada dos corpos de prova para estudo da variabilidade radial

Os sarrafos obtidos foram secos ao ar, por um período de aproximadamente 4 meses sendo então selecionado um sarrafo de cada posição radial, para dele ser confeccionado um corpo de prova de $(3 \times 2,5 \times 2,5)$, como mostrado na Figura 21. Foram obtidos, portanto, 360 corpos de prova para estudo da variabilidade da massa específica da madeira à umidade de equilíbrio ao ar em função dos tratamentos adotados. 


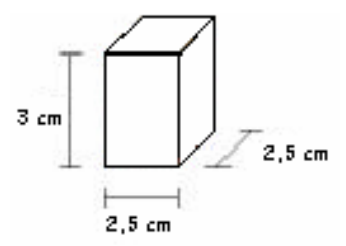

Figura 21- Representação do corpo de prova utilizado na determinação da massa específica da madeira

A massa especifica foi determinada através da eq. (15), obtendo-se o peso do corpo de prova em uma balança digital e obtendo-se as medidas das arestas do corpo de prova com um paquímetro digital.

$$
\begin{aligned}
& \begin{aligned}
M E & =\frac{P S}{V S} \\
\text { Onde: } & \\
M E= & \text { massa específica da madeira à umidade de equilíbrio ao ar } \\
& \left(\mathrm{g} / \mathrm{cm}^{3}\right) ;
\end{aligned} \\
& \mathrm{PS}=\text { peso da amostra à umidade de equilíbrio ao } \mathrm{ar}(\mathrm{g}) ; \\
& \text { VS= volume da amostra à umidade de equilíbrio ao } \mathrm{ar}\left(\mathrm{cm}^{3}\right) .
\end{aligned}
$$

\subsection{Análise estatística}

A avaliação do experimento, foi efetuada, utilizando-se modelos matemáticos, que foram ajustados para considerar a variação completa de todos os tratamentos, dentro de cada uma das posições da altura e das posições radiais. Inicialmente foi efetuado o teste de homogeneidade de variância e para isso utilizou-se o teste de Hartley, posteriormente, foi feito o teste $\mathrm{F}$ de análise de variância segundo o delineamento experimental inteiramente casualizado, adotando-se o esquema fatorial 3 $\mathrm{x} 2 \times 3$ (desbastes $\mathrm{x}$ adubo $\mathrm{x}$ classes de DAP) para estudo da variável obtida da tora 1 e o esquema fatorial $3 \times 2 \times 2$ (desbastes, adubo e classes de DAP) para estudo das variáveis obtidas das toras 2 e 3 .

Foi aplicado o teste de Tukey, sempre que observada influência significativa, ao nível de $5 \%$ de probabilidade, de algum tratamento no teste $\mathrm{F}$. 
No estudo das variáveis do processamento mecânico, ou seja, aquelas medidas nas tábuas, os dados foram separados por tora (tora 1 e tora 2) e, ainda, dentro de cada uma de três posições relativas do raio, ou seja, 0 , 50 e 100\% do raio. No estudo da massa específica à umidade de equilíbrio ao ar, os dados da tora 1 foram separados de tal forma a representar cada uma das posições radias, ou seja, 0, 25, 50 , 75 e $100 \%$ do raio.

O modelo matemático adotado para a variável obtida da tora 1 foi:

$$
\begin{aligned}
& \gamma_{i j k l}=\mu+A_{i}+B_{j}+C_{k}+A B_{i j}+A C_{i k}+B C_{j k}+A B C_{i j k}+\varepsilon_{i j k l} \\
& \text { com } i=1,2,3 ; j=1,2 ; k=1,2,3 ; l=1, \ldots, 4 \text { e, onde: } \\
& \gamma_{i j k l}=\text { é o valor observado para o i-ésimo desbaste, no j-ésimo adubo, na k-ésima } \\
& \text { classe diamétrica e i-ésima repetição. } \\
& \mu=\text { constante inerente } \text { a todas as observações; } \\
& A_{i}=\text { é o efeito do i-ésimo desbaste; } \\
& B_{j}=\text { é o efeito do j-ésimo adubo; } \\
& C_{k}=\text { é o efeito da k-ésima classe; } \\
& A B_{i j}=\text { é o efeito da interação entre desbaste e adubo; } \\
& A C_{i k}=\text { é o efeito da interação desbaste e classe; } \\
& B C_{j k}=\text { é o efeito da interação adubo e classe; } \\
& A B C_{i j k}=\text { é o efeito da interação desbaste, adubo e classe; } \\
& \varepsilon_{i j k l}=\text { é o erro experimental, tal que } \varepsilon_{i j k l} \cap \mathrm{N} \text { IID }\left(0, \sigma^{2}\right) \text {. }
\end{aligned}
$$

O modelo matemático adotado para estudo das variáveis obtidas das toras 2 e 3 foi:

$$
\begin{gathered}
\gamma_{i j k l}=\mu+A_{i}+B_{j}+C_{k}+A B_{i j}+A C_{i k}+B C_{j k}+A B C_{i j k}+\varepsilon_{i j k l} \\
\text { com i=1,2,3; j=1,2; } \mathrm{k}=1,2 ; \mathrm{l}=1, \ldots, 4 \text { e onde: } \\
\gamma_{i j k l}=\text { é o valor observado para o i-ésimo desbaste, no j-ésimo adubo, na k- } \\
\text { ésima classe diamétrica e i-ésima repetição. }
\end{gathered}
$$


$\mu=$ constante inerente a todas as observações;

$A_{i}=$ é o efeito do i-ésimo desbaste;

$B_{j}=$ é o efeito do j-ésimo adubo;

$C_{k}=$ é o efeito da k-ésima classe;

$A B_{i j}=$ é o efeito da interação entre desbaste e adubo;

$A C_{i k}=$ é o efeito da interação desbaste e classe;

$B C_{j k}=$ é o efeito da interação adubo e classe;

$A B C_{i j k}=$ é o efeito da interação desbaste, adubo e classe;

$\varepsilon_{i j k l}=$ é o erro experimental, tal que $\varepsilon_{i j k l} \cap N \| D\left(0, \sigma^{2}\right)$ e independente.

As Tabelas 5 e 6 mostram os esquemas de análise de variância adotados cujos elementos foram calculados através do programa SAS v 6.11.

Tabela 5. Componentes de variância da análise inteiramente casualizada no esquema fatorial $3 \times 2 \times 3$ para a variável da tora 1

\begin{tabular}{|c|c|c|c|c|}
\hline CAUSA DE VARIAÇÃO & GL & SQ & QM & $\mathbf{F}$ \\
\hline $\begin{array}{l}\text { Intensidade } \\
\text { desbaste(I) }\end{array}$ & 2 & SQI & QMI & QMI /QMR \\
\hline Adubo (A) & 1 & SQA & QMA & QMA /QMR \\
\hline Classe (C) & 3 & SQC & QMC & QMC /QMR \\
\hline$(\mathrm{I}) \mathrm{x}(\mathrm{A})$ & 2 & SQIXA & QMIxA & QMIXA /QMR \\
\hline$(\mathrm{I}) \mathrm{x}(\mathrm{C})$ & 3 & SQIXC & QMIxC & QMIxC /QMR \\
\hline$(A) x(C)$ & 3 & SQAXC & QMAxC & QMAxC /QMR \\
\hline$(\mathrm{I}) \mathrm{x}(\mathrm{A}) \mathrm{x}(\mathrm{C})$ & 6 & SQIXAxC & QMIxAxC & QMIxAxC/QMR \\
\hline Resíduo & 51 & SQR & QMR & \\
\hline Total & 71 & SQTotal & & \\
\hline
\end{tabular}


Tabela 6. Componentes de variância da análise inteiramente casualizada no esquema fatorial $3 \times 2 \times 2$ para as variáveis obtidas das toras 2 e 3

\begin{tabular}{|c|c|c|c|c|}
\hline CAUSA DE VARIAÇÃO & GL & SQ & QM & $\mathbf{F}$ \\
\hline $\begin{array}{l}\text { Intensidade } \\
\text { desbaste(I) }\end{array}$ & 2 & SQI & QMI & QMI /QMR \\
\hline Adubo (A) & 1 & SQA & QMA & QMA /QMR \\
\hline Classe (C) & 1 & SQC & QMC & QMC /QMR \\
\hline$(\mathrm{I}) \times(\mathrm{A})$ & 2 & SQIXA & QMIXA & QMIxA /QMR \\
\hline$(\mathrm{I}) \times(\mathrm{C})$ & 2 & SQIXC & QMIxC & QMIxC /QMR \\
\hline$(A) \times(C)$ & 1 & SQAxC & QMAxC & QMAxC /QMR \\
\hline$(\mathrm{I}) \times(\mathrm{A}) \times(\mathrm{C})$ & 2 & SQIXAxC & QMIxAxC & QMIxAxC/QMR \\
\hline Resíduo & 36 & SQR & QMR & \\
\hline Total & 47 & SQTotal & & \\
\hline
\end{tabular}




\section{RESULTADOS E DICUSSÃO}

O DAP e altura, médios de cada uma das parcelas selecionadas na amostragem, estão na Tabela 7.

Tabela 7. Variáveis do inventário realizado nas parcelas selecionadas dentro da população experimental de $E$. grandis de 21 anos

\begin{tabular}{ccc}
\hline $\begin{array}{c}\text { Parcela } \\
\text { (Intensidade de desbaste / presença } \\
\text { de adubo) }\end{array}$ & DAP Médio (cm) & Altura total Média (m) \\
\hline $1(37 \% / N)$ & 25,70 & \\
$2(37 \% / \mathrm{S})$ & 26,65 & 33,05 \\
$3(50 \% / \mathrm{N})$ & 25,70 & 36,15 \\
$4(50 \% / \mathrm{S})$ & 27,40 & 33,10 \\
$5(75 \% / \mathrm{N})$ & 27,05 & 35,85 \\
$6(75 \% / \mathrm{S})$ & 27,90 & 33,10 \\
\hline
\end{tabular}

As Tabelas 8 a 53, que mostram as análises de variância efetuadas para embasar as discussões que se seguem, encontram-se no anexo.

\subsection{Deslocamento da medula (DM)}

Nas Tabelas 8 e 9, encontram-se os resultados das análises de variância realizadas para o deslocamento da medula das toras 2 e 3, respectivamente, e nas Figuras 22 e 23 estão representados os seus valores médios e respectivos desvios padrão. 


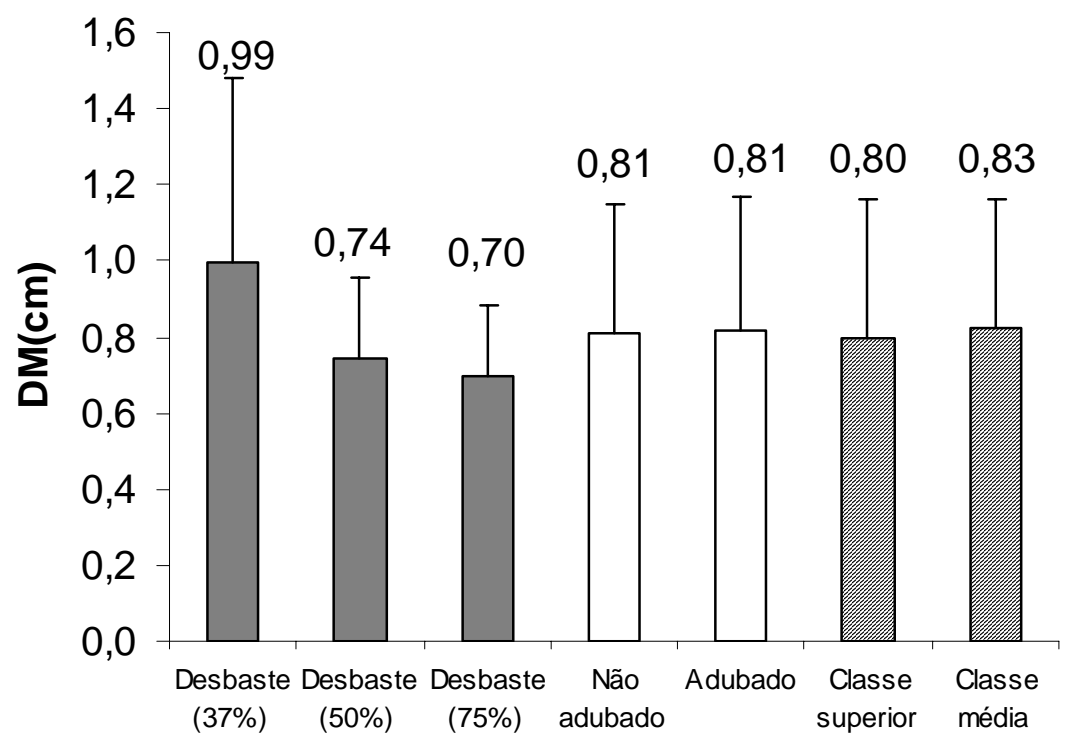

Figura 22 - Deslocamento da medula (DM) na tora 2 de E. grandis de 21 anos de idade

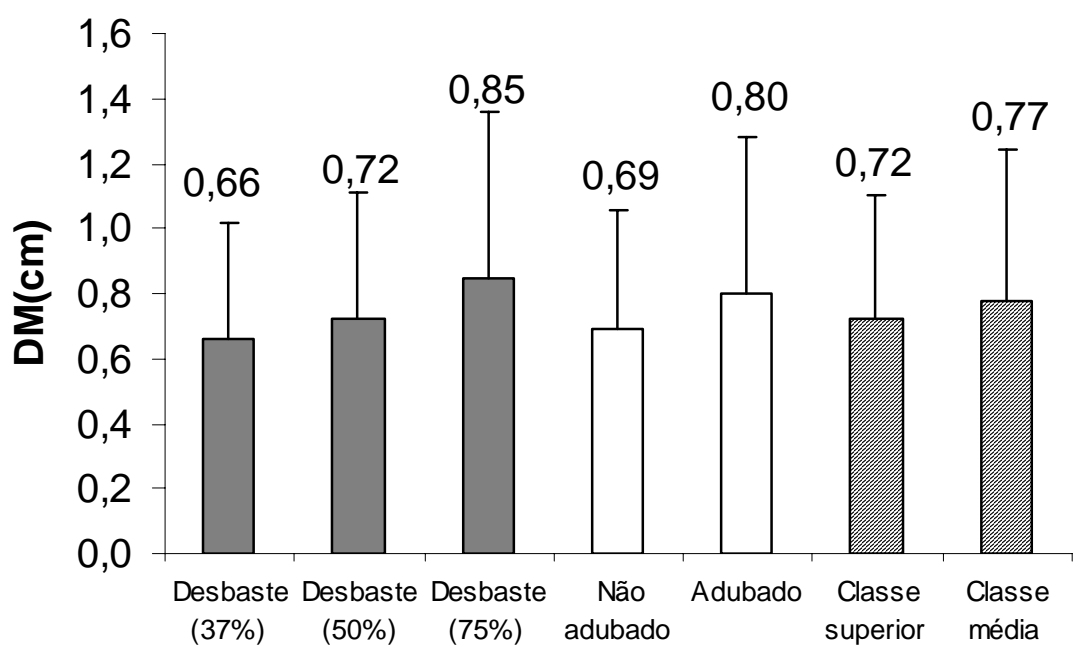

Figura 23 - Deslocamento da medula (DM) na tora 3 de E. grandis de 21 anos de idade

Foi observado para o deslocamento da medula que não houve diferenças significativas entre as três intensidades de desbaste. Isso mostra que essas intensidades não foram prejudiciais no sentido de provocar o deslocamento da medula 
como conseqüência de eventuais reorientações pós-desbaste das árvores, tanto para a tora 2 como para a tora 3. Entretanto, numa análise mais cuidadosa dos dados das Figuras 22 e 23, observa-se que na população original a árvore, na altura da tora 2 , estava sendo forçada a ser excêntrica, provavelmente, por causa de uma possível competição assimétrica. O primeiro desbaste foi benéfico no sentido de reduzir drasticamente a excentricidade, demonstrando a partir daí o crescimento em diâmetro da arvore passa a ser mais simétrico e minimizando a excentricidade que já existia. Do $2^{\circ}$ para o $3^{\circ}$ desbaste praticamente não houve mudança no deslocamento da medula indicando que as árvores já se mostram estabilizadas. Na altura da tora 3, ocorre o contrário, sendo o $3^{\circ}$ desbaste bastante influente no sentido de aumentar a excentricidade da árvore. Depreende-se que qualquer manejo (seja desbaste ou adubação) que provoque crescimento da árvore em diâmetro altera com maior intensidade o deslocamento da medula da árvore na altura da tora 3.

Para o fator adubo na segunda e terceira toras, foi observado que não houve diferenças significativas ao nível de $5 \%$ de probabilidade entre as parcelas adubadas e não adubadas.

No fator classe, em ambas as toras, não ocorreram diferenças significativas ao nível de $5 \%$ de probabilidade entre as duas classes de DAP.

Pode-se então observar que o deslocamento da medula, para a situação em estudo, não sofreu interferência significativa das diferentes intensidades de desbaste e nem da adubação em qualquer das duas classes de diâmetros estudadas.

Esse resultado é importante, pois, a presente situação mostra que é possível aumentar-se o crescimento em diâmetro das árvores através de desbastes e/ou fertilização sem provocar aumento significativo no deslocamento da medula que é uma variável que redunda em arqueamento ou encurvamento das tábuas quando desdobro das toras. Esses defeitos podem ocorrer por causa da excentricidade geométrica que libera tensões de crescimento de forma desequilibrada mesmo que numa estratégia de cortes balanceados (Garcia 2003) ou por causa da presença da madeira de reação que já é por natureza assimétrica e que segundo Burger \& Richter (1991) está presente em toras que apresentem deslocamento acentuado de medula. 


\subsection{Porcentagem de casca (PC)}

Nas Tabelas 10 e 11 encontram-se os resultados das análises de variância para porcentagem de casca (PC) e nas Figuras 24 e 25 estão representados, os valores médios das porcentagens de casca e seus respectivos desvios padrão.

Pode-se observar, de acordo com os resultados obtidos para as toras 2 e 3, que não ocorreram diferenças significativas entre as diferentes intensidades de desbastes, para a porcentagem de casca.

No fator adubo foi observado que também não houve diferenças significativas para as parcelas não adubadas e adubadas.

Para o fator classe de DAP não ocorreram diferenças significativas entre as mesmas. De acordo com a literatura esses valores de porcentagem de casca encontrados (6,01 a 8,36\%) podem ser considerados baixos, interferindo então pouco no rendimento em madeira serrada. Barchet (2001) encontrou valores que variaram de 9,34\% a 18,03\% para várias espécies de eucaliptos.

Os resultados demonstram que os desbastes e a fertilização não interferiram na porcentagem de casca, para as condições desse trabalho.

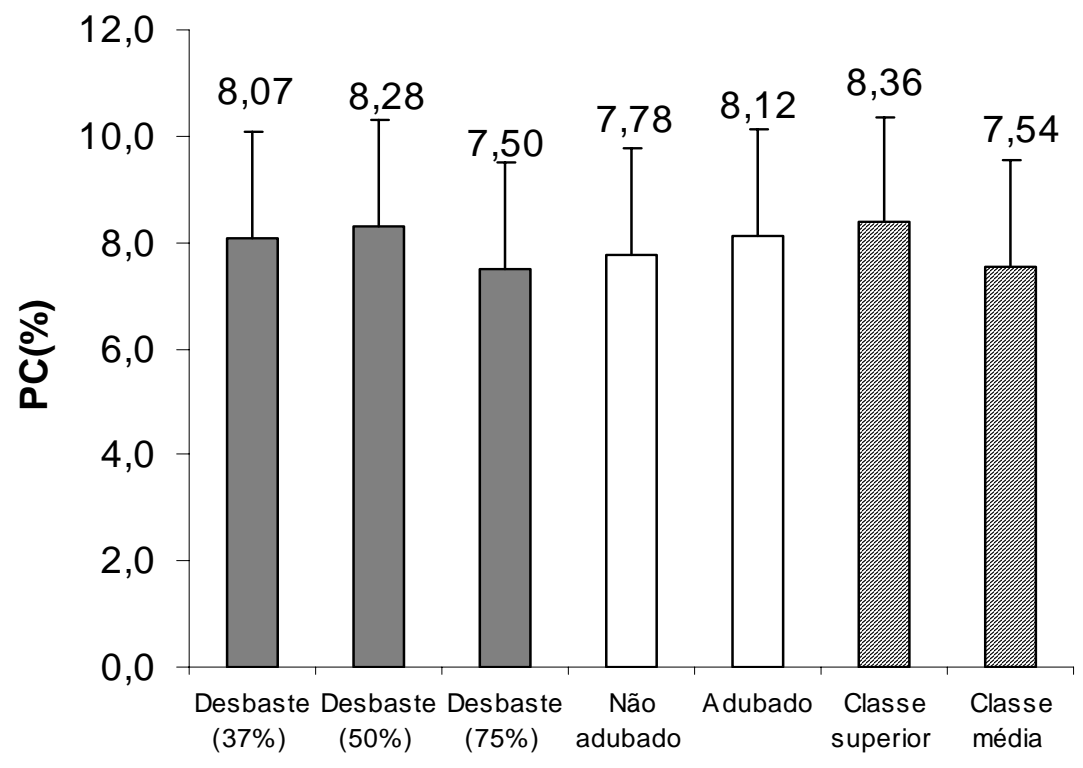

Figura 24 - Porcentagem de casca (PC) na tora 2 de E. grandis, de 21 anos de idade 


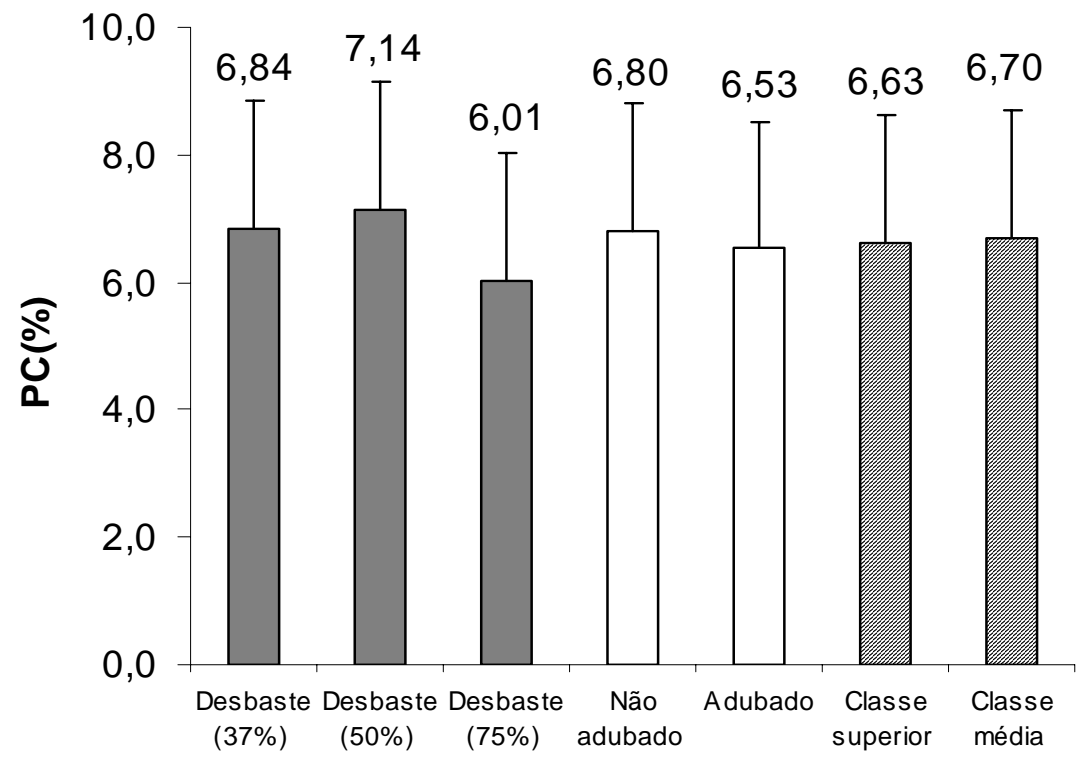

Figura 25 - Porcentagem de casca (PC) na tora 3 de E. grandis, de 21 anos de idade

\subsection{Conicidade (C)}

Nas Tabelas 12 e 13 encontram-se os resultados das análises estatísticas efetuadas para a conicidade das toras, e nas Figuras 26 e 27 estão representados os valores médios da conicidade e seus respectivos desvios padrão, para as toras 2 e 3 , respectivamente.

É possível observar nessas tabelas não ocorreram diferenças significativas de conicidade entre as diferentes intensidades de desbaste.

No caso do fator adubo foi observado que não houve diferenças significativas entre as parcelas adubadas e não adubadas.

Para o fator classe, foi verificado que ocorreram diferenças significativas entre as duas classes de DAP, tanto a tora 2 quanto para a tora 3. As classes superiores apresentaram maiores conicidades, o que já era esperado, pois, segundo a literatura, a conicidade aumenta com o aumento do DAP da árvore. 


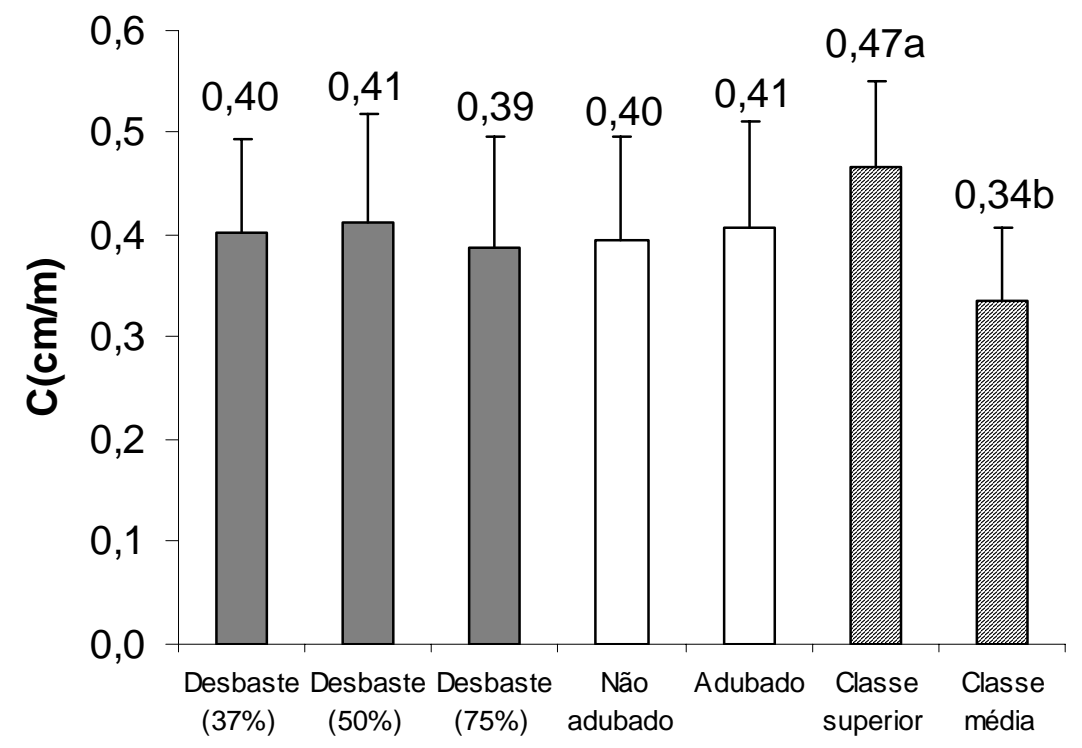

Figura 26 - Conicidade (C) na tora 2 de E. grandis de 21 anos de idade

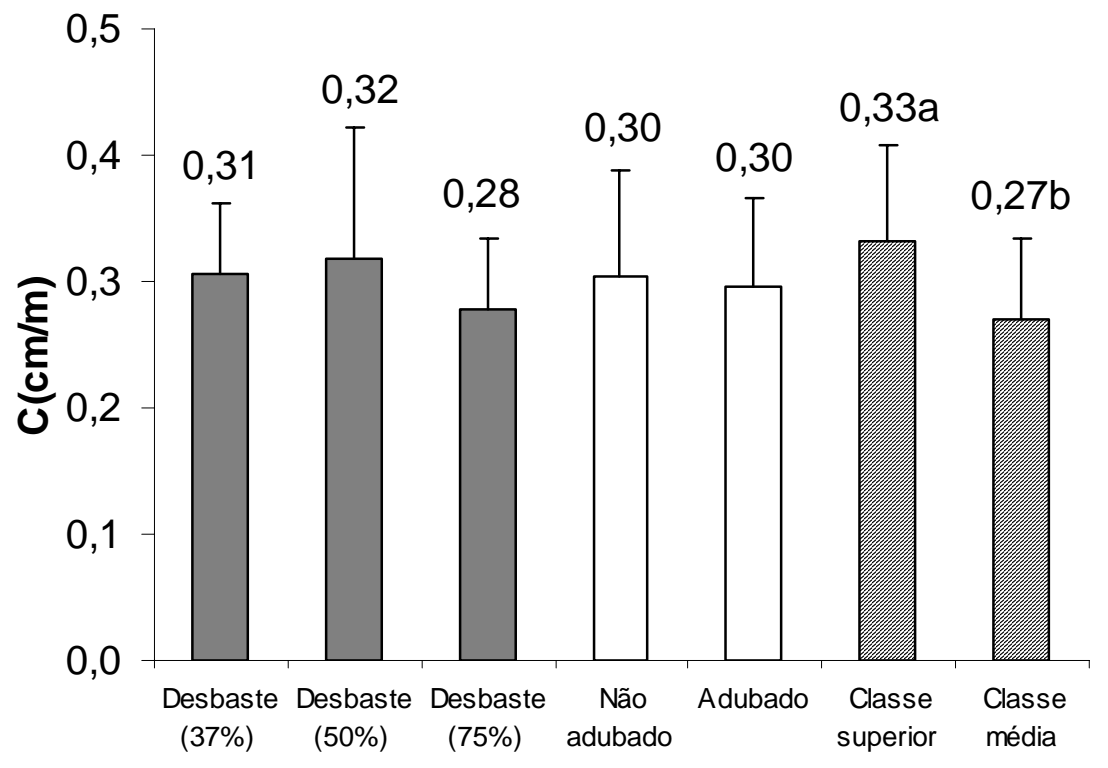

Figura 27 - Conicidade (C) na tora 3 de E. grandis de 21 anos de idade

De modo geral foi observado que as toras apresentaram valores menores que $1 \mathrm{~cm} / \mathrm{m}$ de conicidade, o que não acarreta grandes perdas no 
aproveitamento da madeira. Esse resultado pode ser explicado devido a não utilização das toras da base da árvore que, normalmente, são mais cônicas. Oliveira (1997) encontrou valor médio para toras de $E$. grandis igual a $0,62 \mathrm{~cm} / \mathrm{m}$. Scanavaca Junior (2001), em um estudo numa população E. urophylla, obteve, também, valores menores que $1 \mathrm{~cm} / \mathrm{m}$ para conicidade e, assim, concluiu que a conicidade não influenciou no rendimento em madeira serrada. Barchet (2001) encontrou valores entre 0,55 a 1,36 $(\mathrm{cm} / \mathrm{m})$ para a conicidade das toras para diversas espécies de eucaliptos.

\section{4 Índice de rachadura de topo de tora (IRTT)}

Nas Tabelas 14 e 15 e Figuras 28 e 29 encontram-se os resultados das análises de variância realizada para os índices de rachaduras de extremidade de tora verde e seus valores médios e respectivos desvios padrão, para as toras 2 e 3 , respectivamente.

Observa-se que não houve diferenças significativas entre as três intensidades de desbaste, demonstrando que essas intensidades não foram suficientes para alterar os índices de rachaduras, nas toras 2 e 3, e que os fatores genéticos são mais eficientes no controle da intensidade de rachaduras. Porém, Lima et al. (2000a), em uma pesquisa semelhante, encontraram valores de IRTT que variaram de 0,49(\%) na testemunha sem desbaste, a 0,80(\%) na intensidade de $67 \%$ de desbaste, mas, somente as intensidades de desbaste $50 \%$ e $67 \%$ diferiram da testemunha, enquanto que as outras não diferiram entre si.

Para o fator adubo também não houve diferenças significativas entre as parcelas adubadas e não adubadas, nas rachaduras de extremidade das toras 2 e 3 . Isso demonstra que a fertilização não foi prejudicial no sentido de provocar grandes manifestações da tensão de crescimento na forma de intensidade de rachaduras de topo de tora.

No estudo do fator classe, também pode ser verificado que não houve diferenças significativas entre as duas classes de DAP. Esse intervalo entre classes não foi suficiente para interferir significativamente na intensidade de rachaduras. Em uma outra pesquisa Chafe (1985), também não encontrou correlação significativa entre 
tensão de crescimento e diâmetro de $E$. nitens em árvore em pé, porém, para o $E$. regnans ocorreu correlação altamente significativa e positiva.

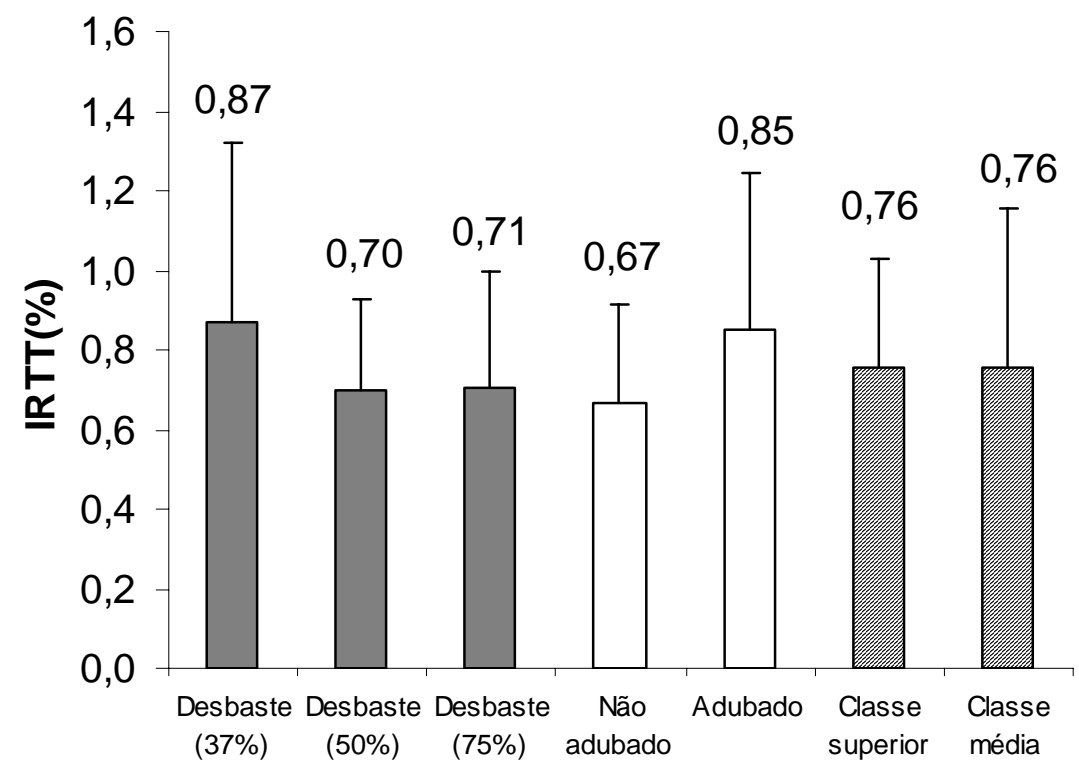

Figura 28 - Índice de rachadura de topo de tora (IRTT) de E. grandis de 21 anos de idade na tora 2

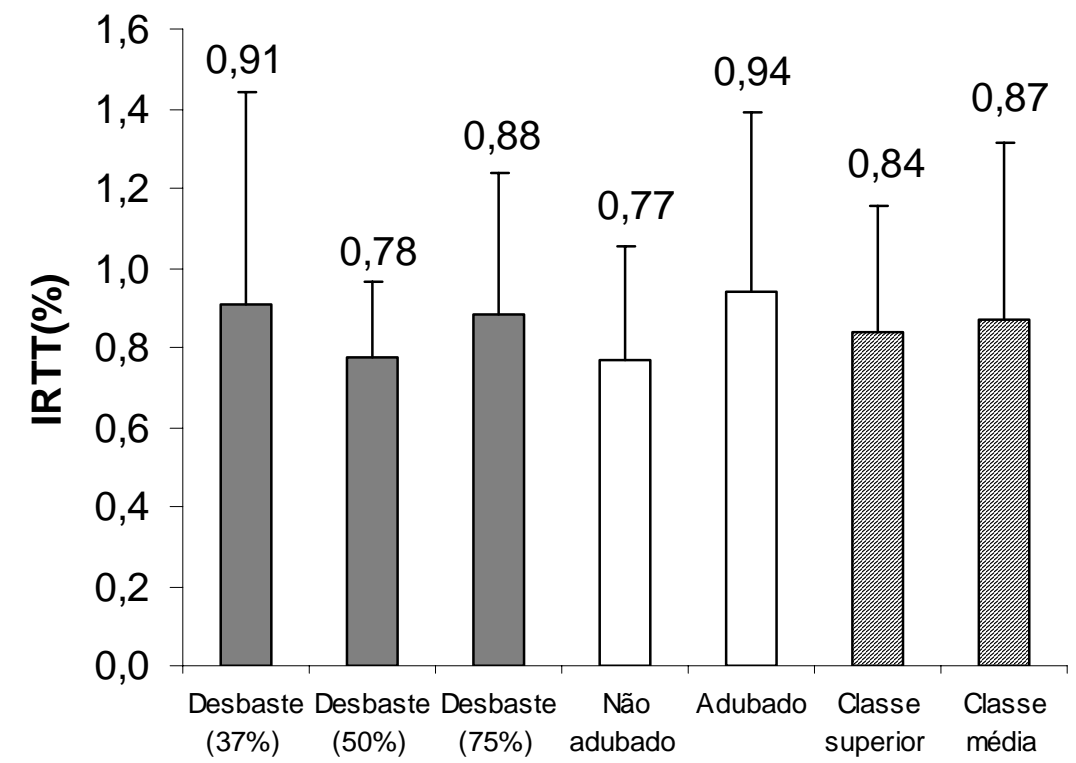

Figura 29 - Índice de rachadura topo de tora (IRTT) de E. grandis de 21 anos de idade na tora 3 
Por outro lado, Wilson (1985), em um estudo de rachadura de topo de toras, observou um aumento de proporção de rachadura com o aumento do diâmetro na mesma idade, para $E$. macarthurii e $E$. elata e presumiu que isso ocorreu devido a maior proporção de madeira juvenil do que adulta nessas espécies.

Esse resultado confirma também a tendência de um alto controle genético nas rachaduras de extremidades de toras em progênie de $E$. urophylla, encontrado por Fernandes (1982).

\section{5 Índice de rachaduras de extremidade de tábua verde (IRTV)}

Nas Tabelas 16 a 21 e na Figura 30, encontram-se os resultados das análises estatísticas realizadas para a variável IRTV, seus valores médios e respectivos desvios padrão.

Observou-se que para o índice de rachaduras de extremidade de tábua verde (IRTV) não ocorreram diferenças significativas entre as três intensidades de desbaste, para cada tora e posição radial. Isso demonstra que as intensidades estudadas não foram suficientes para influir significativamente nos índices de rachaduras de extremidade de tábua verde e que, de acordo com a literatura, as rachaduras de extremidade de tábua são mais fortemente controladas por fatores genéticos. Esses resultados estão de acordo com Malan \& Hoon (1992), que não verificaram efeitos de diferentes intensidade de desbastes na intensidade de rachaduras de extremidade de tábua em diferentes classes de DAP uma população de E. grandis. Lima et al. (2000a) também observaram que diferentes intensidades de desbastes não influenciaram significativamente a intensidade de rachaduras de extremidade de tábua em E. grandis e que isso ocorreu em virtude da alta variação verificada dentro de cada intensidade de desbaste.

Em um trabalho com E. delegatensis e E. nitens, Ferrand (1983) verificou que desbastes moderados não influenciaram na deformação de crescimento, que é a causa principal de rachaduras de extremidade tanto de tora quanto de tábua, mas desbastes precoces e pesados influenciaram significativamente. Segundo esse autor isso ocorreu porque a deformação de crescimento é fortemente relacionada com a competição entre árvores. Wilkins \& Kitahara (1991) verificaram que desbastes 
efetuados em uma população de E. grandis de 12,5 anos de idade aumentaram a taxa de crescimento e diminuíram o nível de deformação de crescimento.

Para o fator adubo foi observado que não houve diferenças significativas entre as parcelas adubadas e não adubadas, para cada tora e posição radial. Devese, então, considerar que a adubação efetuada aos 5 anos de idade, após o primeiro desbaste, não foi suficiente para interferir significativamente nas rachaduras de peça serrada verde que é um dos defeitos causados por altas tensões de crescimento.

No caso do fator classe de DAP, verificou-se que houve diferenças significativas entre as classes superior e média nas posições $0 \%$ e $50 \%$ da tora 3 . A classe superior apresentou, na tora 3 , maior intensidade de rachadura e, embora de maneira não significativa, a mesma tendência na tora 2. A diferença entre os níveis de significância da tora 2 e 3 deve-se ao fato de que a relação entre a largura da tábua e o diâmetro da tora foi maior na tora 3. Crêspo (2000) também encontrou, em populações de $E$. grandis e E. saligna, maiores valores de rachaduras de extremidade de tábua na classe superior e, a partir daí, concluiu que isso pode ser explicado pelo fato desta classe produzir tábuas de larguras maiores do que aquelas que se pode produzir em classes inferiores.

$\mathrm{Na}$ Figura 31 está apresentada a variação radial da rachadura de extremidade de tábua verde, podendo-se observar que há uma tendência das rachaduras diminuírem no sentido da medula para a casca. Del Menezes (1999) observou a mesma tendência para E. grandis e E. cloeziana.

A diminuição da intensidade de rachadura no sentido medula-casca pode ser explicada pelo fato de ocorrer nas tábuas da região próxima à medula um efeito combinado de dois fatores importantes. O primeiro deles é que a madeira central, por ser predominantemente composta de madeira juvenil, apresenta menor resistência à tração normal às fibras e o segundo é que as componentes transversais originárias da tensão de crescimento longitudinal quando esta é liberada no desdobro são as máximas possíveis e coincidem com a direção paralelas às faces, provocando, portanto, tração normal máxima. A madeira da região próxima da medula apresenta menor resistência aos efeitos das tensões de crescimento que se manifestam na forma de rachadura (Kubler,1987; Garcia,1995). 


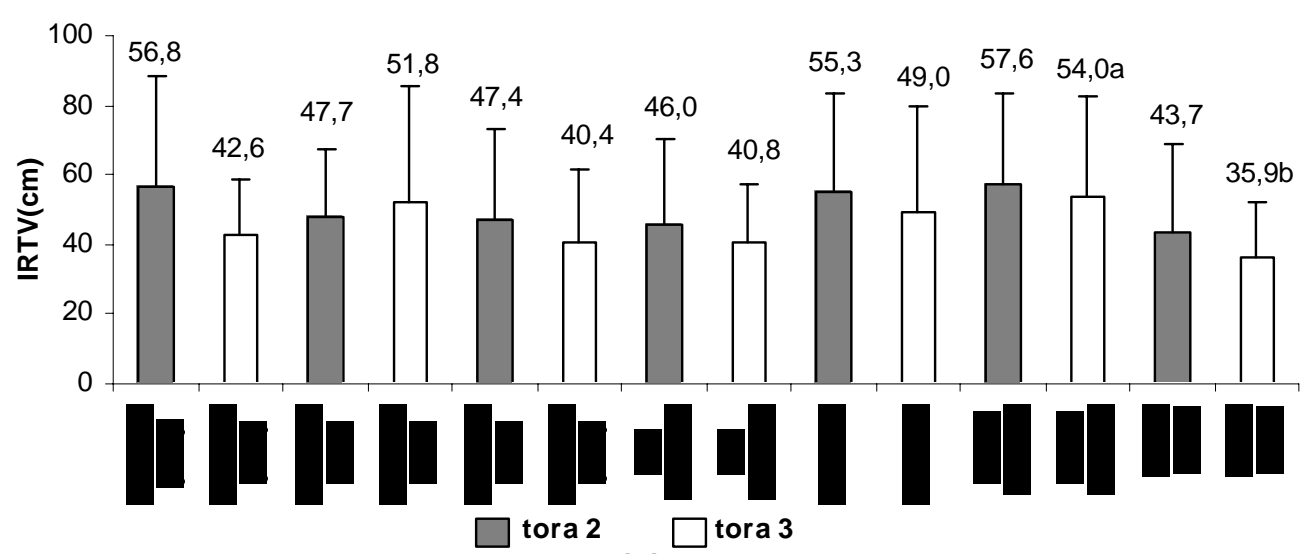

(a)
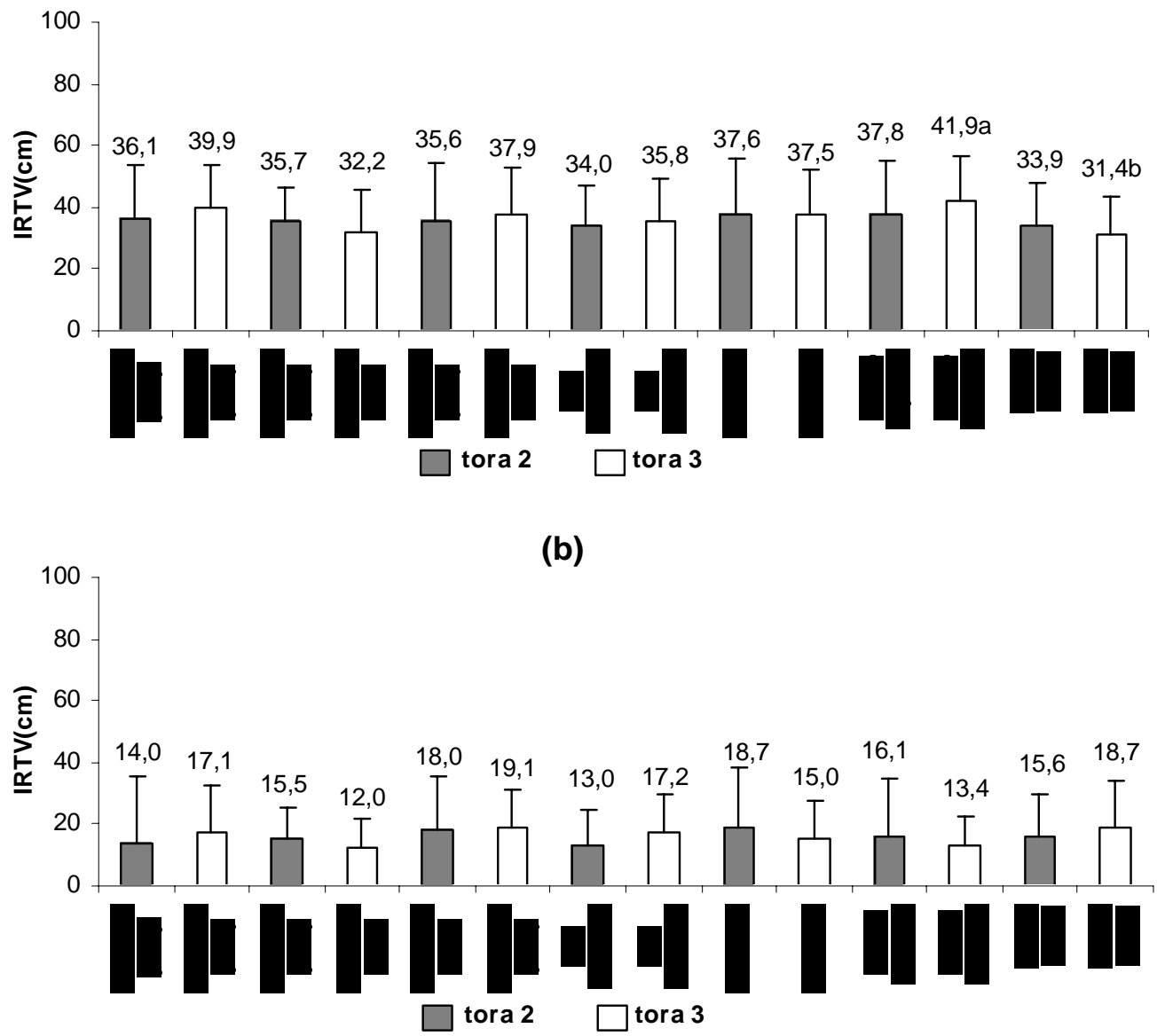

(c)

Figura 30 - Índice de rachaduras de extremidade de tábua verde (IRPV) de E.grandis de 21 anos de idade na posição $0 \%$ (a), na posição 50\% (b) e na posição $100 \%$ (c) do raio da tora 

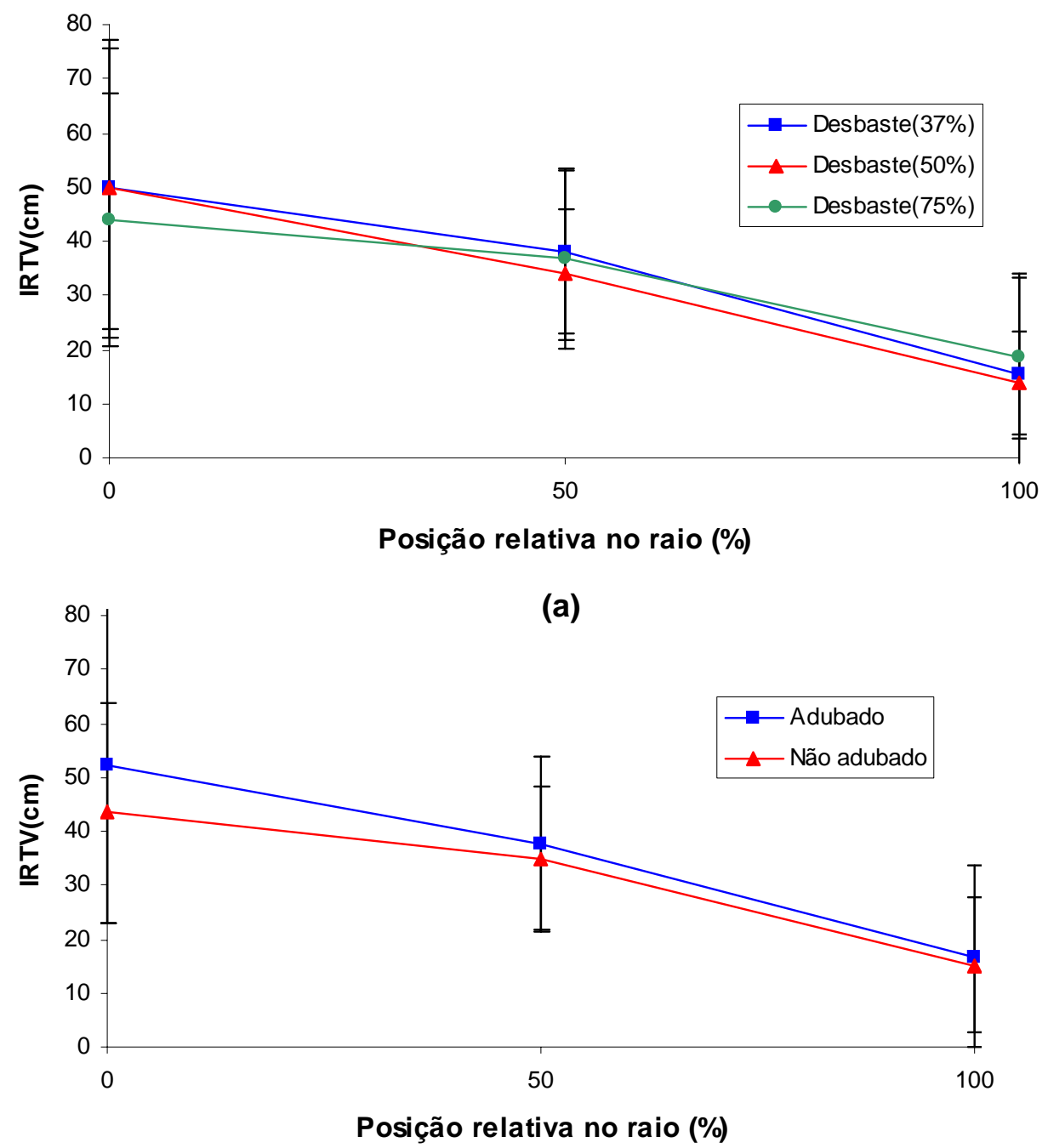

(b)

Figura 31 - Índice de rachaduras de extremidade de tábua verde (IRPV) de E. grandis de 21 anos de idade em função da intensidade de desbaste (a) e da adubação (b)

As componentes transversais vão perdendo intensidade na direção paralela às faces e adquirindo maior importância na direção perpendicular às faces à medida em que se caminha para a periferia da tora. Dessa forma a energia de deformação que provoca rachadura vai se transformando gradativamente em energia de deformação que provoca empenamentos. 
Pode-se observar também na Figura 31 que a intensidade de desbaste de $75 \%$ e as parcelas adubadas apresentaram uma menor variação medula-casca e, também, que as tábuas das parcelas adubadas racharam mais do que as tábuas das parcelas não adubadas em todas as posições radiais. Essa avaliação é importante no estudo da qualidade da madeira, pois pode-se selecionar o tipo de manejo que resulta em madeira mais homogênea para utilizações industriais. Depreende-se que árvores que crescem mais livre de competição tendem a produzir madeira mais homogênea no sentido medula-casca.

\section{6 Índice de rachaduras de extremidade de tábua seca (IRTS)}

Nas Tabelas 22 a 27 e Figura 32 encontram-se os resultados das análises de variância realizadas para a variável IRTS, seus valores médios e respectivos desvios padrão.

Foi observado para o índice de rachaduras de extremidade de tábua seca (IRTS) que não ocorreram diferenças significativas entre as três intensidades de desbaste, para cada tora e posição radial. Resultado diferente foi encontrado por, Miranda \& Nahuz (1999), que observaram que espaçamentos maiores provocaram menores índices de rachaduras das tábuas após a secagem.

No caso do fator adubo foi observado que ocorreram diferenças significativas entre as parcelas adubadas e não adubadas somente para a tora 2 e na posição radial (0\%), mas a tendência é a mesma para a tora 3. Pode-se considerar que a adubação provoca, na posição radial $0 \%$, um efeito de facilitar as rachaduras de extremidade de tábua seca, o que não acontece com a rachadura de extremidade de tábua verde. Trata-se de um fato complexo que necessita de uma análise mais profunda.

Para o fator classe, foi verificado que houve diferenças significativas, entre a classe superior e média para tora 2 na posição (0\%) e tora 3 posição (50\%), podendo aceitar a mesma discussão efetuada para o caso da IRTV.

Observa-se na Figura 33 que o IRTS diminui no sentido da medula para a casca com menor variação na intensidade de desbaste de $75 \%$ e nas parcelas não adubadas. 

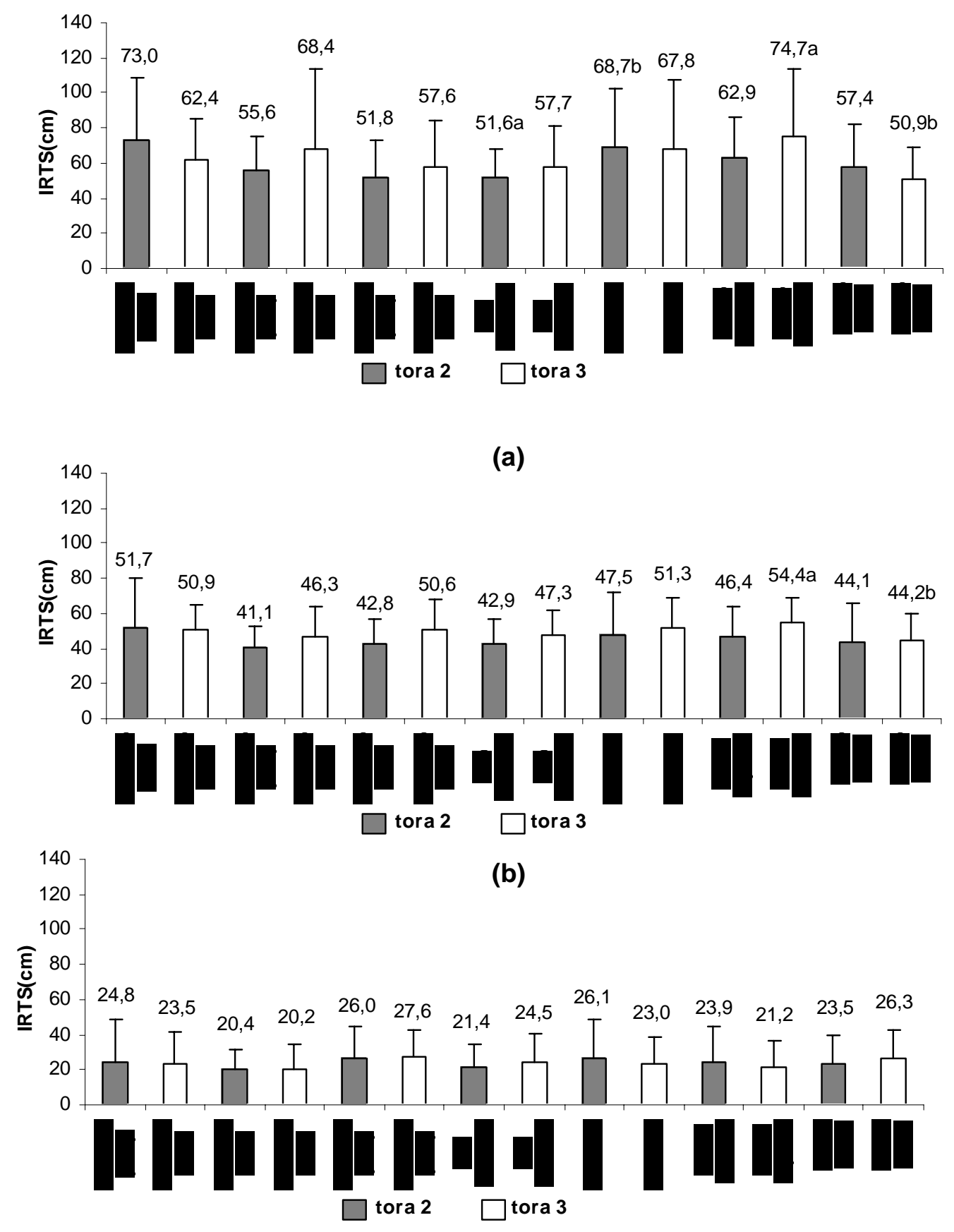

(c)

Figura 32 - Índice de rachaduras de extremidade de tábua seca (IRTS) de E. grandis de 21 anos de idade na posição radial $0 \%$ (a), na posição $50 \%$ (b) e na posição $100 \%$ (c) do raio da tora 


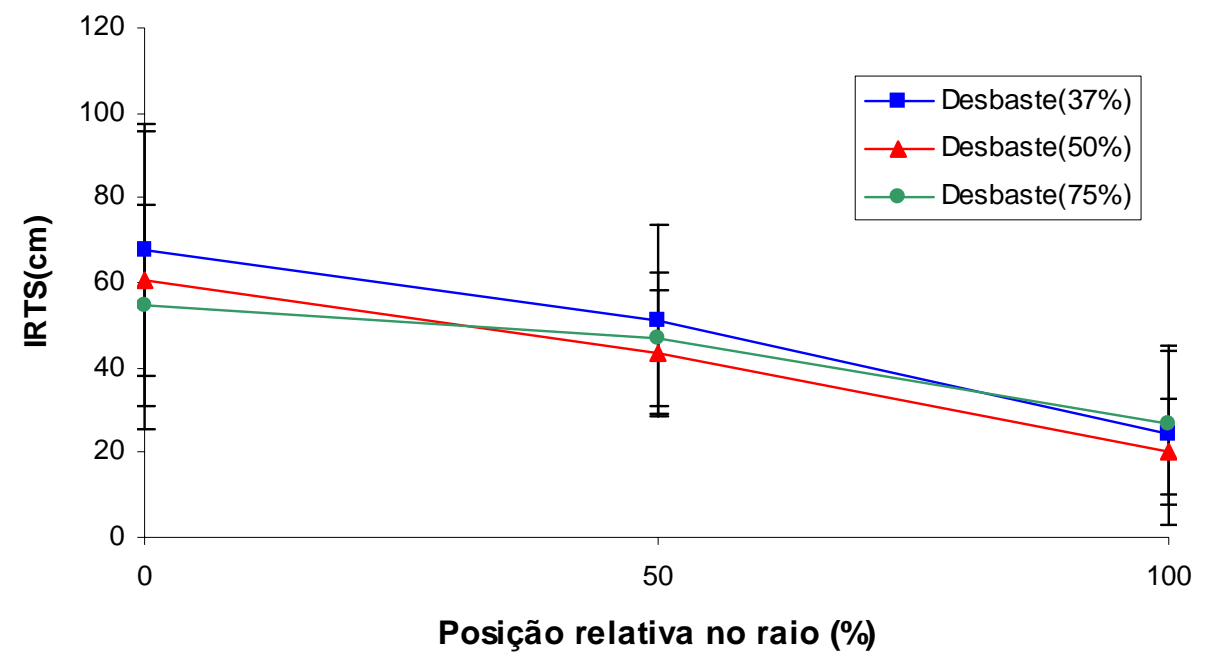

(a)

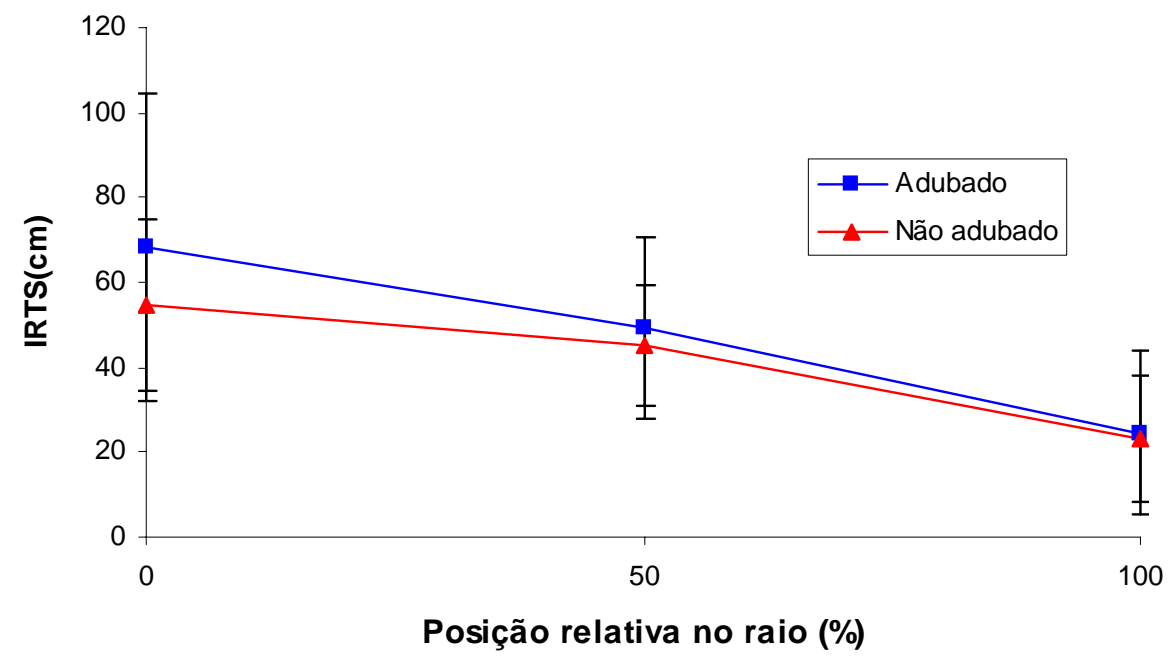

(b)

Figura 33 - Índice de rachaduras de extremidade de tábua seca (IRTS) de E.grandis de 21 anos de idade em função da intensidade de desbaste (a) e da adubação (b)

Quando se compara o valor médio de IRPV $(33,33 \mathrm{~cm})$ com o valor médio de IRTS $(44,15 \mathrm{~cm})$ verifica-se que houve um aumento médio de 10,82 cm no comprimento da rachadura de extremidade de tábua por causa da propagação da 
rachadura que existia na peça verde durante o processo de secagem. Miranda \& Nahuz (1999) verificaram para o $E$. saligna de 9 anos de idade que tábuas que poderiam de $4 \mathrm{~m}$ de comprimento perderam, em média, de 24 a $28 \mathrm{~cm}$ desse valor no processo de desdobro e secagem.

Pode-se, então, concluir para na situação do presente trabalho que as tabuas perdem $33,33 \mathrm{~cm}$ de comprimento devido aos efeitos quase que exclusivo das tensões de crescimento e mais 10,82 cm, de tábua seca, devido a um efeito complexo e combinado de tensões de crescimento com tensões de secagem.

\subsection{Flecha de encurvamento $\left(F_{E}\right)$}

As Tabelas 28 a 33 e Figura 34 mostram os resultados das análises de variância para a flecha de encurvamento, médias e respectivos desvios padrão, obtidos apenas no estado verde das tábuas.

Foi observado que não ocorreram diferenças significativas entre as três intensidades de desbaste. Por outro lado, Lima et al. (2000a) verificaram diferenças significativas entre as diferentes intensidades de desbaste para o encurvamento de

peça de $E$. grandis, sendo que nesse caso houve diferenças entre as intensidades $0 \% \mathrm{e}$ $83 \%$ de desbaste.

No fator adubo foi observado que não ocorreram diferenças significativas entre as parcelas adubadas e não adubadas.

Foi verificado que também não houve diferenças significativas entre as duas classes de DAP.

$\mathrm{Na}$ Figura 35 podem ser observadas a variação radial da flecha de encurvamento. Pode-se observar que a flecha de encurvamento aumenta no sentido da medula para a casca. A explicação para essa tendência foi apresentada na discussão da rachadura de extremidade de tábua verde. Portanto, as tábuas oriundas da região próxima à casca estão mais propensas ao encurvamento conseqüente das tensões de crescimento (Kubler ,1987; Garcia,1995), porém, quando não ocorrer armazenamento de tensões residuais por influência da largura da tábua (Garcia, 2003). Resultados semelhantes foram obtidos por Del Menezzi (1999), Barchet (2001), porém esses autores utilizaram-se de outra metodologia para cálculo do encurvamento.

Na Figura 35 pode-se observar que na intensidade de desbaste de $75 \%$ 
e nas parcelas adubadas houve uma ligeiramente menor variação medula-casca.
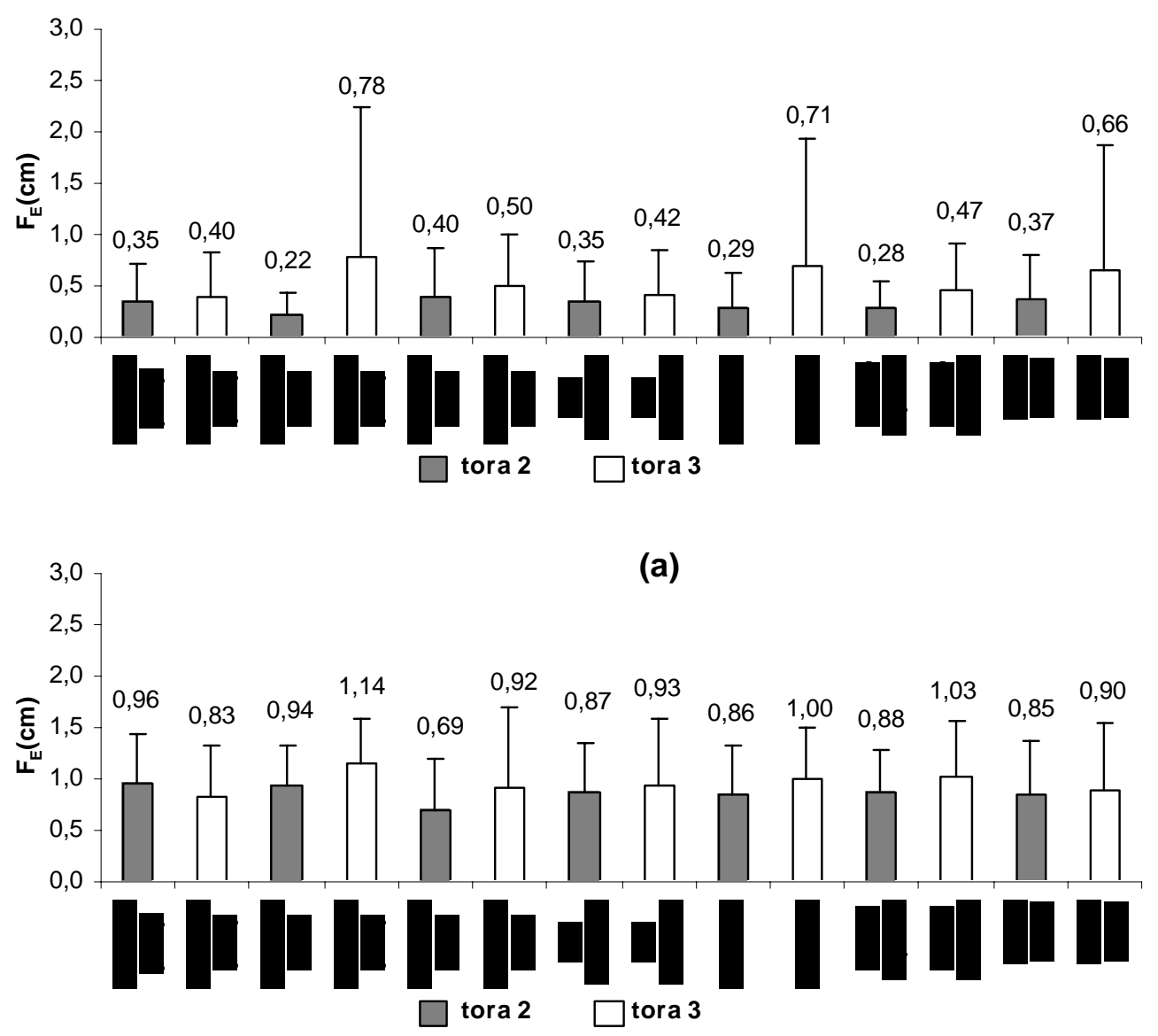

(b)

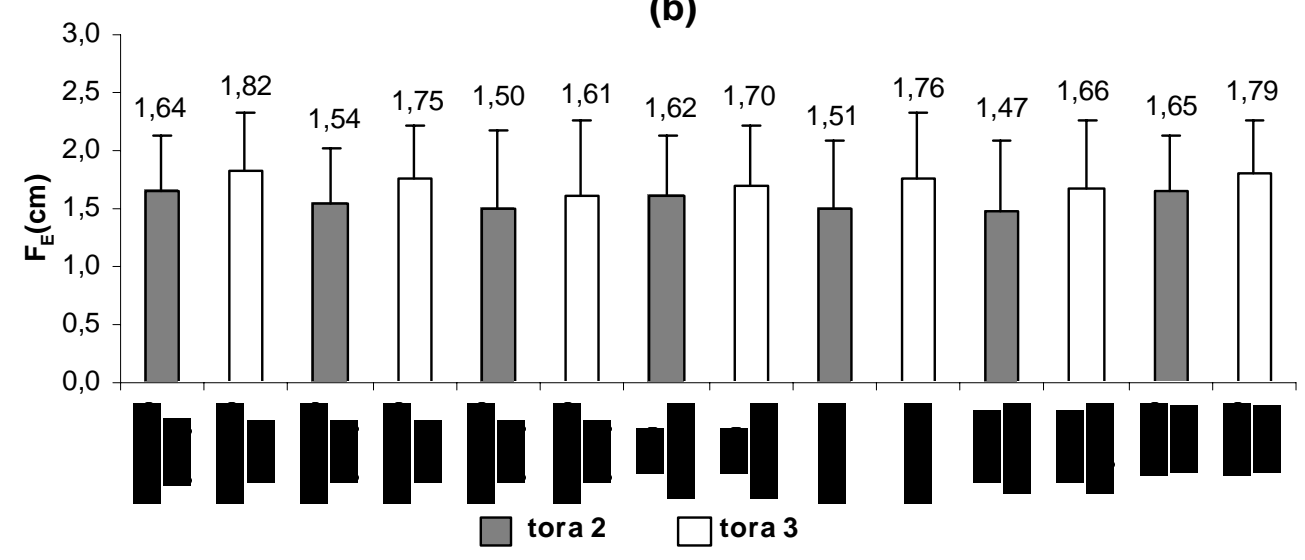

(c)

Figura 34 - Flecha de encurvamento $\left(\mathrm{F}_{\mathrm{E}}\right)$ de E.grandis de 21 anos de idade na posição $0 \%$ (a), na posição $50 \%$ (b) e na posição $100 \%$ (c) do raio da tora 


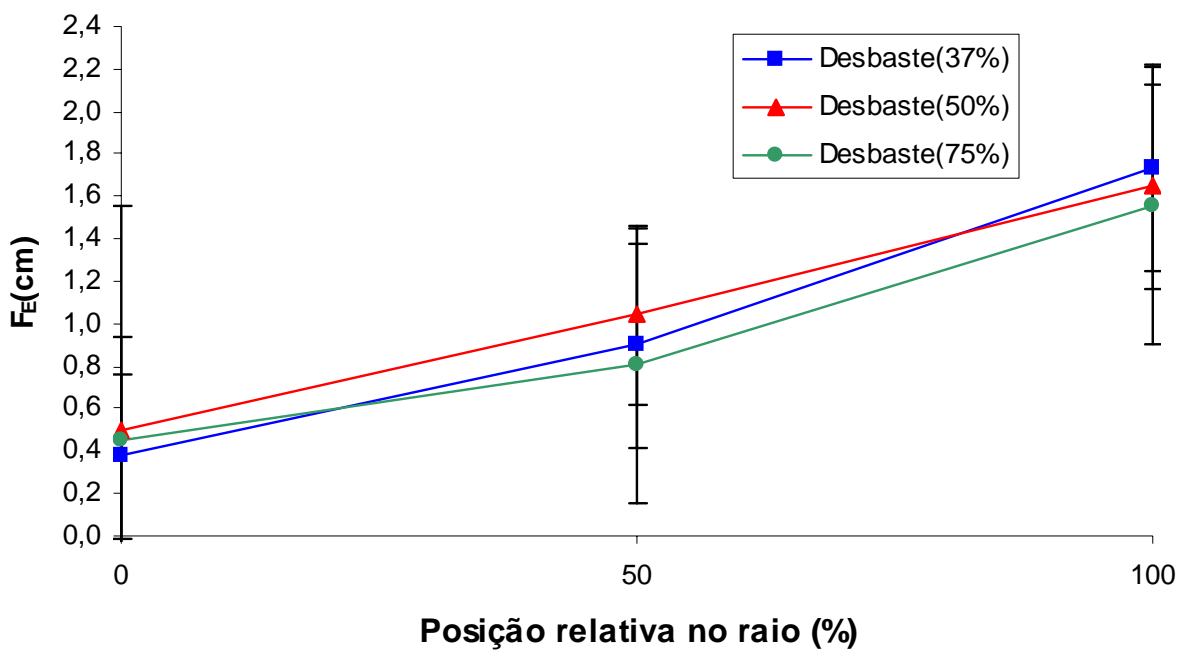

(a)

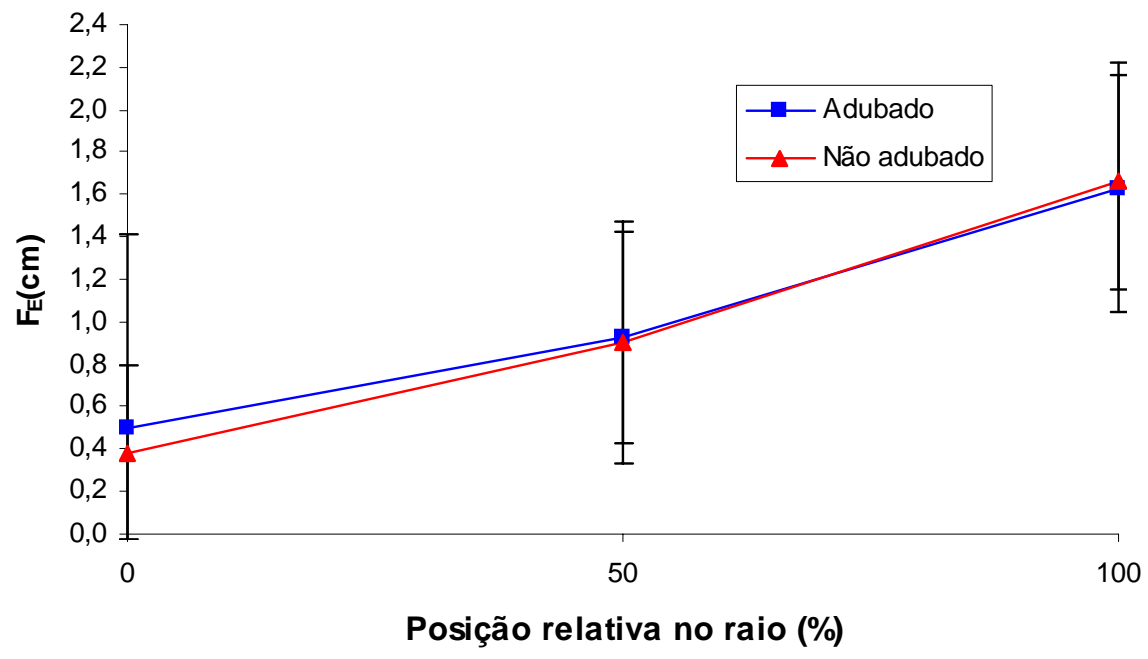

(b)

Figura 35- Flecha de encurvamento $\left(\mathrm{F}_{\mathrm{E}}\right)$ de E.grandis de 21 anos de idade em função da intensidade de desbaste (a) e da adubação (b) 


\subsection{Flecha de arqueamento $\left(F_{A}\right)$}

Nas Tabelas 34 a 39 e Figura 36 pode-se observar os resultados das análises de variância para a flecha de arqueamento, médias e seus respectivos desvios padrão para o caso de tábuas no estado verde.

Para a flecha de arqueamento de tábua verde foi observado que somente ocorreu diferença significativa entre as intensidades de 75 (\%) e de 37 (\%), na posição $0(\%)$ do raio da tora 3 . Esse fato pode ser explicado pelo maior deslocamento de medula que a intensidade de $75 \%$ de desbaste provocou nas toras em relação à intensidade de $37 \%$ como pode ser verificado na Figura 23 . O deslocamento de medula, que pode ser chamado de excentricidade natural da tora, provoca um encurvamento do semi-bloco durante o desdobro, mesmo que efetuado numa serra de cortes simétricos em relação à medula da tora, como foi o caso da serra de fita dupla utilizada no presente estudo. O encurvamento do semi-bloco transforma-se, naturalmente, em arqueamento das tábuas obtidas desse mesmo semi-bloco durante o corte na serra múltipla subseqüente. Pode-se considerar, entretanto, que as intensidades de desbaste estudadas não foram suficientes para provocar valores diferenciados de arqueamento de tábua verde.

No fator adubo foi observado que não houve diferença significativa entre as parcelas adubadas e não adubadas.

Para o fator classe de DAP foi verificado que somente ocorreu diferença significativa na posição $0 \%$ da tora 3 , com maior flecha de arqueamento na classe média. Isso pode ser explicado porque a classe média apresentou, como visto na Figura 23, maior deslocamento de medula do que aquele apresentado pela classe superior.

Na Figura 37 tem-se a representação da variação radial da flecha de arqueamento onde se verifica que essa variável não apresenta, como já esperado pela discussão efetuada acima, uma tendência ascendente ou descendente no sentido da medula para a casca. 


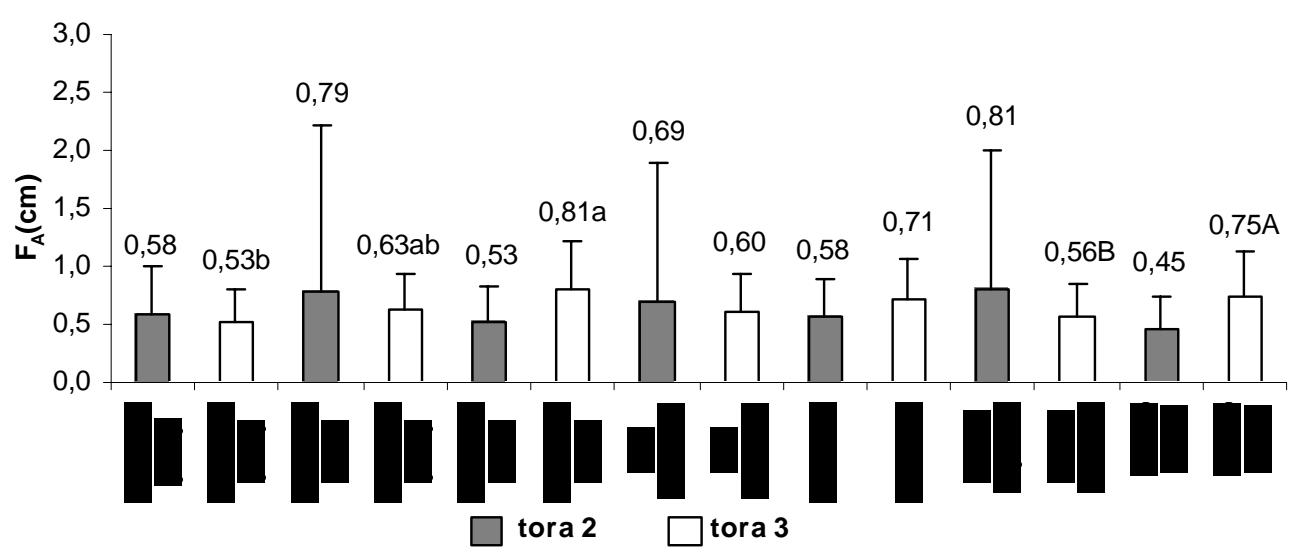

(a)

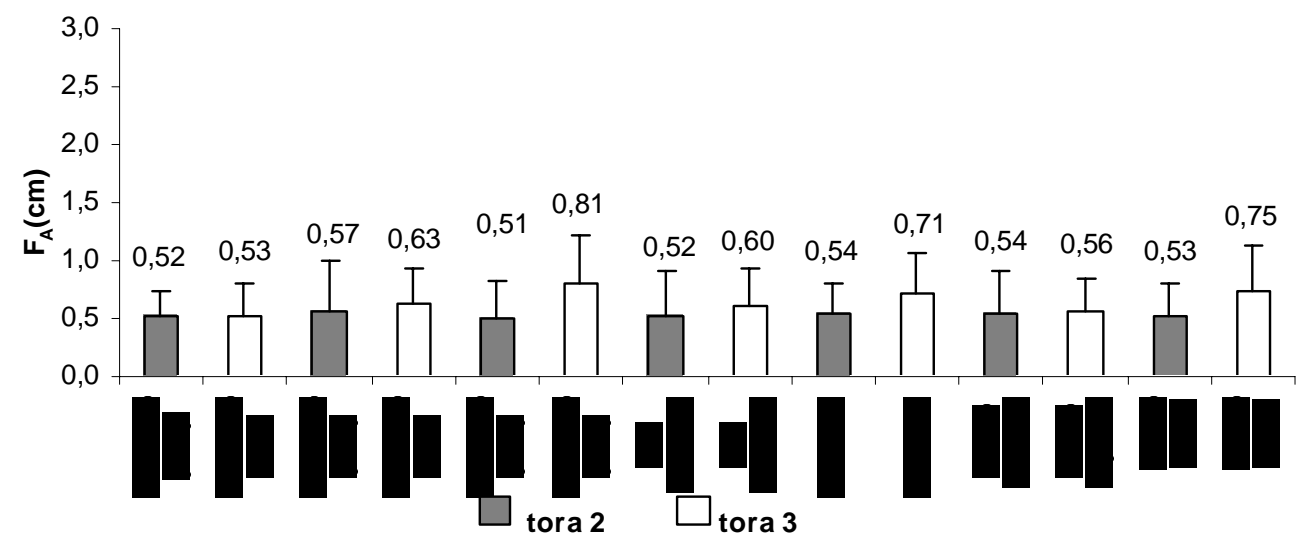

(b)

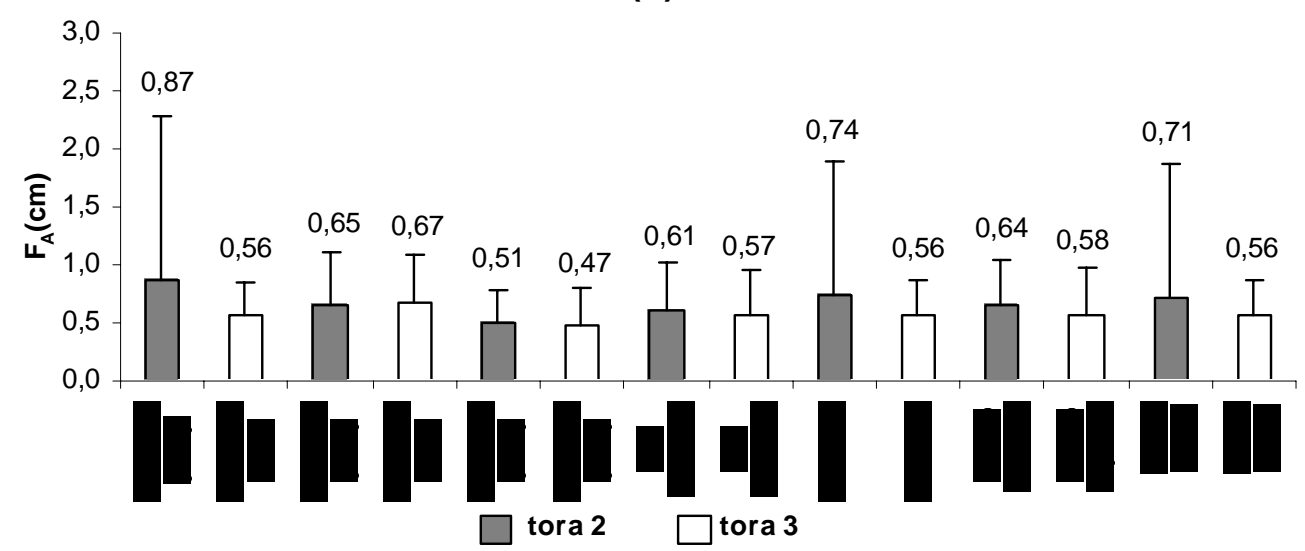

(c)

Figura 36 - Flecha de arqueamento $\left(\mathrm{F}_{\mathrm{A}}\right)$ de E. grandis de 21 anos de idade na posição 0\% (a), na posição 50\% (b) e na posição 100\% (c) do raio da tora 


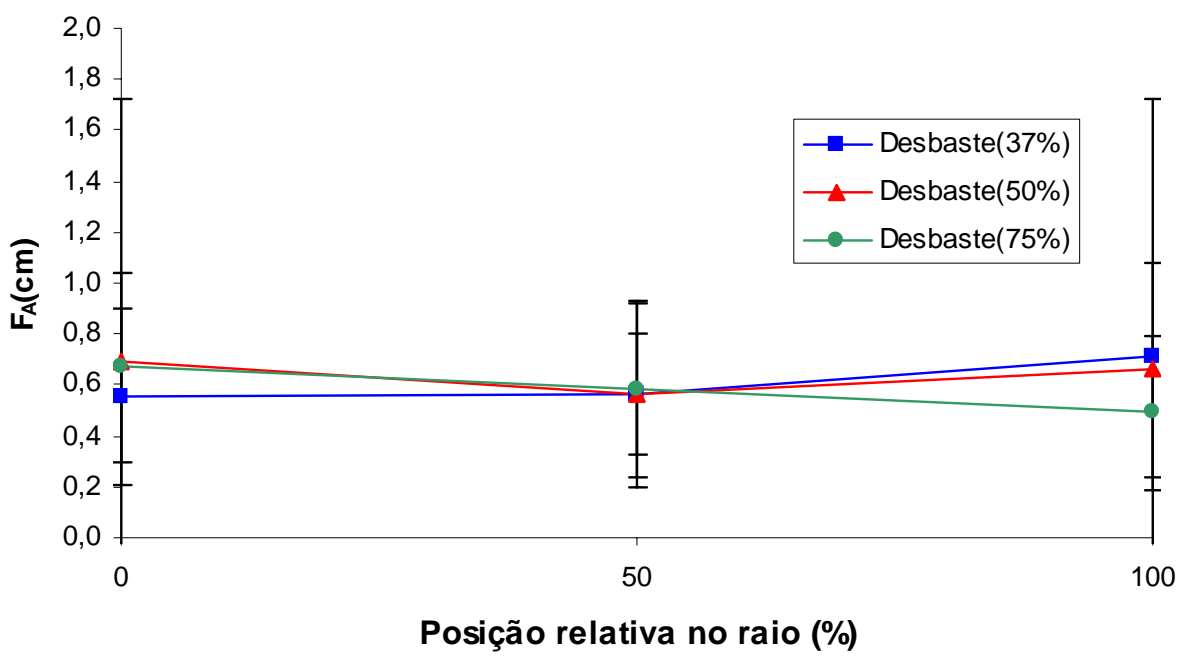

(a)

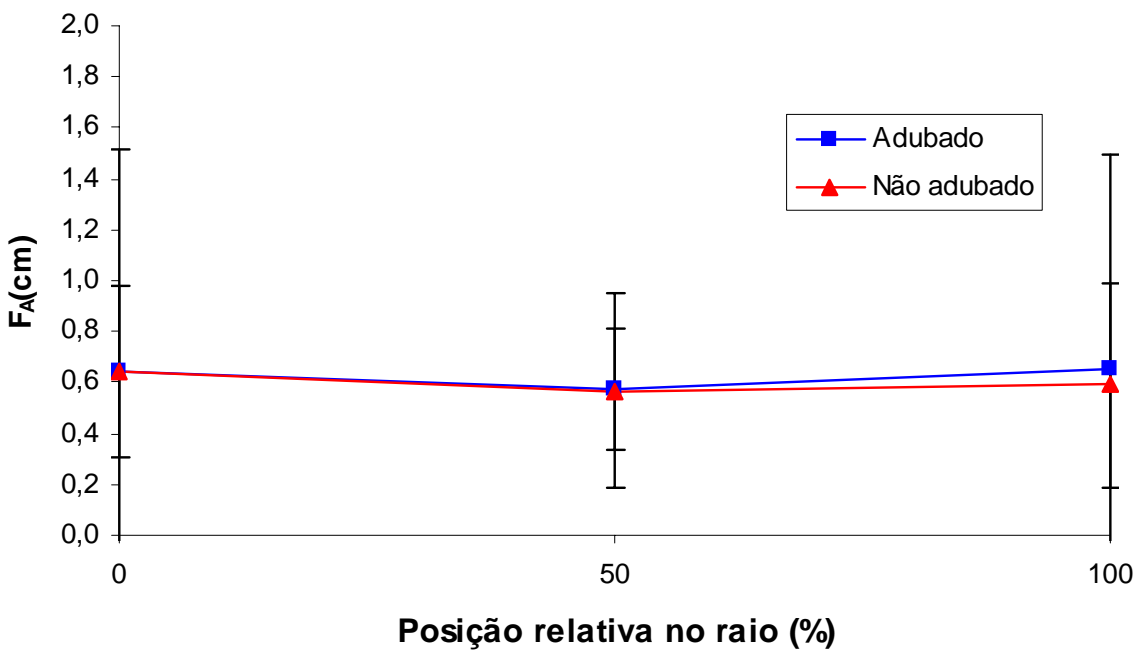

(b)

Figura 37 - Flecha de arqueamento $\left(F_{A}\right)$ de $E$. grandis de 21 anos de idade em função da intensidade de desbaste (a) e da adubação (b)

A não influência, no arqueamento, de qualquer dos fatores estudados já era esperada porque esse defeito não deve aparecer quando a estratégia de desdobro adotada produz liberação de tensões residuais de forma equilibrada. Nessa situação 
somente ocorrerá arqueamento nas tábuas serradas se houver alguma excentricidade natural na tora, dada pelo deslocamento de medula, ou alguma excentricidade operacional na serra, dada por um corte assimétrico causado por um erro de posicionamento da tora na alimentação da serra.

\subsection{Módulo de elasticidade estrutural na flexão estática (MOEe)}

A Figura 38 mostra um exemplo de diagrama carga-deslocamento elaborado com os dados obtidos nos ensaios não destrutivos de determinação do MOEe e a reta ajustada aos dados que, conforme planejado, foram coletados dentro do limite elástico do material. O coeficiente angular da reta (no caso, 108,15 N/cm), conjuntamente com os dados $\mathrm{h}=2,5 \mathrm{~cm}, \mathrm{~b}=20 \mathrm{~cm}$ e $\mathrm{L}=290 \mathrm{~cm}$ foram colocados na eq. (11), fornecendo o valor de 21.101 MPa para o MOEe.

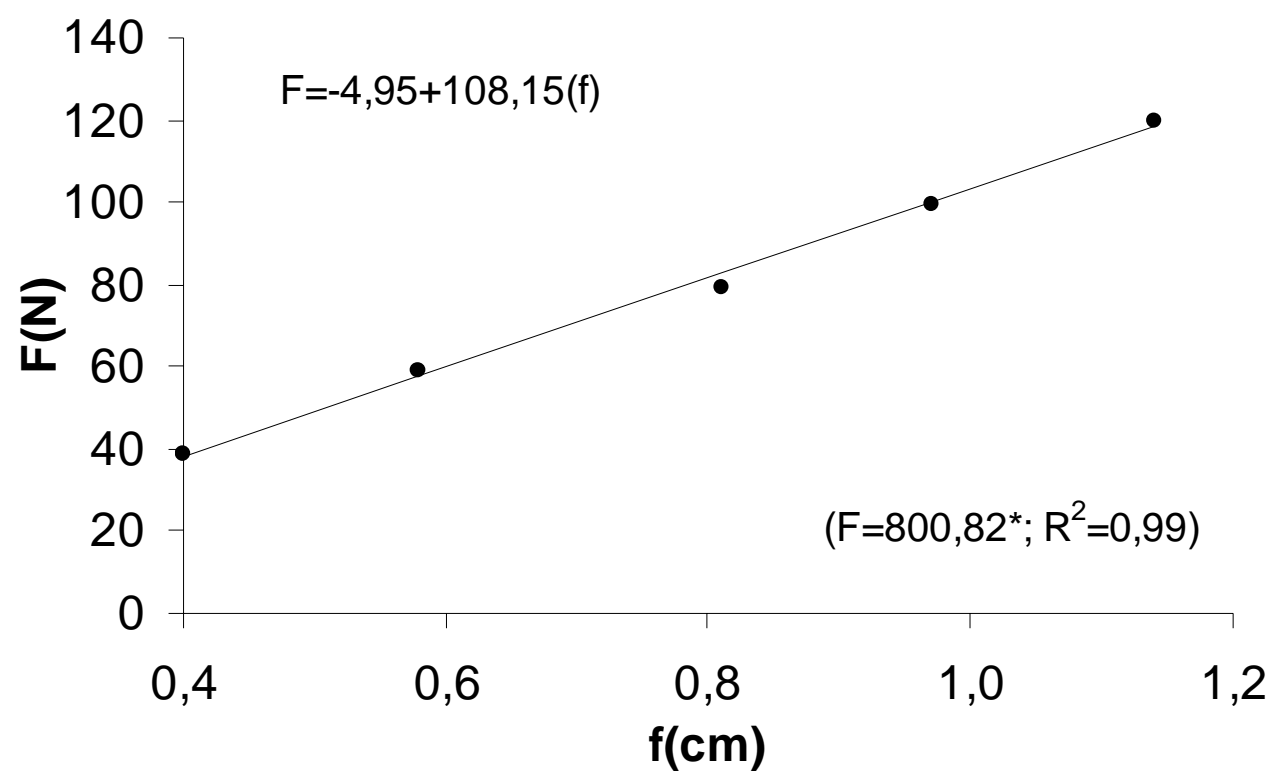

Figura 38 - Relação entre a carga (F) e o deslocamento (f) para a tábua central, (posição $0 \%$ do raio) da tora 2 pertencente à classe superior da intensidade de $37 \%$ de desbaste sem adubação, de E. grandis de 21 anos de idade 
Nas Tabelas 40 a 45 e Figura 39 pode-se observar os resultados das análises de variância, médias e respectivos desvios padrão para o módulo de elasticidade estrutural na flexão estática.

Verifica-se que não ocorreram diferenças significativas entre as três intensidades de desbaste para a variável MOEe.

No fator adubo foi observado que não ocorreram diferenças significativas, entre as árvores provenientes das parcelas adubadas e aquelas das não adubadas.

Para o fator classe foi verificado que ocorreu somente diferença significativa entre classes na posição radial $(0 \%)$ da tora 2 , sendo que a classe média apresentou maior valor para essa propriedade. Considera-se que esta é uma situação muito localizada, mas há uma tendência do efeito de classe de DAP estar influenciado pelo efeito do adubo, pois o adubo contribui para que as árvores estejam na classe superior mas, ao mesmo tempo, influencia negativamente no MOEe.

Diferentemente desses resultados Berger et al. (2000) concluíram, a partir de um estudo de diferentes espaçamentos e doses de NPK avaliados aos 10 anos em uma população de $E$. saligna, que maior dose de adubo e maior espaçamento proporcionaram maiores valores de MOE. Haselein et al.(2002) observaram essa mesma tendência.

No estudo da variação radial foi verificado que o MOEe aumenta no sentido da medula para a casca. Isto pode ser explicado, muito provavelmente, pelo fato da madeira próxima da casca ser mais densa, tendo então uma maior resistência mecânica e também por ser formada por uma proporção maior de madeira adulta. Esses resultados podem ser observados na Figura 40.

Essa tendência de variação medula-casca também foi obtida por Silva (2002) que encontrou 10.687, 11.673, 13.512 e 13.512, respectivamente nas posições $0,33,66$ e $100 \%$ do raio como valores médios de MOE, para E. grandis de diversas idades (10 a 20 anos) obtidos em ensaios destrutivos de corpos de prova isentos de defeito. Lima et al. (2000b) também obtiveram essa mesma tendência.

Quanto à variação medula-casa observou-se, também, que a intensidade de $75 \%$ de desbate e as parcelas adubadas provocaram menores variações ao longo do radio da tora. 

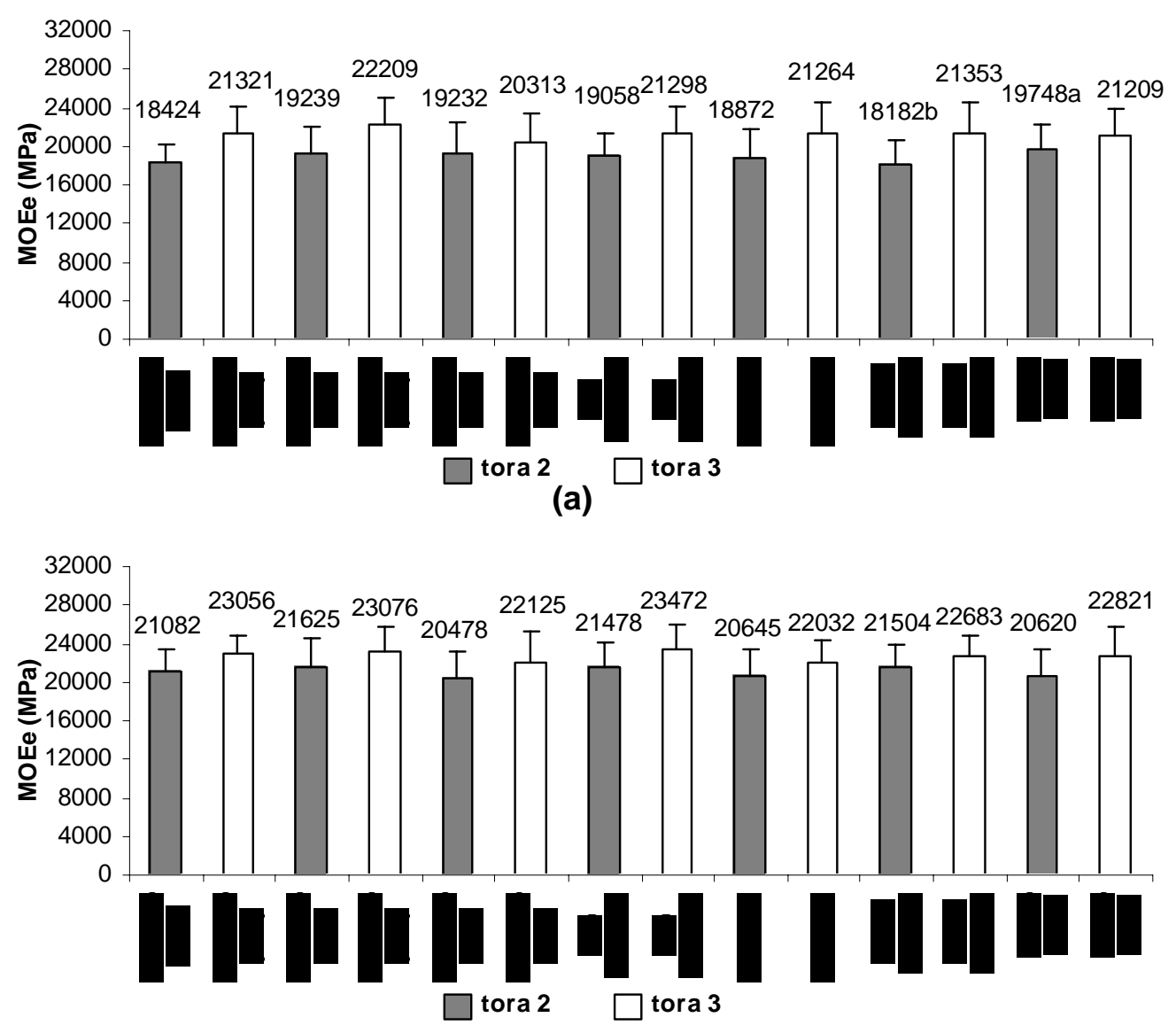

(b)

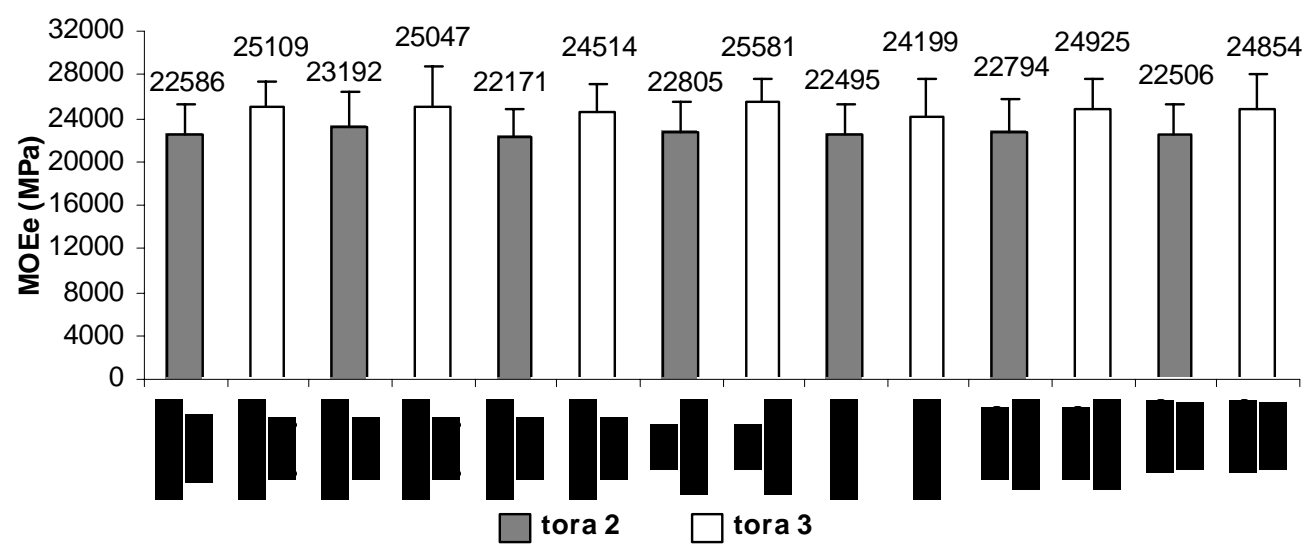

(c)

Figura 39 - Módulo de Elasticidade estrutural na flexão estática (MOEe) de E. grandis de 21 anos de idade na posição $0 \%$ (a), na posição 50\% (b) e na posição $100 \%$ (c) do raio da tora 


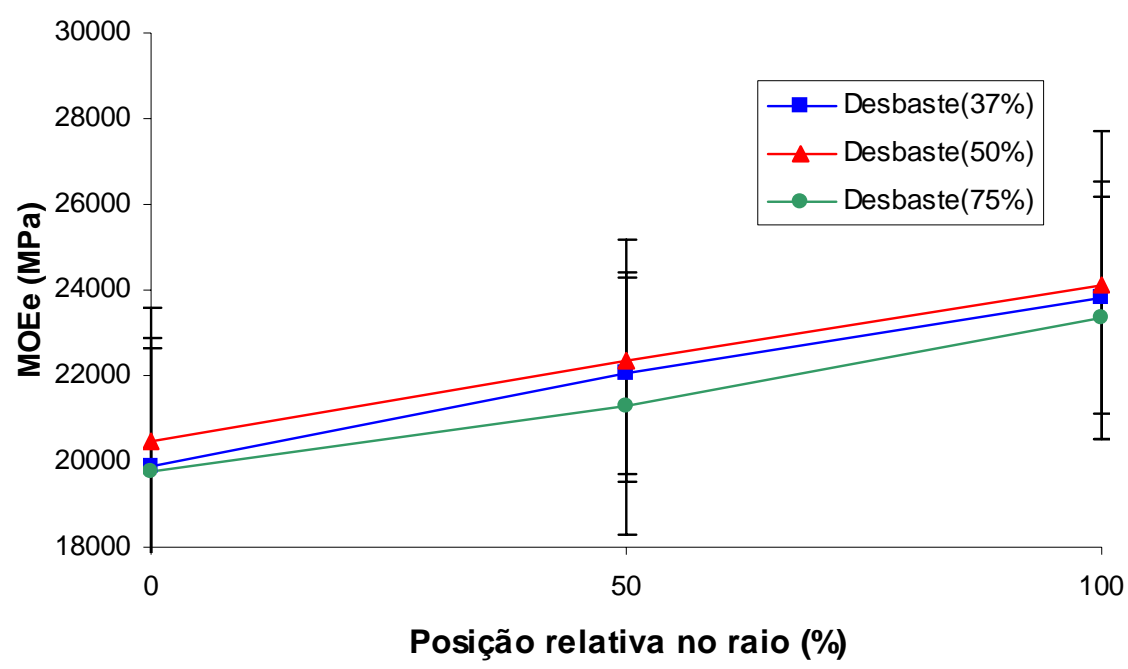

(a)

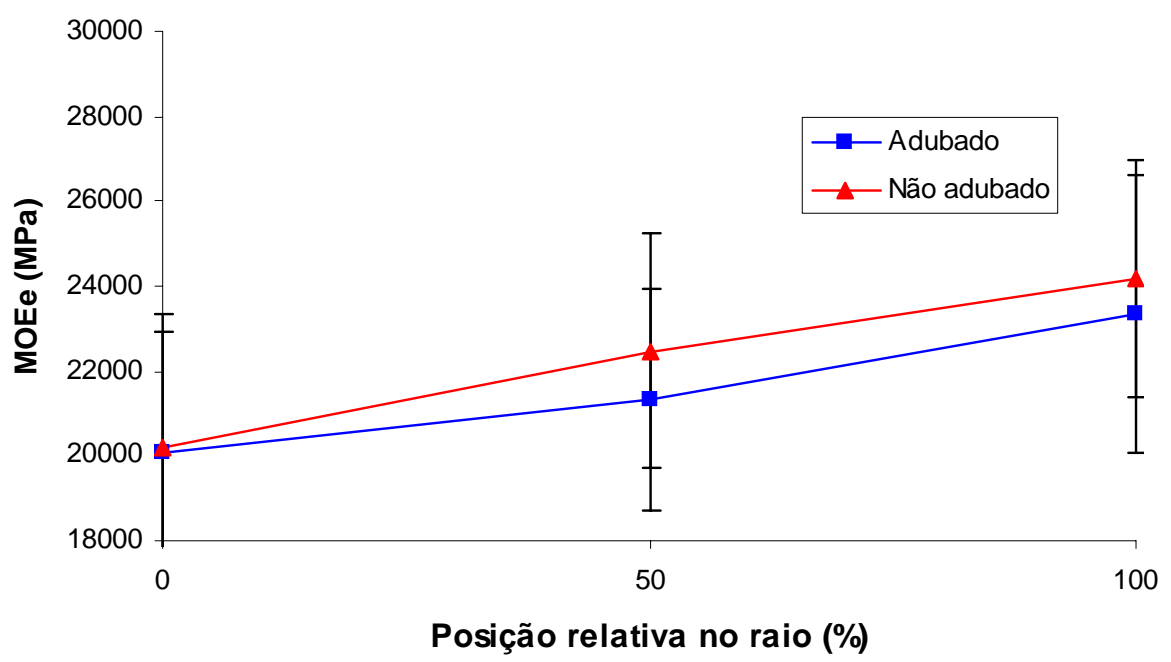

(b)

Figura 40 - Módulo de Elasticidade estrutural na flexão estática (MOEe) de E. grandis de 21 anos de idade em função da intensidade de desbaste (a) e da adubação (b)

$\mathrm{Na}$ avaliação do MOEe, pode-se destacar ainda que a metodologia de qualificação não destrutiva, em peças de grandes dimensões pode ser muito útil pela rapidez, simplicidade, eficiência e menor custo na avaliação. 


\subsection{Rendimento em madeira serrada}

Nas Tabelas 46 e 47 e nas Figuras 41 e 42 estão apresentados os resultados das analises de variância, medias e respectivos desvios padrão dos rendimentos em madeira serrada.

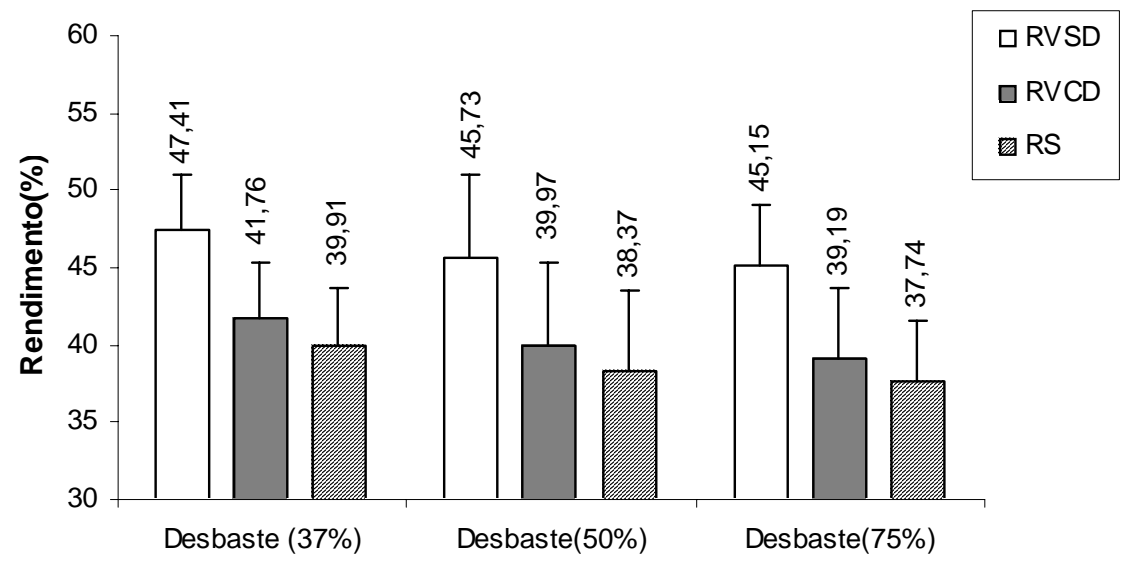

(a)

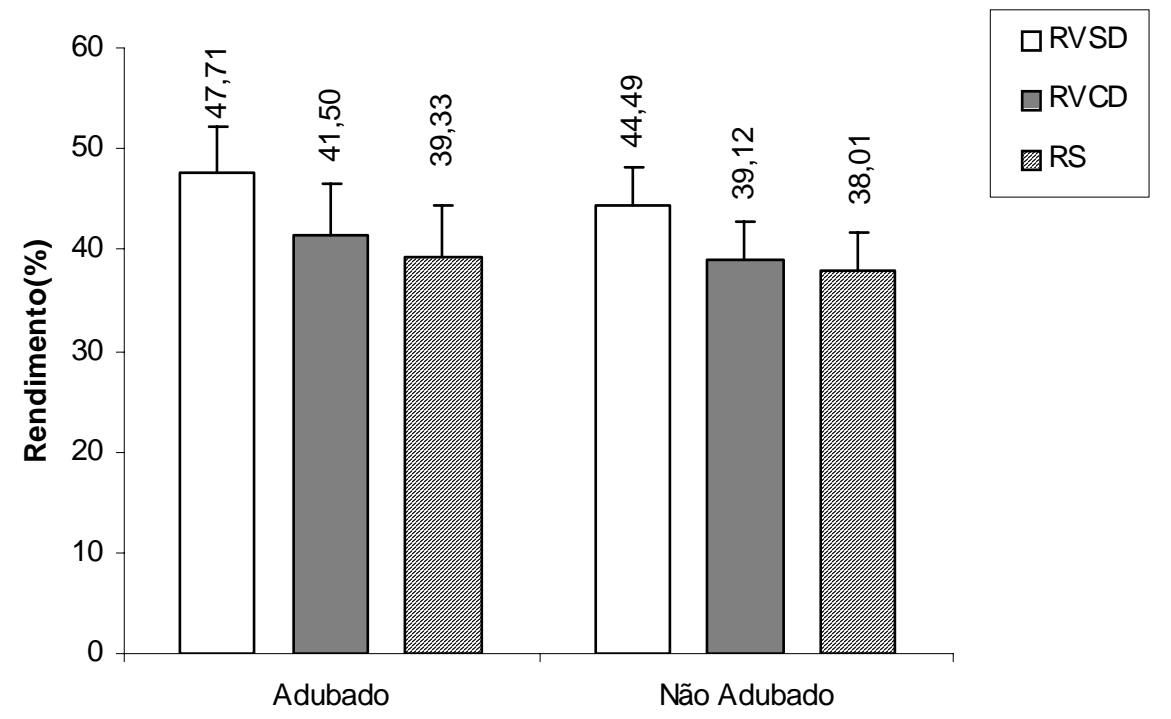

(b)

Figura 41 - Rendimento em madeira serrada de E. grandis de 21 anos de idade na classe superior em função da intensidade de desbaste (a) e da adubação (b) 


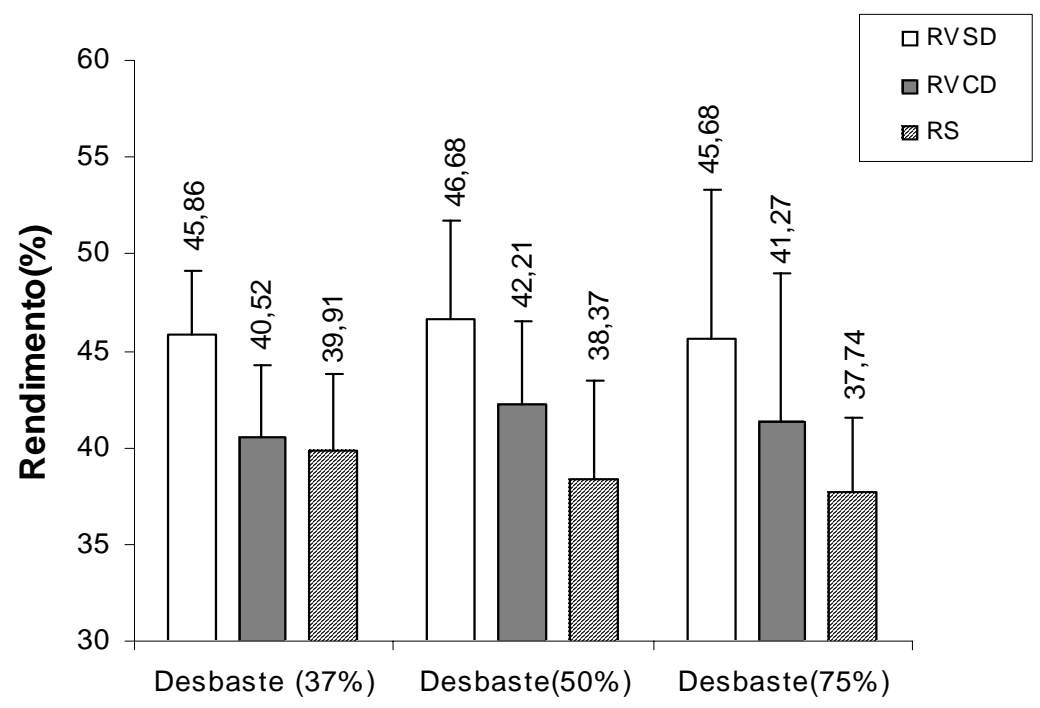

(a)

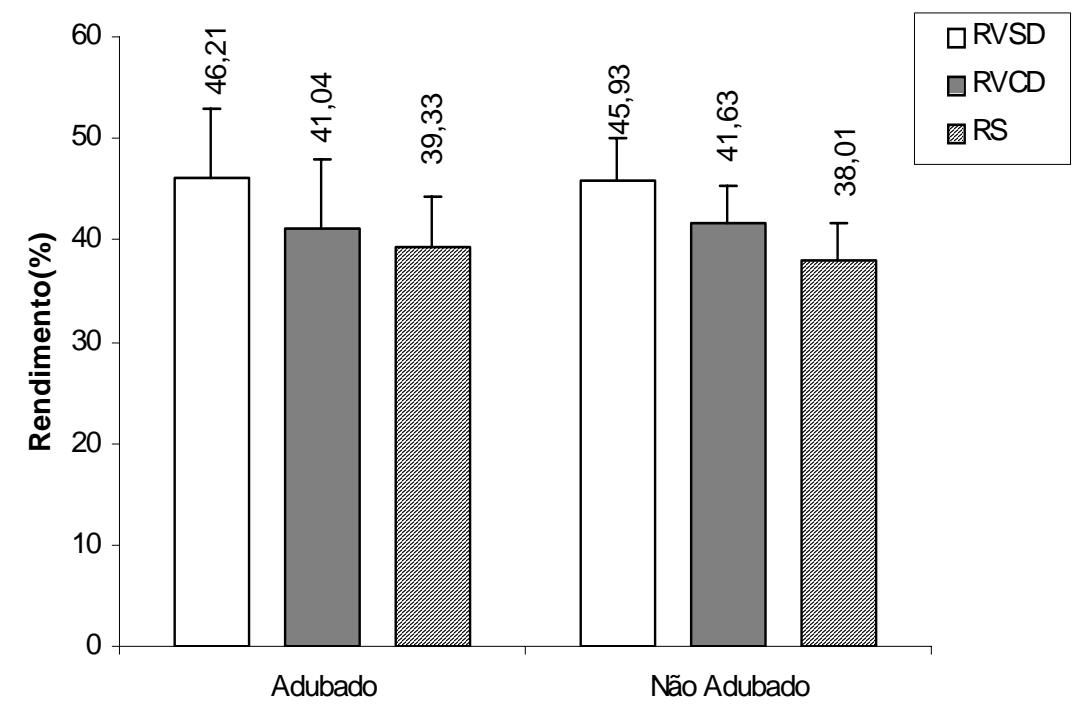

(b)

Figura 42 - Rendimento em madeira serrada de E. grandis de 21 anos de idade na classe média em função da intensidade de desbaste (a) e da adubação (b)

Pode-se observar nas Figuras 41 e 42 que tanto na classe superior quanto na média, ocorreram diminuições nos rendimento à medida em que se agregava valor à madeira serrrada. A operação de destopo, que consiste na eliminação 
das rachaduras de extremidade de tábua verde, provocou uma redução de 5,79\% e $4,73 \%$ no rendimento em madeira serrada para as classes superior e média, respectivamente. A maior redução de rendimento na classe superior deve-se ao fato de que o IRTV foi maior nessa classe, como discutido no item 4.5.

O processo de secagem provocou uma redução de 1,63 \% e 2,66 \% no rendimento em madeira serrada nas classes superior e média, respectivamente.

Scanavaca \& Garcia (2003) obtiveram rendimento em madeira serrada final médio de $42,53 \%$ para o E. urophylla, onde foram descontadas as perdas por rachaduras conseqüentes da combinação das tensões de crescimento com as de secagem.

De maneira geral o rendimento em madeira serrada obtido está de acordo com a literatura (Miranda, 1997, Del Menezzi,1999, Carvalho, 2000, Rocha, 2000).

\subsection{Classificação de tábuas serradas}

Nas Figuras 43 a 45 estão apresentados os resultados da classificação efetuada para as tábuas serradas secas.

Observando-se a Figura 43 pode-se dizer que a intensidade de $37 \%$ de desbaste apresentou a menor disponibilidade de tábuas de $1^{\text {a }}$ classe e a intensidade de $50 \%$ apresentou a maior disponibilidade dessa mesma qualidade. A intensidade $50 \%$ apresentou a menor ocorrência de tábuas de refugo.

Foi interessante observar que a intensidade de $75 \%$ de desbaste ofereceu menor possibilidade de produção de madeira serrada de $1^{\mathrm{a}}$. e de $2^{\mathrm{a}}$. classes de qualidade do que a intensidade de $50 \%$. Isso pode ter sido decorrente do efeito combinado de maiores rachaduras de extremidade de tábua e de maior incidência de nós na intensidade de $75 \%$ de desbaste por causa de uma possível menor desrama natural. 


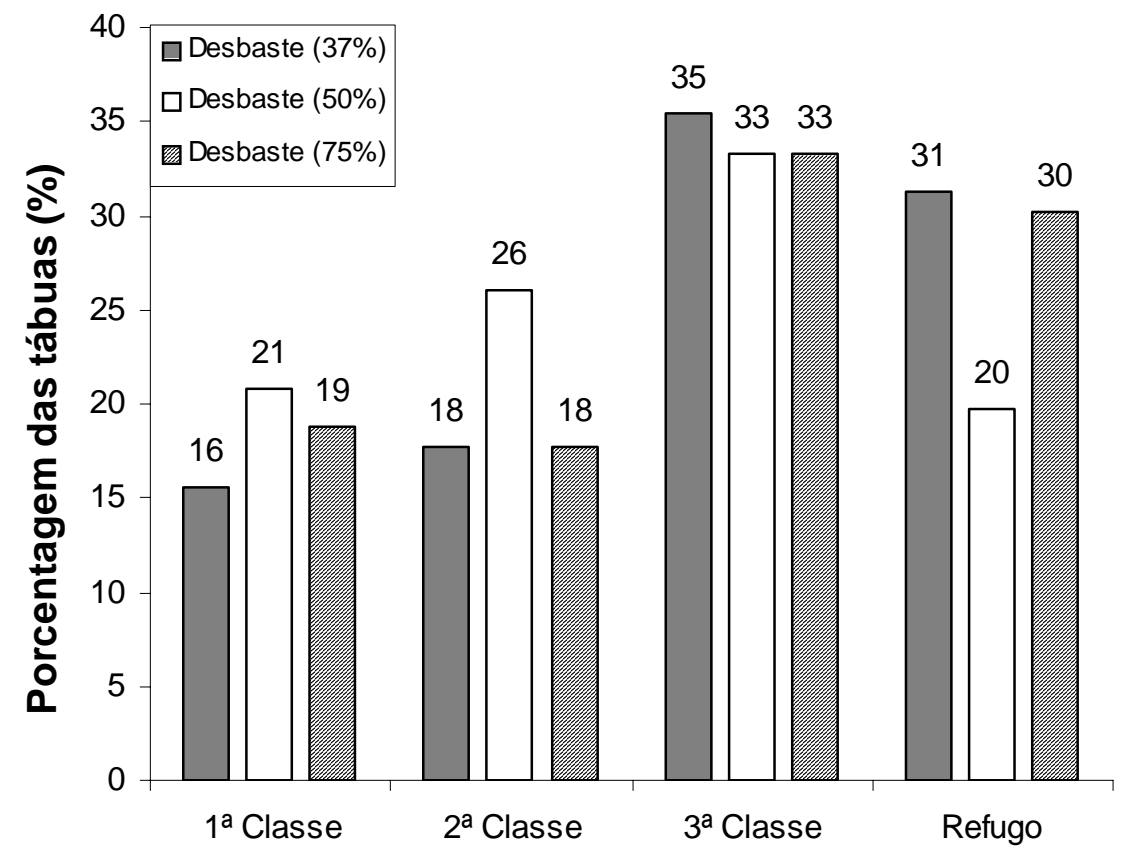

Figura 43 - Freqüência percentual de tábuas serradas secas por classe de qualidade em função da intensidade de desbaste de $E$. grandis de 21 anos de idade

$\mathrm{Na}$ Figura 44 pode-se verificar que na classe superior há uma maior ocorrência de tábuas de $1^{\mathrm{a}}$ classe, enquanto que na classe média há uma maior ocorrência de tábuas de $3^{a}$ classe. As tábuas originadas das parcelas adubadas enquadram-se com maior freqüência nas $1^{\mathrm{a}}$ e $2^{\mathrm{a}}$ classes, enquanto que as das parcelas não adubadas colocam-se na $3^{\mathrm{a}}$ classe e na classe de refugo. 


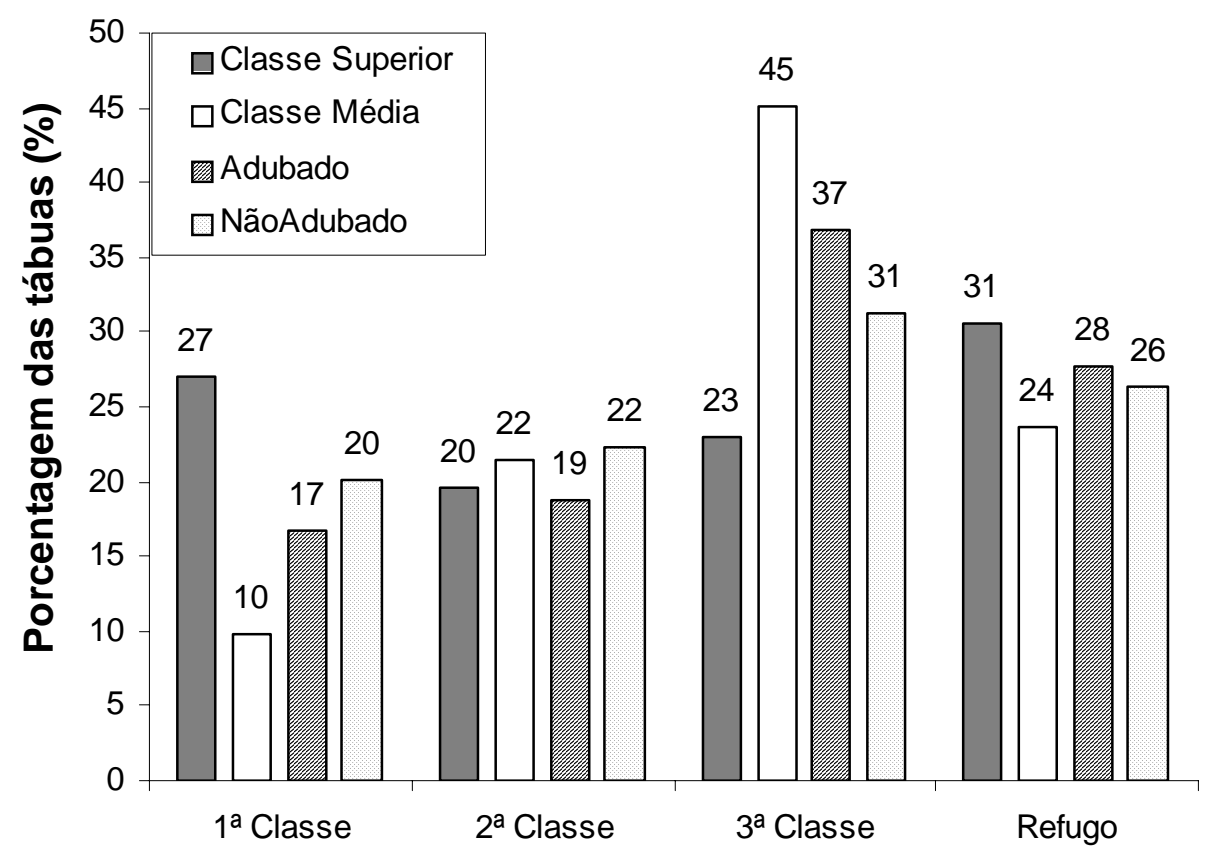

Figura 44 - Freqüência percentual de tábuas serradas secas por classe de qualidade em função da adubação e classe de DAP, de E. grandis de 21 anos de idade

Na Figura 45 é constatado que a posição relativa no raio interfere nas classes de qualidade da madeira, ou seja, na freqüência de tábuas nas diferentes classes de qualidade. A freqüência de tábuas da $1^{\text {a }}$ classe aumenta da medula para a casca enquanto que o número de tábuas de refugo diminui da medula para casca. Isto pode ser explicado pelo fato de a região da medula apresentar uma maior proporção de madeira juvenil que apresenta menor resistência mecânica e conseqüentemente maior índice de rachaduras e maior ocorrência de nós.

Observa-se, ainda, na Figura 45, que não ocorreu nenhuma peça de $1^{\mathrm{a}}$ classe na região da medula, enquanto que na região da casca a maioria das tábuas foram colocadas nesta categoria. 


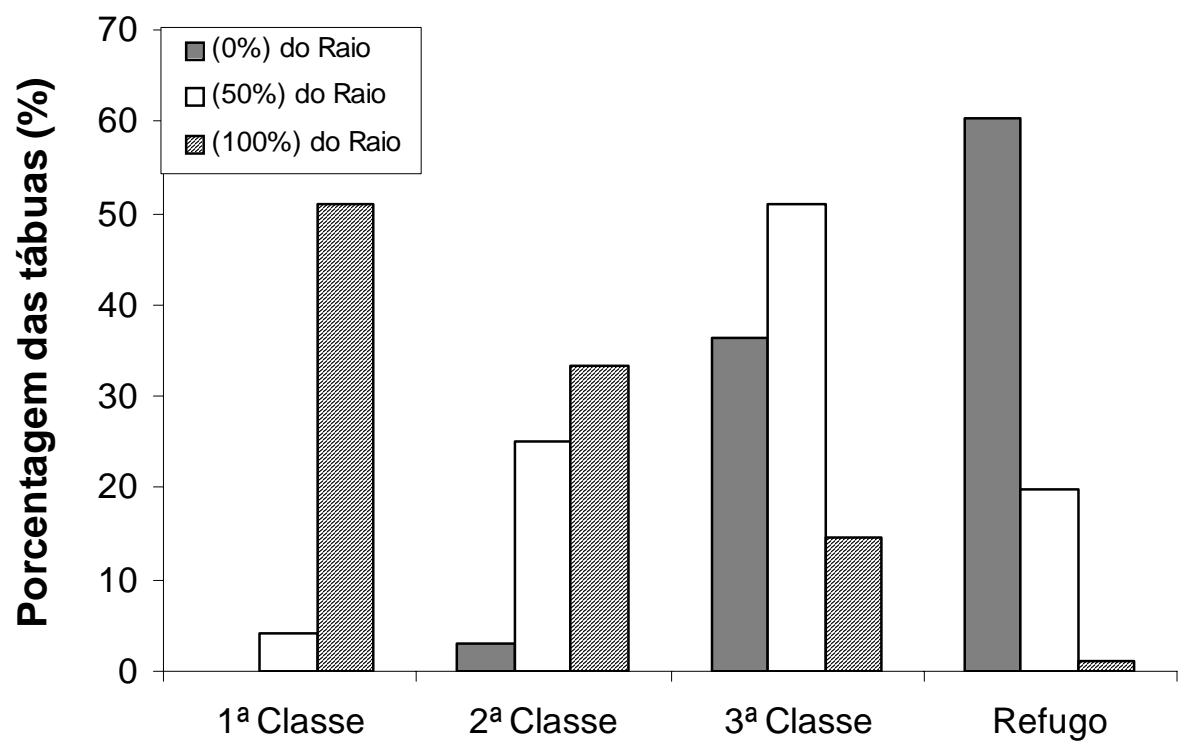

Figura 45 - Freqüência percentual de tábuas serradas secas por classe de qualidade em função da posição relativa no raio de E. grandis de 21 anos de idade

Esses resultados reforçam a necessidade de novos estudos no sentido de melhorar a qualidade ou minimizar a quantidade da madeira da região da medula, através de técnicas silviculturais aliadas ao melhoramento genético florestal e à tecnologia do processamento mecânico da madeira.

\subsection{Massa específica (ME)}

Observa-se nas Tabelas 48 a 52 e nas Figuras 46 a 50, que apresentam os resultados das análises de variância, as médias e os respectivos desvios padrão para a massa especifica à umidade de equilíbrio ao ar, que as diferentes intensidades de desbastes não influenciaram significativamente nessa propriedade, qualquer que seja a posição radial considerada.

No fator adubo foi verificado que a massa específica das amostras oriundas das árvores das parcelas adubadas diferiram significativamente da massa específica daquelas provenientes das parcelas não adubadas, em todas as posições 
radiais. Foi verificado que a massa específica da madeira produzida nas parcelas adubadas foi menor do que a da madeira produzida nas parcelas não adubadas.

Com relação às classes de DAP, verificou-se que há uma tendência de haver diferenças significativas entre elas, nas posições em qualquer das posições do raio da tora. Em quase todos os casos a classe superior apresentou os maiores valores de massa específica e a classe inferior apresentou os menores valores dessa variável.

Depreende-se, pelos resultados obtidos, que a massa especifica não sofreu influência significativa das diferentes formas de competição proporcionada pelas diferentes intensidades de desbaste aplicadas, quando avaliadas aos 21 anos de idade da população. Também não foi observada uma tendência sistemática de a massa específica aumentar proporcionalmente com o aumento da intensidade de desbaste como foi observado por Land et al. (1983) e Malan \& Hoon (1992). Entretanto, esses resultados podem ser considerados muito interessantes no sentido de poder-se aumentar o volume de madeira por área através da prática de desbaste, sem prejuízo significativo da massa específica da madeira.

A aplicação de fertilizantes, após o desbaste aos cinco anos, influenciou diretamente na produção de madeira de menor massa específica, quando comparada com a madeira produzida nas parcelas não adubadas. Considerando-se que as parcelas adubadas produziram um maior volume de madeira por unidade de área, então, pode-se pensar que houve uma compensação da perda ocorrida na massa específica. Entretanto, isso só é verdade se o aumento do volume for mais do que proporcional à diminuição da massa específica o que possibilitaria um incremento da massa seca produzida por unidade de área. Land et al. (1983) fizeram e comprovaram essa observação. Os resultados encontrados no presente trabalho estão de acordo com Mello (1968); Higgs \& Rudman (1973); Daniel et al. (1979); Valeri et al. (1990) e Andrade et al. (1994). Entretanto, Wilkins \& Kitaraha (1991), Vigneron et al. (1995); Berger et al. (2000) e Haselein et al. (2002) observaram que a fertilização aumentou a densidade da madeira e Vital (1990) destacou a existência de resultados conflitantes sobre o efeito da fertilização na densidade da madeira. 


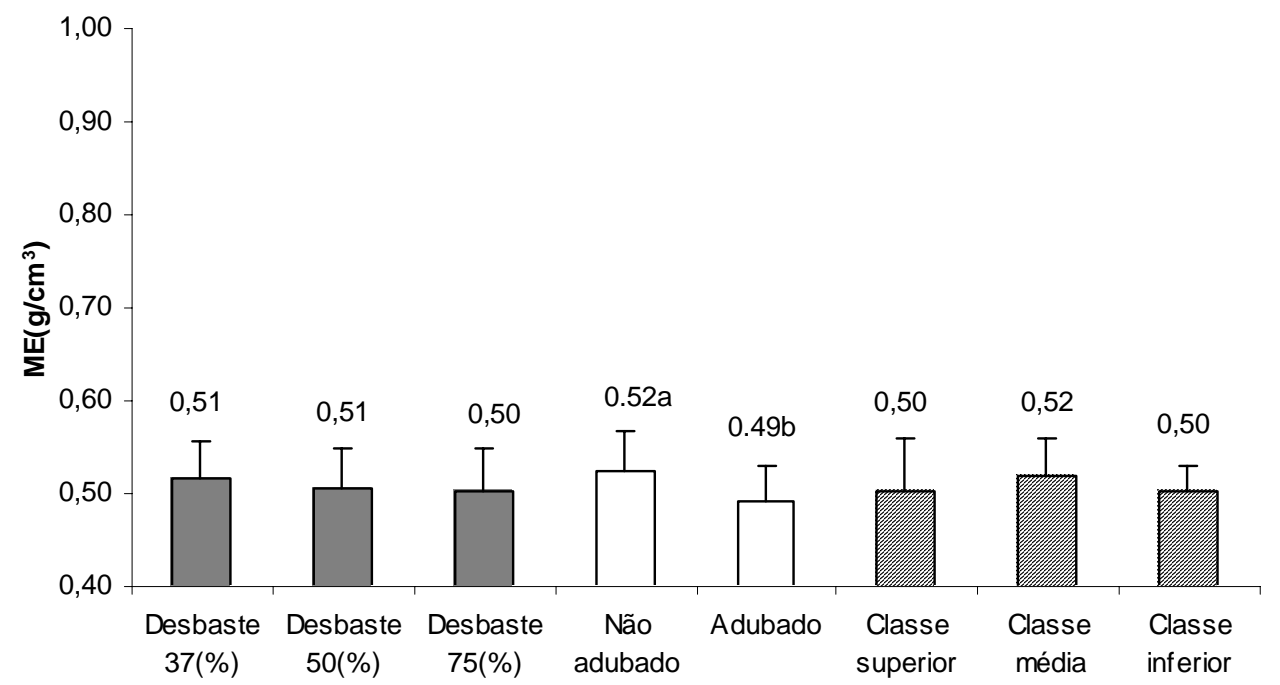

Figura 46 - Massa específica à umidade de equilíbrio ao ar (ME) da madeira de $E$. grandis de 21 anos de idade na posição radial (0\%)

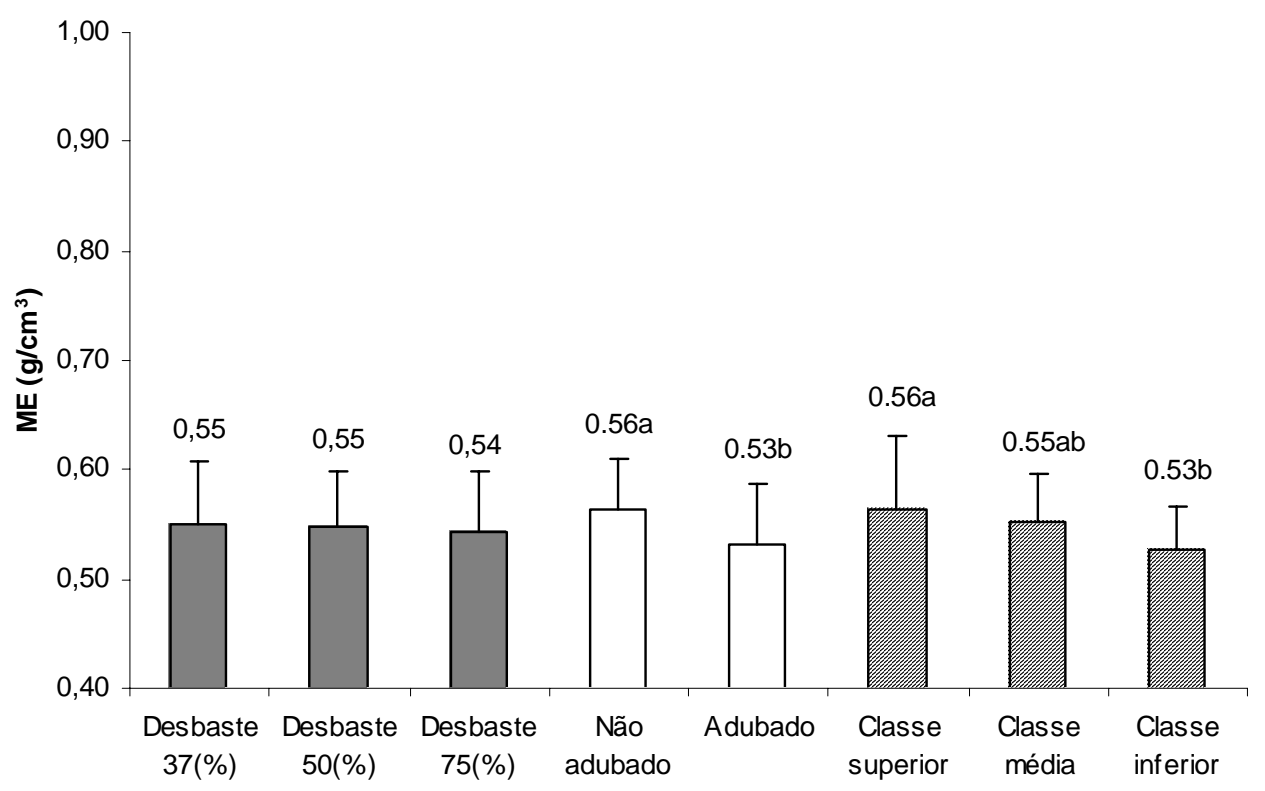

Figura 47 - Massa específica à umidade de equilíbrio ao ar (ME) da madeira de $E$. grandis de 21 anos de idade na posição radial (25\%) 


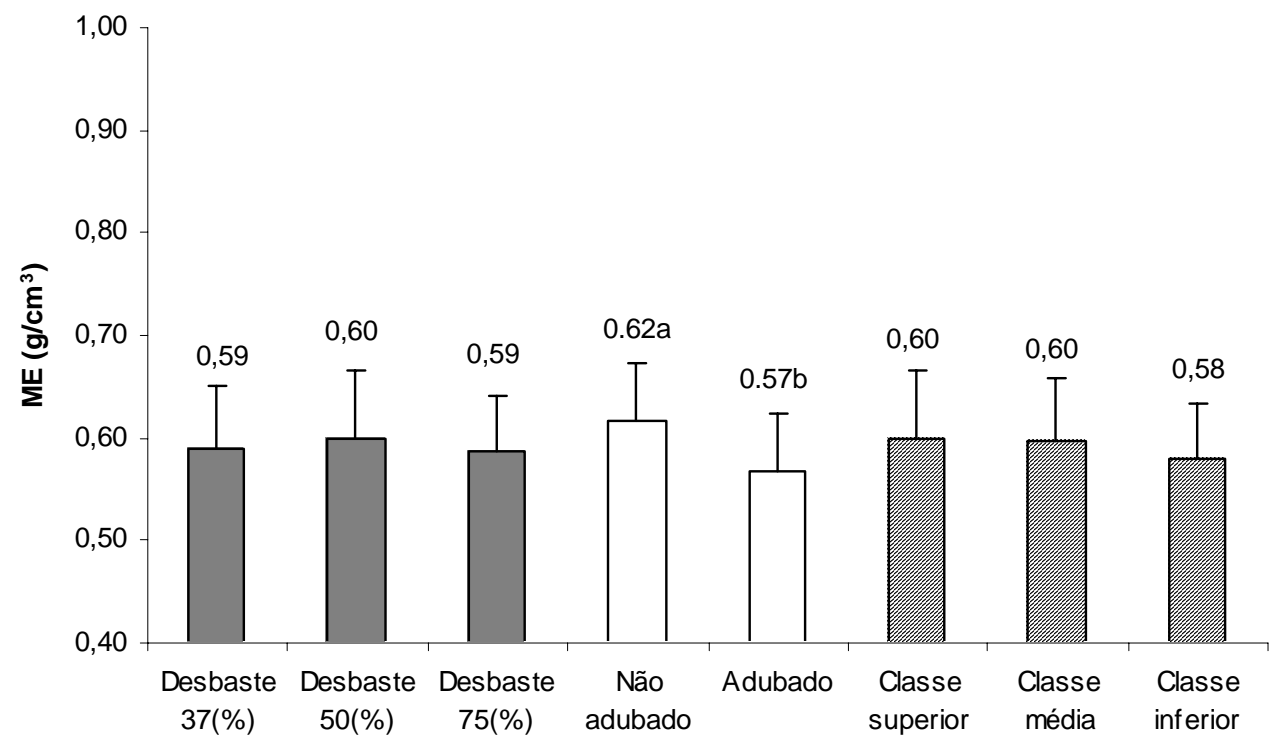

Figura 48 - Massa específica à umidade de equilíbrio ao ar (ME) da madeira de $E$. grandis de 21 anos de idade na posição radial (50\%)

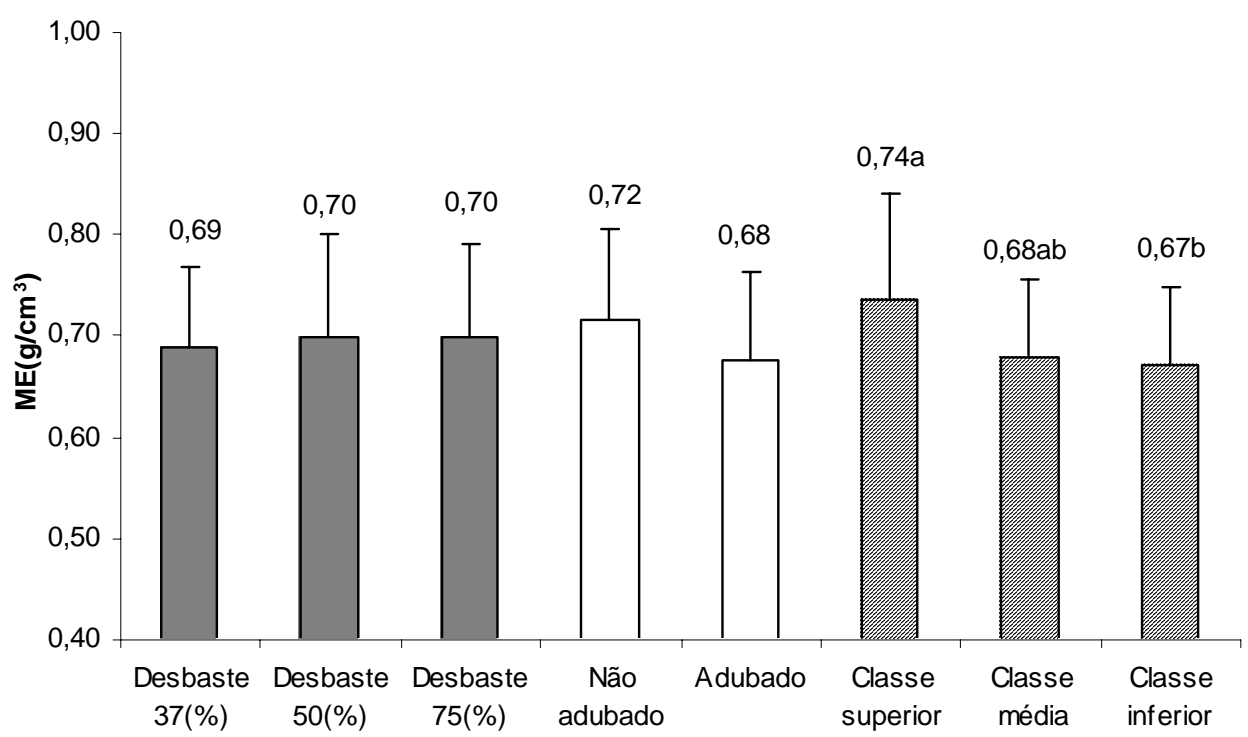

Figura 49 -Massa específica à umidade de equilíbrio ao ar (ME) da madeira de $E$. grandis de 21 anos de idade na posição radial (75\%) 


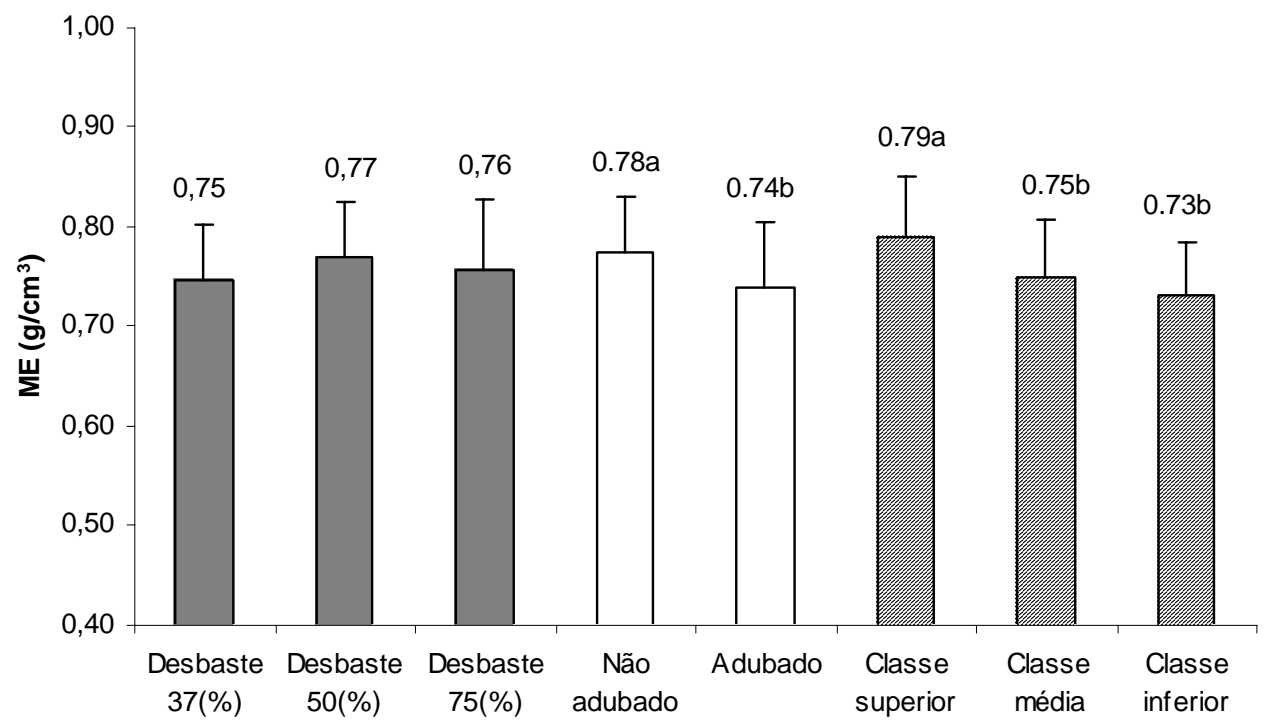

Figura 50 - Massa específica à umidade de equilíbrio ao ar (ME) da madeira de $E$. grandis de 21 anos de idade na posição radial (100\%)

Na Figura 51 pode-se observar que a massa especifica aumenta no sentido da medula para a casca e, segundo uma análise estatística efetuada especificamente para esse caso, todas as posições radiais apresentaram valores diferentes entre si. Observa-se, claramente, a não influência dos desbaste na massa específica e que as parcelas adubadas produziram madeira com menor massa especifica ao longo do raio da árvore. 


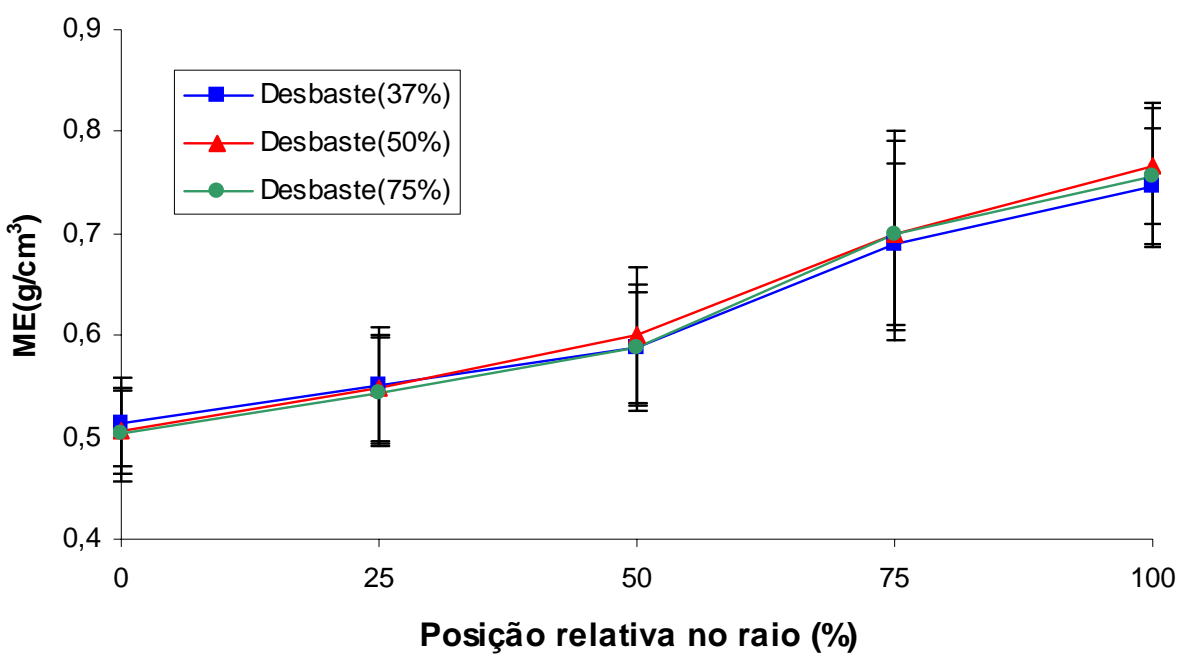

(a)

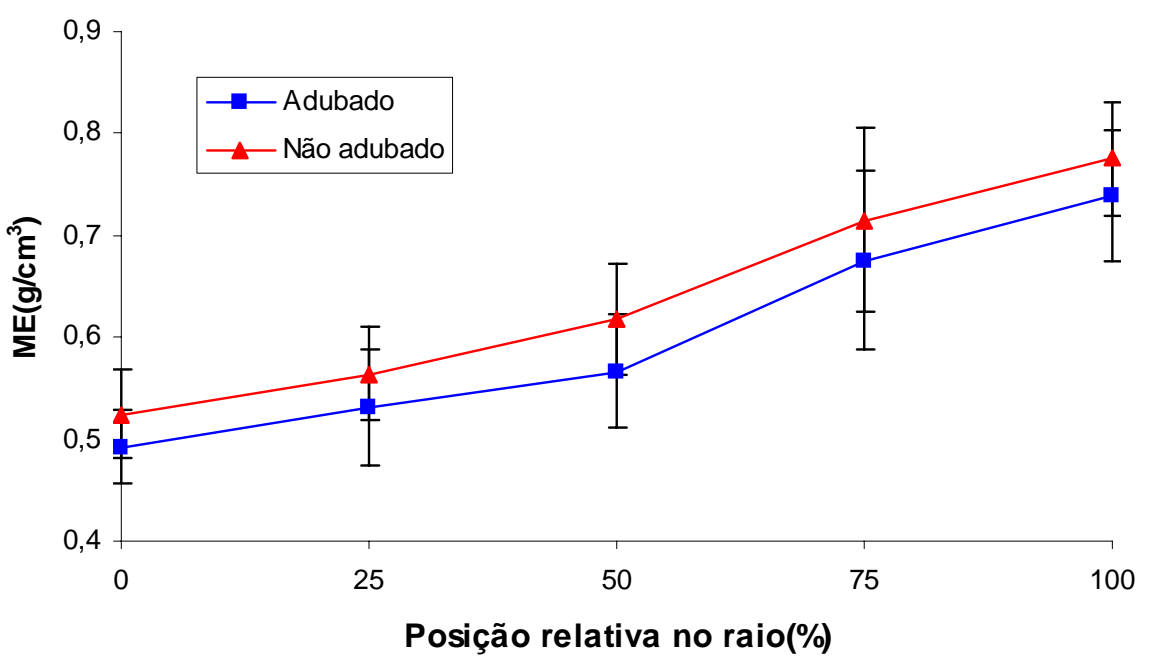

(b)

Figura 51 - Massa especifica (ME) de E.grandis de 21 anos de idade em função da intensidade de desbaste(a) e da adubação (b) 


\subsection{Estudo de correlações entre as variáveis}

Neste estudo foram feitas análises de correlações entre todas as variáveis, por árvore. As melhores correlações e seus respectivos coeficientes de correlação estão apresentados na Tabela 53.

As Figuras 52 a 58 mostram, graficamente, apenas as regressões lineares que foram estatisticamente significativas.

Pelos resultados apresentados foi possível observar-se que somente algumas das variáveis tiveram boas correlações entre si, com destaque para a correlação entre RVCD e RS, porém, outras correlações importantes foram observadas.

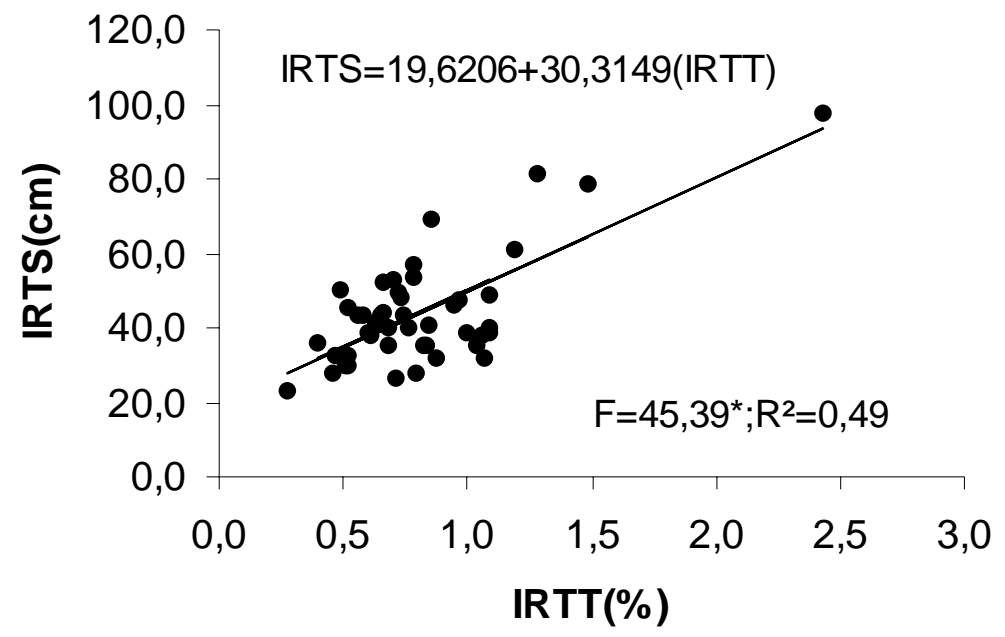

Figura 52 - Relação entre índice de rachaduras de extremidade de tábua seca ( IRTS) e índice de rachaduras de topo de tora (IRTT) para E. grandis de 21 de idade 


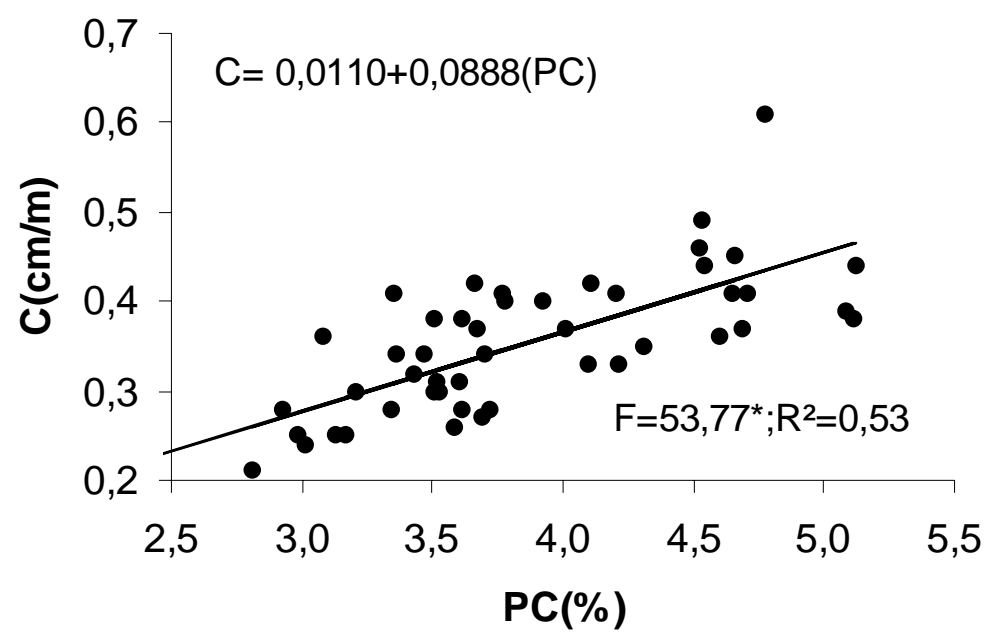

Figura 53 - Relação entre conicidade (C) e porcentagem de casca ( PC) para E. grandis de 21 anos de idade

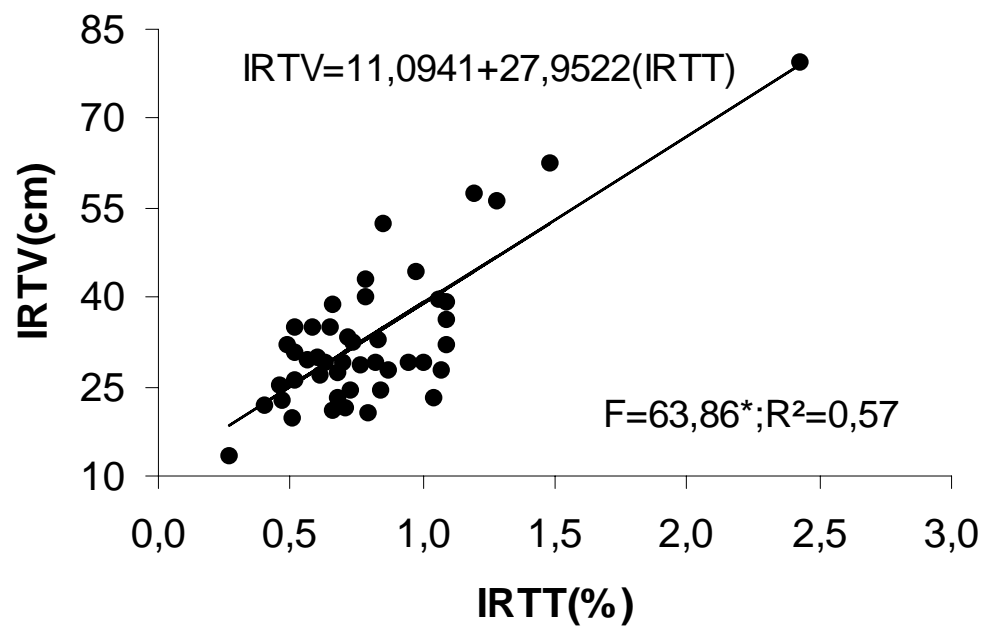

Figura 54 - Relação entre índice de rachaduras de extremidade de tábua verde (IRTV) e índice de rachaduras de topo de tora (IRTT) para E. grandis de 21 anos de idade 


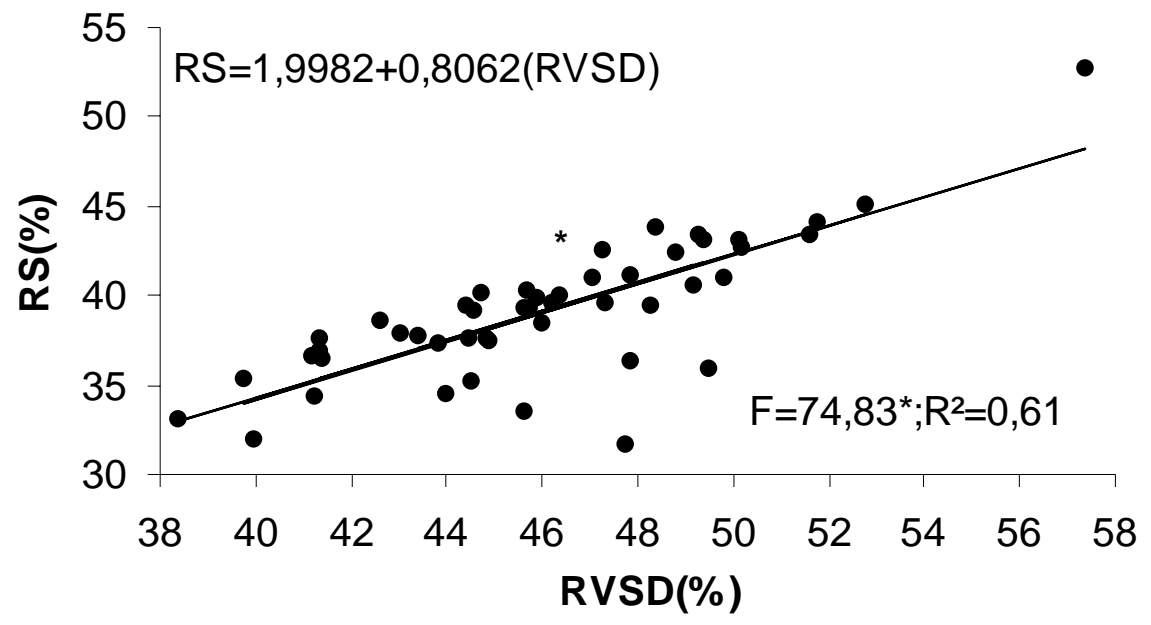

Figura 55 - Relação entre rendimento em madeira serrada verde sem destopo (RVSD) e Rendimento em madeira serrada seca com destopo (RS) para $E$. grandis de 21 anos de idade

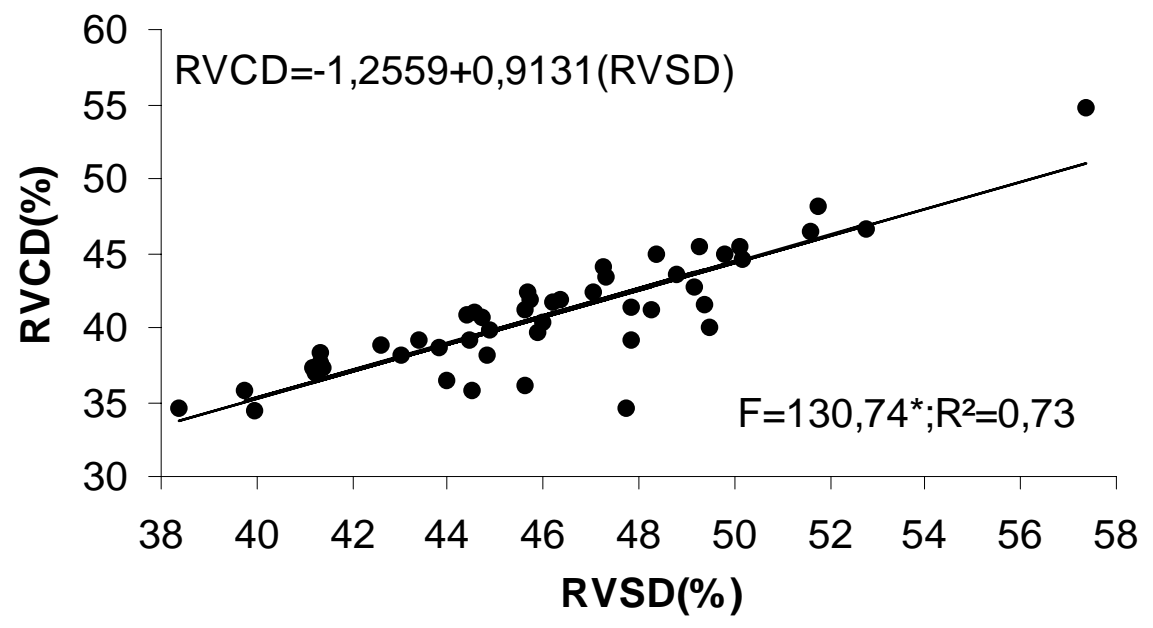

Figura 56 - Relação entre rendimento em madeira serrada verde com destopo (RVCD) e rendimento em madeira serrada verde sem destopo (RVSD) para $E$. grandis de 21 anos de idade 


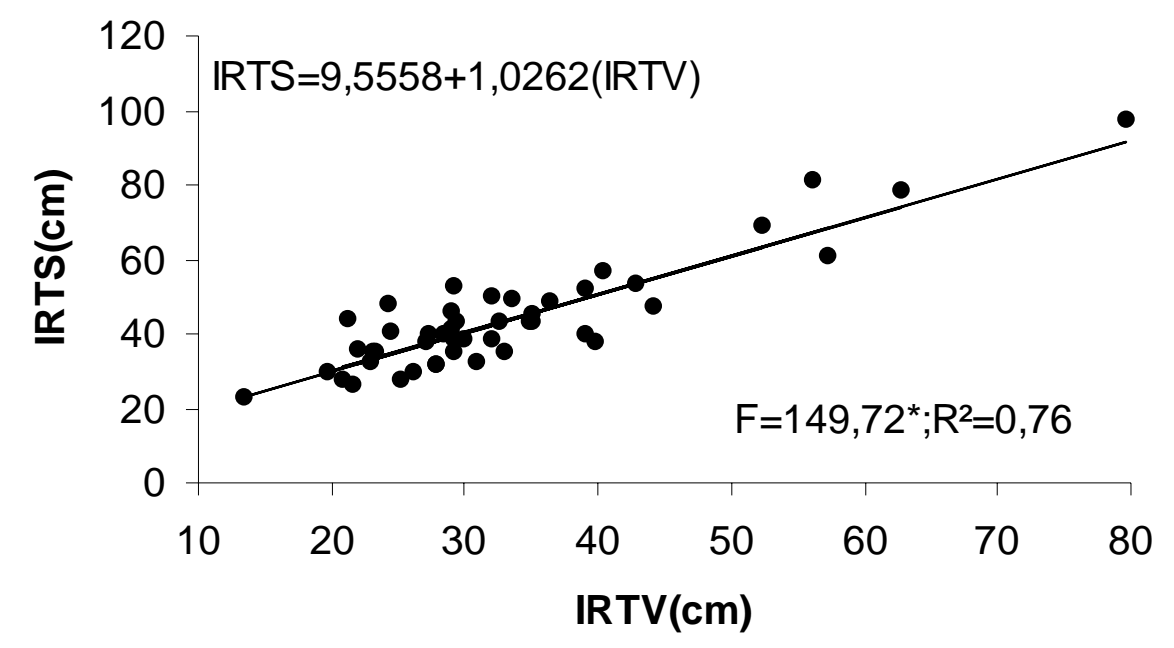

Figura 57 - Relação entre índice de rachaduras de extremidade de tábua seca (IRTS) e índice de rachaduras de extremidade de tábua verde (IRTV) para $E$. grandis de 21 anos de idade

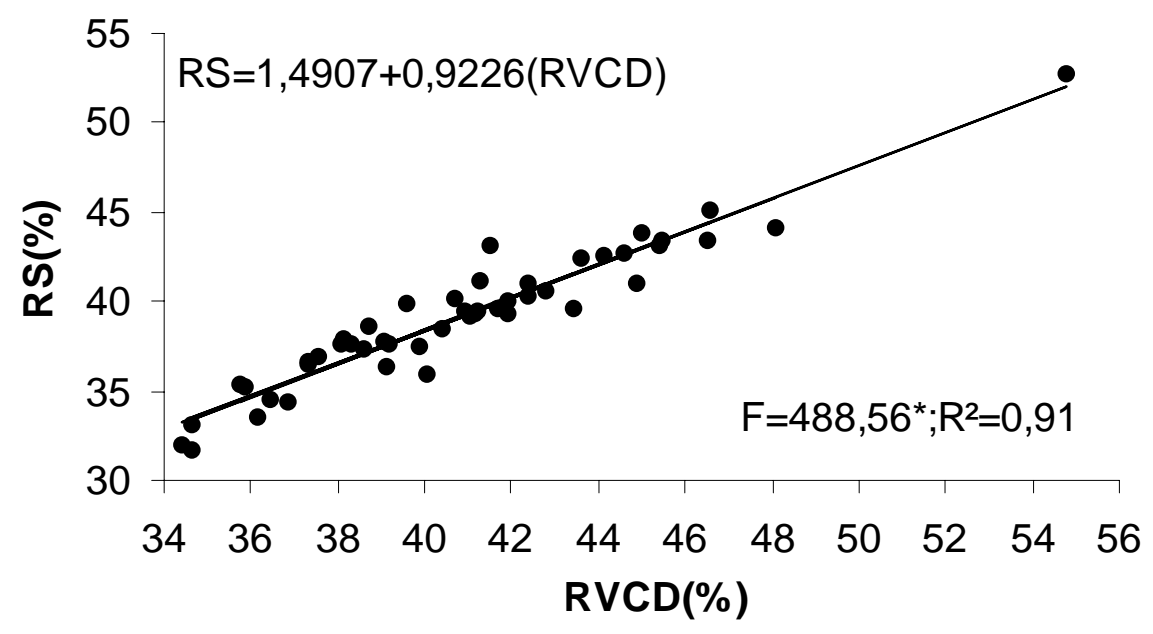

Figura 58 - Relação entre rendimento em madeira serrada seca com destopo (RS) e rendimento em madeira serrada verde com destopo (RVCD) para $E$. grandis de 21 anos de idade 
Procedeu-se uma análise do comportamento dos resíduos para regressão e verificou-se, em todos os casos, que os resíduos se encontravam bem distribuídos em torno da linha de zero.

Foi observado que ocorre uma boa relação entre conicidade e porcentagem de casca das toras.

No estudo da relação entre rachadura de topo de tábua e rachadura de topo de tora, admite-se que as regressões encontradas são muito úteis na predição das rachaduras da madeira serrada a partir das rachaduras da extremidade da tora, principalmente, para toras com índices de rachaduras de até 1,5\%. Pôde-se observar que a relação entre rachaduras de topo de tábua verde e rachaduras de topo de tora é um pouco melhor do que a relação entre rachaduras de topo de tábua serrada seca e rachaduras de topo de tora. Resultado muito semelhante foi obtido por Lima et al. (2000a) e Crêspo (2000).

Uma boa relação positiva foi obtida entre rachaduras de tábua seca e rachaduras de tábua verde, o que permite estimar, com certa segurança, a perda de comprimento que a tábua terá por efeito do processo de secagem. Lima et al. (2000) e Malan (2000) obtiveram a mesma forma de relação entre essas variáveis.

A melhor relação foi obtida entre rendimento seco com destopo e rendimento verde com destopo, possibilitando então estimar o volume de madeira que é perdido por influência do processo de secagem. 


\section{CONCLUSÕES}

Pelos resultados obtidos pode-se concluir que:

O deslocamento da medula e a porcentagem de casca não são influenciados pelo desbaste, adubação e não variam segundo a classe de diâmetro;

A conicidade varia com a classe de diâmetro sendo maior nas toras da classe superior;

As rachaduras de extremidade de tora não são influenciadas significativamente pelos fatores desbaste, adubação e classe de diâmetro;

A rachadura longitudinal mais extensa de extremidade de tábua verde ou seca, diminui no sentido da medula para a casca;

O encurvamento de tábua não sofre nenhuma influência significativa dos fatores desbaste, adubação e classe de diâmetro e aumenta da medula para a casca;

O arqueamento de tábua não apresenta tendência definida de crescimento ou diminuição ao longo do raio, quando obtida de um desdobro balanceado. Pode, variar em função de excentricidade da tora ou excentricidade operacional no desdobro;

O módulo de elasticidade estrutural obtido de ensaios de flexão estática não destrutivo aumenta no sentido da medula para a casca. A metodologia não destrutiva utilizada demonstra ser simples e eficiente na determinação dessa importante propriedade;

Baixa intensidade de desbaste redunda na menor disponibilidade de madeira serrada de primeira classe na população, mas alta intensidade de desbaste não inverte essa situação. O equilíbrio deve ser procurado caso a caso por causa da combinação de variáveis silviculturais e do processamento mecânico da madeira. Obteve-se no presente trabalho um rendimento em madeira serrada de $1^{a}$ classe significativamente superior aos encontrados nas intensidades de 37 e $75 \%$. Árvores da classe superior de DAP apresentam maior disponibilidade de tábuas de $1^{\mathrm{a}}$ classe; 
Parcelas adubadas oferecem maiores possibilidades de produção de tábuas de melhor qualidade. A maior freqüência de tábuas de $1^{\mathrm{a}}$ e $2^{\mathrm{a}}$ classes foi obtida nas parcelas adubadas, enquanto que nas parcelas não adubadas foi verificada a maior freqüência de tábuas de $3^{\mathrm{a}}$ classe e de refugo;

A posição relativa no raio interfere na classe de qualidade da madeira serrada. O número de ocorrência de tábuas de $1^{\text {a }}$ classe aumenta da medula para a casca enquanto que as peças de refugo diminuem da medula para casca;

O rendimento em madeira serrada não é influenciado pelo desbaste, adubação e não varia para classes de diâmetro não muito distante uma da outra;

A massa específica da madeira à umidade de equilíbrio é menor nas árvores oriundas de parcelas adubadas quando comparada com aquela de árvores procedentes de parcelas não adubadas. Essa propriedade aumenta significativamente da medula para casca;

Existe boa relação entre rachaduras de extremidade de tábua e rachaduras de extremidade de topo de tora. Admite-se que as regressões encontradas são muito úteis na predição das rachaduras das peças serradas a partir das rachaduras observadas na extremidade da tora, principalmente para toras com índices de rachaduras de até 1,5 $\%$;

Uma boa relação positiva também existe entre rachaduras de tábua seca rachaduras de tábua verde. A estimativa do comprimento de rachadura propagado durante o processo de secagem é muito boa. Como conseqüência, o rendimento em madeira serrada seca pode ser bem estimado em função do rendimento em madeira serrada verde;

Alta intensidade de desbaste tende a produzir madeira serrada mais homogênea. No presente trabalho verificou-se maior homogeneidade de qualidade na intensidade de $75 \%$ de desbaste, quando comparada com as intensidades de $37 \mathrm{e}$ $50 \%$. 
ANEXOS 
ANEXO A: Resultados das análises estatísticas 
Tabela 8. Análise de variância do deslocamento da medula (DM) da tora 2

\begin{tabular}{lccc}
\hline \multicolumn{1}{c}{ CAUSA DE VARIAÇÃO } & GL & F & Pr $>$ F \\
\hline Intensidade de desbaste(I) & 2 & 3,42 & 0,0436 \\
Adubo (A) & 1 & 0,00 & 0,9503 \\
Classe (C) & 1 & 0,07 & 0,7873 \\
$($ I)x(A) & 2 & 0,47 & 0,6265 \\
$($ I)x(C) & 2 & 0,87 & 0,4290 \\
(A)x(C) & 1 & 0,54 & 0,4689 \\
(I)x(A)x(C) & 2 & 0,41 & 0,6685 \\
Resíduo & 36 & & \\
\hline
\end{tabular}

Tabela 9. Análise de variância do deslocamento da medula (DM) da tora 3

\begin{tabular}{lccc}
\hline \multicolumn{1}{c}{ CAUSA DE VARIAÇÃO } & GL & F & Pr >F \\
\hline Intensidade de desbaste(I) & 2 & 0,66 & 0,5236 \\
Adubo (A) & 1 & 0,74 & 0,3949 \\
Classe (C) & 1 & 0,16 & 0,6870 \\
$(\mathrm{I}) \times(A)$ & 2 & 0,32 & 0,7298 \\
$(\mathrm{I}) \times(C)$ & 2 & 1,18 & 0,3191 \\
$(\mathrm{~A}) \times(\mathrm{C})$ & 1 & 0,01 & 0,9101 \\
$(\mathrm{I}) \times(\mathrm{A}) \times(\mathrm{C})$ & 2 & 0,88 & 0,4241 \\
Resíduo & 36 & & \\
\hline
\end{tabular}

Tabela 10. Análise de variância da porcentagem de casca (PC) da tora 2

\begin{tabular}{lccc}
\hline \multicolumn{1}{c}{ CAUSA DE VARIAÇÃO } & GL & F & Pr >F \\
\hline Intensidade de desbaste(I) & 2 & 0,98 & 0,3865 \\
Adubo (A) & 1 & 0,52 & 0,4756 \\
Classe (C) & 1 & 3,01 & 0,0913 \\
$(\mathrm{I}) \times(A)$ & 2 & 0,23 & 0,7934 \\
$(\mathrm{I}) \times(\mathrm{C})$ & 2 & 0,03 & 0,9718 \\
$(\mathrm{~A}) \times(\mathrm{C})$ & 1 & 0,00 & 0,9652 \\
$(\mathrm{I}) \times(\mathrm{A}) \times(\mathrm{C})$ & 2 & 0,25 & 0,7827 \\
Resíduo & 36 & & \\
\hline
\end{tabular}


Tabela 11. Análise de variância da porcentagem de casca (PC) da tora 3

\begin{tabular}{lccc}
\hline \multicolumn{1}{c}{ CAUSA DE VARIAÇÃO } & GL & F & Pr >F \\
\hline Intensidade de desbaste(I) & 2 & 2,37 & 0,1078 \\
Adubo (A) & 1 & 0,38 & 0,5432 \\
Classe (C) & 1 & 0,02 & 0,8801 \\
$(\mathrm{I}) \times(A)$ & 2 & 3,41 & 0,0439 \\
$(\mathrm{I}) \times(C)$ & 2 & 0,94 & 0,4002 \\
$($ A) $\times(C)$ & 1 & 0,12 & 0,7320 \\
(I)x(A)x(C) & 2 & 0,84 & 0,4403 \\
Resíduo & 36 & & \\
\hline
\end{tabular}

Tabela 12. Análise de variância da conicidade (C) da tora 2

\begin{tabular}{lccc}
\hline \multicolumn{1}{c}{ CAUSA DE VARIAÇÃO } & GL & F & Pr >F \\
\hline Intensidade de desbaste(I) & 2 & 0,44 & 0,6449 \\
Adubo (A) & 1 & 0,18 & 0,6719 \\
Classe (C) & 1 & 29,37 & 0,0001 \\
$(\mathrm{I}) \times(A)$ & 2 & 0,08 & 0,9272 \\
$(\mathrm{I}) \times(\mathrm{C})$ & 2 & 0,50 & 0,6085 \\
$(\mathrm{~A}) \times(\mathrm{C})$ & 1 & 0,18 & 0,6716 \\
$(\mathrm{I}) \times(\mathrm{A}) \times(\mathrm{C})$ & 2 & 0,12 & 0,8892 \\
$\operatorname{Resíduo~}$ & 36 & & \\
\hline
\end{tabular}

Tabela 13. Analise de variância da conicidade (C) da tora 3

\begin{tabular}{lccc}
\hline \multicolumn{1}{c}{ CAUSA DE VARIAÇÃO } & GL & F & Pr >F \\
\hline Intensidade de desbaste(I) & 2 & 1,50 & 0,2357 \\
Adubo (A) & 1 & 0,16 & 0,6922 \\
Classe (C) & 1 & 9,79 & 0,0035 \\
$(\mathrm{I}) \times(A)$ & 2 & 1,61 & 0,2145 \\
$(\mathrm{I}) \times(\mathrm{C})$ & 2 & 1,77 & 0,1842 \\
$(\mathrm{~A}) \times(\mathrm{C})$ & 1 & 0,07 & 0,7864 \\
$(\mathrm{I}) \times(\mathrm{A}) \times(\mathrm{C})$ & 2 & 0,80 & 0,4573 \\
Resíduo & 36 & & \\
\hline
\end{tabular}


Tabela 14. Análise de variância do índice de rachaduras de topo de tora (IRTT) da tora 2

\begin{tabular}{lccc}
\hline \multicolumn{1}{c}{ CAUSA DE VARIAÇÃO } & GL & F & Pr > F \\
\hline Intensidade de desbaste(I) & 2 & 1,34 & 0,2743 \\
Adubo (A) & 1 & 3,70 & 0,0622 \\
Classe (C) & 1 & 0,00 & 0,9863 \\
$(\mathrm{I}) \times(A)$ & 2 & 0,65 & 0,5280 \\
$(\mathrm{I}) \times(\mathrm{C})$ & 2 & 1,09 & 0,3486 \\
$(\mathrm{~A}) \times(\mathrm{C})$ & 1 & 0,25 & 0,6181 \\
$(\mathrm{I}) \times($ A $) \times(C)$ & 2 & 1,11 & 0,3416 \\
$\operatorname{Resíduo~}$ & 36 & & \\
\hline
\end{tabular}

Tabela 15. Análise de variância do índice de rachaduras de topo de tora (IRTT) da tora 3

\begin{tabular}{lccc}
\hline \multicolumn{1}{c}{ CAUSA DE VARIAÇÃO } & GL & F & Pr $>$ F \\
\hline Intensidade de desbaste(I) & 2 & 0,54 & 0,5885 \\
Adubo (A) & 1 & 2,30 & 0,1383 \\
Classe (C) & 1 & 0,09 & 0,7714 \\
$(\mathrm{I}) \times(A)$ & 2 & 1,26 & 0,2947 \\
$(\mathrm{I}) \times(C)$ & 2 & 0,20 & 0,8211 \\
(A)x(C) & 1 & 0,00 & 0,9881 \\
$(\mathrm{I}) \times(A) \times(C)$ & 2 & 1,95 & 0,1568 \\
Resíduo & 36 & & \\
\hline
\end{tabular}

Tabela 16. Análise de variância do (IRTV) para a posição radial (0\%) da tora 2

\begin{tabular}{lccc}
\hline \multicolumn{1}{c}{ CAUSA DE VARIAÇÃO } & GL & F & Pr $>$ F \\
\hline Intensidade de desbaste(I) & 2 & 0,67 & 0,5168 \\
Adubo (A) & 1 & 1,52 & 0,2250 \\
Classe (C) & 1 & 3,37 & 0,0745 \\
$(\mathrm{I}) \times(A)$ & 2 & 1,20 & 0,3122 \\
$(\mathrm{I}) \times(\mathrm{C})$ & 2 & 0,53 & 0,5918 \\
$(\mathrm{~A}) \times(\mathrm{C})$ & 1 & 0,36 & 0,5531 \\
$(\mathrm{I}) \times(\mathrm{A}) \times(\mathrm{C})$ & 2 & 0,35 & 0,7056 \\
Resíduo & 36 & & \\
\hline
\end{tabular}


Tabela 17. Análise de variância do (IRTV) da posição radial (50\%) da tora 2

\begin{tabular}{lccc}
\hline \multicolumn{1}{c}{ CAUSA DE VARIAÇÃO } & GL & F & Pr >F \\
\hline Intensidade de desbaste(I) & 2 & 0,00 & 0,9958 \\
Adubo (A) & 1 & 0,50 & 0,4851 \\
Classe (C) & 1 & 0,61 & 0,4382 \\
$(\mathrm{I}) \times(A)$ & 2 & 0,47 & 0,6261 \\
$(\mathrm{I}) \times(\mathrm{C})$ & 2 & 0,14 & 0,8711 \\
$(\mathrm{~A}) \times(\mathrm{C})$ & 1 & 0,05 & 0,8246 \\
$(\mathrm{I}) \times(\mathrm{A}) \times(\mathrm{C})$ & 2 & 0,29 & 0,7520 \\
Resíduo & 36 & & \\
\hline
\end{tabular}

Tabela 18. Análise de variância do (IRTV) da posição radial (100\%) da tora 2

\begin{tabular}{lccc}
\hline \multicolumn{1}{c}{ CAUSA DE VARIAÇÃO } & GL & F & Pr >F \\
\hline Intensidade de desbaste(I) & 2 & 0,20 & 0,8167 \\
Adubo (A) & 1 & 1,26 & 0,2691 \\
Classe (C) & 1 & 0,01 & 0,9196 \\
$(\mathrm{I}) \times(A)$ & 2 & 0,26 & 0,7722 \\
$(\mathrm{I}) \times(\mathrm{C})$ & 2 & 0,75 & 0,4811 \\
$(\mathrm{~A}) \times(\mathrm{C})$ & 1 & 0,22 & 0,6410 \\
$(\mathrm{I}) \times(\mathrm{A}) \times(\mathrm{C})$ & 2 & 0,70 & 0,5053 \\
Resíduo & 36 & & \\
\hline
\end{tabular}

Tabela 19. Análise de variância do (IRTV) da posição radial (0\%) da tora 3

\begin{tabular}{lccc}
\hline \multicolumn{1}{c}{ CAUSA DE VARIAÇÃO } & GL & F & Pr >F \\
\hline Intensidade de desbaste(I) & 2 & 1,06 & 0,3575 \\
Adubo (A) & 1 & 1,46 & 0,2355 \\
Classe (C) & 1 & 7,04 & 0,0118 \\
$(\mathrm{I}) \times(A)$ & 2 & 1,20 & 0,3119 \\
$(\mathrm{I}) \times(C)$ & 2 & 1,38 & 0,2640 \\
$(A) \times(C)$ & 1 & 0,09 & 0,7712 \\
$($ I) $\times(A) \times(C)$ & 2 & 0,29 & 0,7495 \\
Resíduo & 36 & & \\
\hline
\end{tabular}


Tabela 20. Análise de variância do (IRTV) da posição radial (50\%) da tora 3

\begin{tabular}{lccc}
\hline \multicolumn{1}{c}{ CAUSA DE VARIAÇÃO } & GL & F & Pr $>$ F \\
\hline Intensidade de desbaste(I) & 2 & 1,71 & 0,1950 \\
Adubo (A) & 1 & 0,24 & 0,6300 \\
Classe (C) & 1 & 8,67 & 0,0056 \\
$(\mathrm{I}) \times(A)$ & 2 & 2,96 & 0,0644 \\
$(\mathrm{I}) \times(\mathrm{C})$ & 2 & 0,16 & 0,8528 \\
$(\mathrm{~A}) \times(\mathrm{C})$ & 1 & 0,00 & 0,9893 \\
$(\mathrm{I}) \times(\mathrm{A}) \times(\mathrm{C})$ & 2 & 2,80 & 0,0743 \\
Resíduo & 36 & & \\
\hline
\end{tabular}

Tabela 21. Análise de variância do (IRTV) da posição radial (100\%) da tora 3

\begin{tabular}{lccc}
\hline \multicolumn{1}{c}{ CAUSA DE VARIAÇÃO } & GL & F & Pr >F \\
\hline Intensidade de desbaste(I) & 2 & 1,34 & 0,2747 \\
Adubo (A) & 1 & 0,36 & 0,5519 \\
Classe (C) & 1 & 2,13 & 0,1534 \\
$(\mathrm{I}) \times(A)$ & 2 & 0,37 & 0,6913 \\
$(\mathrm{I}) \times(C)$ & 2 & 0,74 & 0,4820 \\
$(\mathrm{~A}) \times(\mathrm{C})$ & 1 & 0,05 & 0,8230 \\
$(\mathrm{I}) \times(\mathrm{A}) \times(\mathrm{C})$ & 2 & 2,39 & 0,1060 \\
Resíduo & 36 & & \\
\hline
\end{tabular}

Tabela 22. Análise de variância do (IRTS )da posição radial (0\%) da tora 2

\begin{tabular}{lccc}
\hline \multicolumn{1}{c}{ CAUSA DE VARIAÇÃO } & GL & F & Pr >F \\
\hline Intensidade de desbaste(I) & 2 & 3,10 & 0,0571 \\
Adubo (A) & 1 & 5,25 & 0,0279 \\
Classe (C) & 1 & 0,56 & 0,4586 \\
$(\mathrm{I}) \times(A)$ & 2 & 0,38 & 0,6866 \\
$(\mathrm{I}) \times(C)$ & 2 & 0,82 & 0,4481 \\
$(A) \times(C)$ & 1 & 0,29 & 0,5914 \\
$($ I) $\times(A) \times(C)$ & 2 & 1,05 & 0,3610 \\
Resíduo & 36 & & \\
\hline
\end{tabular}


Tabela 23. Análise de variância do (IRTS) da posição radial (50\%) da tora 2

\begin{tabular}{lccc}
\hline \multicolumn{1}{c}{ CAUSA DE VARIAÇÃO } & GL & F & Pr > F \\
\hline Intensidade de desbaste(I) & 2 & 1,20 & 0,3133 \\
Adubo (A) & 1 & 0,57 & 0,4570 \\
Classe (C) & 1 & 0,14 & 0,7066 \\
$(\mathrm{I}) \times(A)$ & 2 & 0,12 & 0,8856 \\
$(\mathrm{I}) \times(\mathrm{C})$ & 2 & 0,11 & 0,8950 \\
$(\mathrm{~A}) \times(\mathrm{C})$ & 1 & 0,02 & 0,8883 \\
$(\mathrm{I}) \times(\mathrm{A}) \times(\mathrm{C})$ & 2 & 1,18 & 0,3178 \\
Resíduo & 36 & & \\
\hline
\end{tabular}

Tabela 24. Análise de variância do (IRTS) da posição radial (100\%) da tora 2

\begin{tabular}{lccc}
\hline \multicolumn{1}{c}{ CAUSA DE VARIAÇÃO } & GL & F & Pr >F \\
\hline Intensidade de desbaste(I) & 2 & 0,35 & 0,7042 \\
Adubo (A) & 1 & 0,68 & 0,4142 \\
Classe (C) & 1 & 0,00 & 0,9506 \\
$(\mathrm{I}) \times(A)$ & 2 & 0,16 & 0,8519 \\
$(\mathrm{I}) \times(\mathrm{C})$ & 2 & 0,50 & 0,6080 \\
$(\mathrm{~A}) \times(\mathrm{C})$ & 1 & 0,88 & 0,3540 \\
$(\mathrm{I}) \times(\mathrm{A}) \times(\mathrm{C})$ & 2 & 1,07 & 0,3544 \\
Resíduo & 36 & & \\
\hline
\end{tabular}

Tabela 25. Análise de variância do (IRTS) da posição radial (0\%) da tora 3

\begin{tabular}{lccc}
\hline \multicolumn{1}{c}{ CAUSA DE VARIAÇÃO } & GL & F & Pr >F \\
\hline Intensidade de desbaste(I) & 2 & 0,48 & 0,6232 \\
Adubo (A) & 1 & 1,27 & 0,2670 \\
Classe (C) & 1 & 7,08 & 0,0116 \\
$(\mathrm{I}) \times(A)$ & 2 & 0,85 & 0,4372 \\
$(\mathrm{I}) \times(\mathrm{C})$ & 2 & 2,33 & 0,1121 \\
$(\mathrm{~A}) \times(\mathrm{C})$ & 1 & 0,47 & 0,4983 \\
$(\mathrm{I}) \times(\mathrm{A}) \times(\mathrm{C})$ & 2 & 0,02 & 0,9755 \\
Resíduo & 36 & &
\end{tabular}


Tabela 26. Análise de variância do (IRTS) da posição radial (50\%) da tora 3

\begin{tabular}{lccc}
\hline \multicolumn{1}{c}{ CAUSA DE VARIAÇÃO } & GL & F & Pr $>$ F \\
\hline Intensidade de desbaste(I) & 2 & 0,57 & 0,5728 \\
Adubo (A) & 1 & 1,01 & 0,3221 \\
Classe (C) & 1 & 6,69 & 0,0139 \\
$(\mathrm{I}) \times(A)$ & 2 & 5,52 & 0,0081 \\
$(\mathrm{I}) \times(C)$ & 2 & 0,60 & 0,5561 \\
$(\mathrm{~A}) \times(\mathrm{C})$ & 1 & 1,21 & 0,2778 \\
$(\mathrm{I}) \times(\mathrm{A}) \times(\mathrm{C})$ & 2 & 2,96 & 0,0647 \\
Resíduo & 36 & & \\
\hline
\end{tabular}

Tabela 27. Análise de variância do (IRTS) da posição radial (100\%) da tora 3

\begin{tabular}{lccc}
\hline \multicolumn{1}{c}{ CAUSA DE VARIAÇÃO } & GL & F & Pr > F \\
\hline Intensidade de desbaste(I) & 2 & 0,79 & 0,4623 \\
Adubo (A) & 1 & 0,11 & 0,7440 \\
Classe (C) & 1 & 1,13 & 0,2939 \\
$($ I)x(A) & 2 & 0,23 & 0,7995 \\
$($ I)x(C) & 2 & 1,09 & 0,3476 \\
(A)x(C) & 1 & 0,34 & 0,5608 \\
(I)x(A)x(C) & 2 & 0,60 & 0,5545 \\
Resíduo & 36 & & \\
\hline
\end{tabular}

Tabela 28. Análise de variância da Flecha de encurvamento $\left(F_{E}\right)$ da posição radial (0\%) da tora 2

\begin{tabular}{lccc}
\hline \multicolumn{1}{c}{ CAUSA DE VARIAÇÃO } & GL & F & Pr $>$ F \\
\hline Intensidade de desbaste(I) & 2 & 0,91 & 0,4112 \\
Adubo (A) & 1 & 0,33 & 0,5719 \\
Classe (C) & 1 & 0,56 & 0,4575 \\
$(\mathrm{I}) \times(A)$ & 2 & 0,01 & 0,9936 \\
$(\mathrm{I}) \times(\mathrm{C})$ & 2 & 0,17 & 0,8470 \\
$(\mathrm{~A}) \times(\mathrm{C})$ & 1 & 0,92 & 0,3432 \\
$(\mathrm{I}) \times($ A $) \times(C)$ & 2 & 0,09 & 0,9140 \\
Resíduo & 36 & & \\
\hline
\end{tabular}


Tabela 29. Análise de variância da Flecha de encurvamento $\left(F_{E}\right)$ da posição radial (50\%) da tora 2

\begin{tabular}{lccc}
\hline \multicolumn{1}{c}{ CAUSA DE VARIAÇÃO } & GL & F & Pr >F \\
\hline Intensidade de desbaste(I) & 2 & 1,58 & 0,2193 \\
Adubo (A) & 1 & 0,02 & 0,8895 \\
Classe (C) & 1 & 0,05 & 0,8278 \\
$($ I)x(A) & 2 & 0,10 & 0,9053 \\
$($ I)x(C) & 2 & 1,88 & 0,1678 \\
(A)x(C) & 1 & 0,29 & 0,5914 \\
$($ I)x(A)x(C) & 2 & 1,05 & 0,3593 \\
Resíduo & 36 & & \\
\hline
\end{tabular}

Tabela 30. Análise de variância da Flecha de encurvamento $\left(F_{E}\right)$ da posição radial $(100 \%)$ da tora 2

\begin{tabular}{lccc}
\hline \multicolumn{1}{c}{ CAUSA DE VARIAÇÃO } & GL & F & Pr >F \\
\hline Intensidade de desbaste(I) & 2 & 0,27 & 0,7653 \\
Adubo (A) & 1 & 0,46 & 0,5023 \\
Classe (C) & 1 & 1,33 & 0,2940 \\
$($ I)x(A) & 2 & 0,88 & 0,4247 \\
$($ I)x(C) & 2 & 1,15 & 0,3273 \\
(A)x(C) & 1 & 0,02 & 0,8993 \\
$($ I)x(A)x(C) & 2 & 0,88 & 0,4242 \\
Resíduo & 36 & & \\
\hline
\end{tabular}


Tabela 31. Análise de variância da Flecha de encurvamento $\left(F_{E}\right)$ da posição radial $(0 \%)$ da tora 3

\begin{tabular}{lccc}
\hline \multicolumn{1}{c}{ CAUSA DE VARIAÇÃO } & GL & F & Pr > F \\
\hline Intensidade de desbaste(I) & 2 & 0,64 & 0,5327 \\
Adubo (A) & 1 & 1,37 & 0,3080 \\
Classe (C) & 1 & 0,47 & 0,4990 \\
$(\mathrm{I}) \times(A)$ & 2 & 0,36 & 0,7009 \\
$(\mathrm{I}) \times(\mathrm{C})$ & 2 & 0,09 & 0,9154 \\
$(\mathrm{~A}) \times(\mathrm{C})$ & 1 & 1,16 & 0,2892 \\
$(\mathrm{I}) \times($ A $) \times(C)$ & 2 & 0,55 & 0,5804 \\
Resíduo & 36 & &
\end{tabular}

Tabela 32. Análise de variância da Flecha de encurvamento $\left(F_{E}\right)$ da posição radial (50\%) da tora 3

\begin{tabular}{lccc}
\hline \multicolumn{1}{c}{ CAUSA DE VARIAÇÃO } & GL & F & Pr $>$ F \\
\hline Intensidade de desbaste(I) & 2 & 1,05 & 0,3592 \\
Adubo (A) & 1 & 0,14 & 0,7101 \\
Classe (C) & 1 & 0,56 & 0,4599 \\
$(\mathrm{I}) \times(A)$ & 2 & 0,78 & 0,4661 \\
$(\mathrm{I}) \times(C)$ & 2 & 0,25 & 0,7811 \\
(A)x(C) & 1 & 0,22 & 0,6428 \\
(I)x(A)x(C) & 2 & 0,49 & 0,6176 \\
Resíduo & 36 & & \\
\hline
\end{tabular}


Tabela 33. Análise de variância da Flecha de encurvamento $\left(F_{E}\right)$ da posição radial $(100 \%)$ da tora 3

\begin{tabular}{lccc}
\hline \multicolumn{1}{c}{ CAUSA DE VARIAÇÃO } & GL & F & Pr > F \\
\hline Intensidade de desbaste(I) & 2 & 0,60 & 0,5536 \\
Adubo (A) & 1 & 0,13 & 0,7198 \\
Classe (C) & 1 & 0,64 & 0,4292 \\
$($ I)x(A) & 2 & 0,31 & 0,7385 \\
$($ I)x(C) & 2 & 1,01 & 0,3730 \\
(A)x(C) & 1 & 0,79 & 0,3787 \\
$($ I)x(A)x(C) & 2 & 0,20 & 0,8156 \\
Resíduo & 36 & & \\
\hline
\end{tabular}

Tabela 34. Análise de variância da Flecha de arqueamento $\left(F_{A}\right)$ da posição radial $(0 \%)$ da tora 2

\begin{tabular}{lccc}
\hline \multicolumn{1}{c}{ CAUSA DE VARIAÇÃO } & GL & F & Pr $>\mathbf{F}$ \\
\hline Intensidade de desbaste(I) & 2 & 0,39 & 0,6782 \\
Adubo (A) & 1 & 0,20 & 0,6546 \\
Classe (C) & 1 & 2,05 & 0,1605 \\
$($ I)x(A) & 2 & 1,32 & 0,2802 \\
$($ I)x(C) & 2 & 1,17 & 0,3231 \\
(A)x(C) & 1 & 0,75 & 0,3913 \\
(I)x(A)x(C) & 2 & 0,78 & 0,4661 \\
Resíduo & 36 & & \\
\hline
\end{tabular}


Tabela 35. Análise de variância da Flecha de arqueamento $\left(F_{A}\right)$ da posição radial (50\%) da tora 2

\begin{tabular}{lccc}
\hline \multicolumn{1}{c}{ CAUSA DE VARIAÇÃO } & GL & F & Pr $>$ F \\
\hline Intensidade de desbaste(I) & 2 & 0,13 & 0,8792 \\
Adubo (A) & 1 & 0,03 & 0,8750 \\
Classe (C) & 1 & 0,00 & 0,9710 \\
$(\mathrm{I}) \times(A)$ & 2 & 0,27 & 0,7634 \\
$(\mathrm{I}) \times(\mathrm{C})$ & 2 & 0,03 & 0,9658 \\
$(\mathrm{~A}) \times(\mathrm{C})$ & 1 & 0,62 & 0,4380 \\
$(\mathrm{I}) \times(\mathrm{A}) \times(\mathrm{C})$ & 2 & 1,11 & 0,3397 \\
Resíduo & 36 & & \\
\hline
\end{tabular}

Tabela 36. Análise de variância da Flecha de arqueamento $\left(F_{A}\right)$ da posição radial $(100 \%)$ da tora 2

\begin{tabular}{lccc}
\hline \multicolumn{1}{c}{ CAUSA DE VARIAÇÃO } & GL & F & Pr > F \\
\hline Intensidade de desbaste(I) & 2 & 0,72 & 0,4938 \\
Adubo (A) & 1 & 0,30 & 0,5880 \\
Classe (C) & 1 & 0,06 & 0,8003 \\
$($ I)x(A) & 2 & 1,37 & 0,2661 \\
$($ I)x(C) & 2 & 1,05 & 0,3598 \\
$($ A)x(C) & 1 & 1,79 & 0,1893 \\
$($ I)x(A)x(C) & 2 & 1,38 & 0,2646 \\
Resíduo & 36 & & \\
\hline
\end{tabular}


Tabela 37. Análise de variância da Flecha de arqueamento $\left(F_{A}\right)$ da posição radial $(0 \%)$ da tora 3

\begin{tabular}{|c|c|c|c|}
\hline CAUSA DE VARIAÇÃO & GL & $\mathbf{F}$ & $\operatorname{Pr}>\mathrm{F}$ \\
\hline Intensidade de desbaste(I) & 2 & 3,41 & 0,0441 \\
\hline Adubo (A) & 1 & 1,53 & 0,2238 \\
\hline Classe (C) & 1 & 4,28 & 0,0620 \\
\hline$(I) \times(A)$ & 2 & 1,66 & 0,2045 \\
\hline$(\mathrm{I}) \times(\mathrm{C})$ & 2 & 1,85 & 0,1715 \\
\hline$(A) \times(C)$ & 1 & 0,24 & 0,6274 \\
\hline$(\mathrm{I}) \times(\mathrm{A}) \times(\mathrm{C})$ & 2 & 0,84 & 0,4381 \\
\hline Resíduo & 36 & & \\
\hline
\end{tabular}

Tabela 38. Análise de variância da Flecha de arqueamento $\left(F_{A}\right)$ da posição radial $(50 \%)$ da tora 3

\begin{tabular}{lccc}
\hline \multicolumn{1}{c}{ CAUSA DE VARIAÇÃO } & GL & F & Pr $>$ F \\
\hline Intensidade de desbaste(I) & 2 & 0,54 & 0,5849 \\
Adubo (A) & 1 & 0,00 & 1,0000 \\
Classe (C) & 1 & 2,29 & 0,1390 \\
$(\mathrm{I}) \times(A)$ & 2 & 2,98 & 0,0633 \\
$(\mathrm{I}) \times(\mathrm{C})$ & 2 & 0,85 & 0,4352 \\
$(\mathrm{~A}) \times(\mathrm{C})$ & 1 & 0,56 & 0,4572 \\
$(\mathrm{I}) \times(\mathrm{A}) \times(\mathrm{C})$ & 2 & 2,26 & 0,1189 \\
Resíduo & 36 & & \\
\hline
\end{tabular}


Tabela 39. Análise de variância da Flecha de arqueamento $\left(F_{A}\right)$ da posição radial $(100 \%)$ da tora 3

\begin{tabular}{lccc}
\hline \multicolumn{1}{c}{ CAUSA DE VARIAÇÃO } & GL & F & Pr $>$ F \\
\hline Intensidade de desbaste(I) & 2 & 1,24 & 0,3004 \\
Adubo (A) & 1 & 0,01 & 0,9241 \\
Classe (C) & 1 & 0,02 & 0,8863 \\
$($ I)x(A) & 2 & 0,78 & 0,4650 \\
$($ I)x(C) & 2 & 0,59 & 0,5585 \\
(A)x(C) & 1 & 0,11 & 0,7388 \\
$($ I)x(A)x(C) & 2 & 1,51 & 0,2339 \\
Resíduo & 36 & & \\
\hline
\end{tabular}

Tabela 40. Análise de variância do (MOEe) da posição radial (0\%) da tora 2

\begin{tabular}{lccc}
\hline \multicolumn{1}{c}{ CAUSA DE VARIAÇÃO } & GL & F & Pr $>$ F \\
\hline Intensidade de desbaste(I) & 2 & 0,49 & 0,6141 \\
Adubo (A) & 1 & 0,06 & 0,8108 \\
Classe (C) & 1 & 4,14 & 0,0492 \\
$(\mathrm{I}) \times(A)$ & 2 & 0,44 & 0,6498 \\
$(\mathrm{I}) \times(\mathrm{C})$ & 2 & 1,29 & 0,2878 \\
$(\mathrm{~A}) \times(\mathrm{C})$ & 1 & 0,00 & 0,9704 \\
$(\mathrm{I}) \times(\mathrm{A}) \times(\mathrm{C})$ & 2 & 0,51 & 0,6062 \\
Resíduo & 36 & & \\
\hline
\end{tabular}


Tabela 41. Análise de variância do (MOEe) da posição radial (50\%) da tora 2

\begin{tabular}{lccc}
\hline \multicolumn{1}{c}{ CAUSA DE VARIAÇÃO } & GL & F & Pr $>$ F \\
\hline Intensidade de desbaste(I) & 2 & 0,65 & 0,5292 \\
Adubo (A) & 1 & 1,02 & 0,3186 \\
Classe (C) & 1 & 1,15 & 0,2900 \\
$($ I)x(A) & 2 & 0,17 & 0,8470 \\
$($ I)x(C) & 2 & 0,01 & 0,9858 \\
(A)x(C) & 1 & 0,01 & 0,9437 \\
(I)x(A)x(C) & 2 & 0,69 & 0,5076 \\
Resíduo & 36 & & \\
\hline
\end{tabular}

Tabela 42. Análise de variância do (MOEe) da posição radial (100\%) da tora 2

\begin{tabular}{lccc}
\hline \multicolumn{1}{c}{ CAUSA DE VARIAÇÃO } & GL & F & Pr $>$ F \\
\hline Intensidade de desbaste(I) & 2 & 0,50 & 0,6119 \\
Adubo (A) & 1 & 0,14 & 0,7146 \\
Classe (C) & 1 & 0,12 & 0,9668 \\
$(\mathrm{I}) \times(A)$ & 2 & 0,76 & 0,4768 \\
$(\mathrm{I}) \times(\mathrm{C})$ & 2 & 1,55 & 0,2264 \\
$(\mathrm{~A}) \times(\mathrm{C})$ & 1 & 0,03 & 0,8690 \\
$(\mathrm{I}) \times(\mathrm{A}) \times(\mathrm{C})$ & 2 & 0,76 & 0,4768 \\
Resíduo & 36 & & \\
\hline
\end{tabular}

Tabela 43. Análise de variância do (MOEe) da posição radial (0\%) da tora 3

\begin{tabular}{lccc}
\hline \multicolumn{1}{c}{ CAUSA DE VARIAÇÃO } & GL & F & Pr $>$ F \\
\hline Intensidade de desbaste(I) & 2 & 1,63 & 0,2093 \\
Adubo (A) & 1 & 0,00 & 0,9687 \\
Classe (C) & 1 & 0,03 & 0,8682 \\
$(\mathrm{I}) \times(A)$ & 2 & 1,16 & 0,3259 \\
$(\mathrm{I}) \times(\mathrm{C})$ & 2 & 0,33 & 0,7185 \\
$(\mathrm{~A}) \times(\mathrm{C})$ & 1 & 2,84 & 0,1008 \\
$(\mathrm{I}) \times(\mathrm{A}) \times(\mathrm{C})$ & 2 & 0,60 & 0,5523 \\
Resíduo & 36 & & \\
\hline
\end{tabular}


Tabela 44. Análise de variância do (MOEe) da posição radial (50\%) da tora 3

\begin{tabular}{lccc}
\hline \multicolumn{1}{c}{ CAUSA DE VARIAÇÃO } & GL & F & Pr $>\mathbf{F}$ \\
\hline Intensidade de desbaste(I) & 2 & 0,72 & 0,4928 \\
Adubo (A) & 1 & 3,81 & 0,0588 \\
Classe (C) & 1 & 0,03 & 0,8530 \\
$($ I)x(A) & 2 & 1,82 & 0,1765 \\
$($ I)x(C) & 2 & 0,39 & 0,6800 \\
(A)x(C) & 1 & 0,86 & 0,3595 \\
(I)x(A)x(C) & 2 & 0,51 & 0,6066 \\
Resíduo & 36 & & \\
\hline
\end{tabular}

Tabela 45. Análise de variância do (MOEe) da posição radial (100\%) da tora 3

\begin{tabular}{lccc}
\hline \multicolumn{1}{c}{ CAUSA DE VARIAÇÃO } & GL & F & Pr > F \\
\hline Intensidade de desbaste(I) & 2 & 0,20 & 0,8190 \\
Adubo (A) & 1 & 2,69 & 0,1096 \\
Classe (C) & 1 & 0,01 & 0,9332 \\
$(\mathrm{I}) \times(A)$ & 2 & 1,93 & 0,1602 \\
$(\mathrm{I}) \times(\mathrm{C})$ & 2 & 1,23 & 0,3046 \\
$(\mathrm{~A}) \times(\mathrm{C})$ & 1 & 0,88 & 0,3558 \\
$(\mathrm{I}) \times(\mathrm{A}) \times(\mathrm{C})$ & 2 & 0,21 & 0,8085 \\
Resíduo & 36 & & \\
\hline
\end{tabular}

Tabela 46. Resultados do teste F da análise de variância do RVSD, RVCD e RS da tora 2

\begin{tabular}{lccc}
\hline & RVSD & RVCD & RS \\
& $\mathbf{F}$ & $\mathbf{F}$ & $\mathbf{F}$ \\
\hline C.V. (\%) & 12,25 & 14,72 & 14,67 \\
Desbaste & $0,82^{\text {n.s }}$ & $0,17^{\text {n.s }}$ & $0,58^{\text {n.s }}$ \\
Adubo & $0,26^{\text {n.s }}$ & $0,22^{\text {n.s }}$ & $0,02^{\text {n.s }}$ \\
Classe & $0,25^{\text {n.s }}$ & $2,21^{\text {n.s }}$ & $1,47^{\text {n.s }}$
\end{tabular}

Onde: ns = não significativo, C.V. = coeficiente de variação 
Tabela 47. Resultados do teste F da análise de variância do RVSD, RVCD e RS da tora 3

\begin{tabular}{lccc}
\hline & RVSD & RVCD & RS \\
& $\mathbf{F}$ & $\mathbf{F}$ & $\mathbf{F}$ \\
\hline C.V. (\%) & 8,92 & 10,69 & 11,22 \\
Desbaste & $0,67^{\text {n.s }}$ & $0,62^{\text {n.s }}$ & $0,53^{\text {n.s }}$ \\
Adubo & $1,90^{\text {n.s }}$ & $0,60^{\text {n.s }}$ & $0,27^{\text {n.s }}$ \\
Classe & $2,66^{\text {n.s }}$ & $0,16^{\text {n.s }}$ & $0,01^{\text {n.s }}$ \\
\hline
\end{tabular}

Onde: ns = não significativo, C.V. = coeficiente de variação

Tabela 48. Resultados do teste $F$ da análise de variância da (ME) da posição radial (0\%) da tora 1

\begin{tabular}{lccc}
\hline \multicolumn{1}{c}{ CAUSA DE VARIAÇÃO } & G.L. & F & Pr>F \\
\hline DESBASTE(D) & 2 & 0,51 & 0.6015 \\
ADUBO $(A)$ & 1 & 12,05 & 0.0010 \\
CLASSE(C) & 2 & 1,33 & 0.2729 \\
DxA & 2 & 2,54 & 0.0885 \\
DxC & 4 & 0,14 & 0.9676 \\
AxC & 2 & 1,11 & 0.3358 \\
DxAxC & 4 & 1,79 & 0.1442 \\
Resíduo & 54 & &
\end{tabular}

Tabela 49. Resultados do teste $F$ da análise de variância da (ME) da posição radial $(25 \%)$ da tora 1

\begin{tabular}{lccc}
\hline \multicolumn{1}{c}{ CAUSA DE VARIAÇÃO } & G.L. & $\mathbf{F}$ & Pr>F \\
\hline DESBASTE(D) & 2 & 0,10 & 0,9025 \\
ADUBO (A) & 1 & 8,53 & 0,0051 \\
CLASSE(C) & 2 & 3,45 & 0,0391 \\
DxA & 2 & 0,62 & 0,5395 \\
DxC & 4 & 1,94 & 0,1171 \\
AxC & 2 & 0,46 & 0,6334 \\
DxAxC & 4 & 1,63 & 0,1796 \\
Resíduo & 54 & & \\
\hline
\end{tabular}


Tabela 50. Resultados do teste F da análise de variância da (ME) da posição radial $(50 \%)$ da tora 1

\begin{tabular}{lccc}
\hline CAUSA DE VARIAÇÃO & G.L. & F & Pr>F \\
\hline DESBASTE(D) & 2 & 0,41 & 0,6687 \\
ADUBO (A) & 1 & 15,61 & 0,0002 \\
CLASSE(C) & 2 & 1,10 & 0,3399 \\
DxA & 2 & 0,05 & 0,9510 \\
DxC & 4 & 2,11 & 0,0916 \\
AxC & 2 & 1,01 & 0,3727 \\
DxAxC & 4 & 1,25 & 0,3028 \\
Resíduo & 54 & & \\
\hline
\end{tabular}

Tabela 51. Resultados do teste $F$ da análise de variância da (ME) da posição radial (75\%) da tora 1

\begin{tabular}{lccc}
\hline CAUSA DE VARIAÇÃO & G.L. & F & Pr>F \\
\hline DESBASTE(D) & 2 & 0,09 & 0.9101 \\
ADUBO (A) & 1 & 3,87 & 0.0543 \\
CLASSE(C) & 2 & 4,12 & 0.0216 \\
DxA & 2 & 0,28 & 0.7532 \\
DxC & 4 & 2,71 & 0.0395 \\
AxC & 2 & 0,91 & 0.4087 \\
DxAxC & 4 & 0,27 & 0.8953 \\
Resíduo & 54 & & \\
\hline
\end{tabular}


Tabela 52. Resultados do teste F da análise de variância da (ME) da posição radial $(100 \%)$ da tora 1

\begin{tabular}{lccc}
\hline \multicolumn{1}{c}{ CAUSA DE VARIAÇÃO } & G.L. & F & Pr>F \\
\hline DESBASTE(D) & 2 & 1.05 & 0.3562 \\
ADUBO (A) & 1 & 7.77 & 0.0073 \\
CLASSE(C) & 2 & 7.53 & 0.0013 \\
DxA & 2 & 1.45 & 0.24380 \\
DxC & 4 & 1.95 & 0.1156 \\
AxC & 2 & 0.39 & 0.6778 \\
DxAxC & 4 & 1.15 & 0.3431 \\
Resíduo & 54 & & \\
\hline
\end{tabular}

Tabela 53. Resultados da análise de correlações entre diversas variáveis estudadas

\begin{tabular}{cccc}
\hline VARIÁVEL(y) & VARIÁVEL(x) & $\mathbf{R}$ & Prob > F \\
\hline IRTS & IR & 0,7047 & 0,0001 \\
C & PC & 0,7341 & 0,0001 \\
IRTV & IR & 0,7624 & 0,0001 \\
RVSD & RS & 0,7869 & 0,0001 \\
RVSD & RVCD & 0,8601 & 0,0001 \\
IRTS & IRTV & 0,8746 & 0,0001 \\
RVCD & RS & 0,9560 & 0,0001 \\
\hline
\end{tabular}




\section{REFERÊNCIA BIBLIOGRÁFICA}

ASSOCIAÇÃO BRASILEIRA DE NORMAS TÉCNICAS - Classificação de madeira serrada de folhosas: NBR 94987. São Paulo, 1986. 53p.

ASSOCIAÇÃO BRASILEIRA DE NORMAS TÉCNICAS. Projeto de estruturas de madeira: projeto NBR 7190/1997. Rio de Janeiro, 1997. 107p.

ANDRADE, A.M., VITAL, B.R., BARROS, N.F. et al. Efeitos da fertilização mineral e da calagem do solo na produção e na qualidade da madeira de eucalipto. Revista Árvore, v.18,n. 1. p. 69-78, 1994.

ASSIS,T. F. Qualificação tecnológica da madeira de Eucalyptus para serraria: aspectos genéticos e de manejo. In: SIMPÓSIO LATINO-AMERICANO SOBRE MANEJO FLORESTAL, 1. Santa Maria, 2000. Anais. Santa Maria: UFSM, 2000. p. 59-80.

BAMBER, R. K.; FLOYD, A. G.; HUMPHREYS, F. R. Wood properties of folooded gum. Australian Foresty, n. 33,p.3-17,1969.

BAMBER, R. K.; HORNE, R. ; GRAHAM-HIGGS, A. Effect of fast growth on the wood properties of Eucalyptus grandis. Australian Foresty Research, n.12,p. 163-167, 1982.

BARCHET, V. G. Potencialidade de espécie de Eucalyptus para produção de madeira serrada. Piracicaba, 2001. 166p. Dissertação (Mestrado) - Escola Superior de Agricultura "Luiz de Queiroz", Universidade de São Paulo.

BARISKA, M. A method for predicting timber quality in eucalypts, In: MANAGEMENT OF Eucalyptus grandis IN SOUTH AFRICA, Stellenbosch:, 1990. Proceedings. Stellenbosch: Southern African Institute of Forestry, 1990. p. 215-228.

BARNACLE J. E. Rapid effect of drying on develoment of heart craks. Australian Forestry, v.35,n.4,p. 251-257, 1971.

BARRICHELO, L.E.G.; SHIMOYAMA, V.R.S. Importância da adubação na qualidade da madeira e celulose. In: SÁ, M.E.; BUZETTI, S. (Ed). Importância da adubação na qualidade dos produtos agrícolas. São Paulo: Cone, 1994. cap.9, p.153-160. 
BARRICHELO, L. E. G.;BRITO, J. O.;MIGLIORINI, A. J. Estudo da variação longitudinal da densidade básica de Eucalyptus spp. SILVICULTURA, v. 8,n. 28,p. 726-31,1983.

BERGER, R.; SCHNEIDER, P. R.; FINGER, C. A. G. et al. feito do espaçamento e da fertilização sobre o crescimento e qualidade da madeira de um clone de Eucalyptus saligna SMITH. In: SIMPÓSIO LATINO-AMERICANO SOBRE MANEJO FLORESTAL, 1. Santa Maria, 2000. Anais. Santa Maria: UFSM, 2000. p. 209-236.

BOUCHARDET, J. A. Crescimento, características físicas e anatômicas da madeira juvenil de dois clones de Eucalyptus grandis ex Maiden em resposta à aplicação de boro. Piracicaba, 2002. 69p. Dissertação (Mestrado) - Escola superior de Agricultura "Luiz de Queiroz", Universidade de São Paulo.

BOYD, J. D. Tree growth stresses. I - Growth stresses evaluation. Australian Journal Science Research, v.3,p.270-293, 1950.

BOYD, J. D. Tree growth stresses. V- Evidence of an origin and differentiation and lignification. Wood Science and Technology, v.6,n.4,p. 251-262, 1972.

BREDENKEMP, B. V.; MALAN, F. S.; CONRADIE, W. Some effects of pruning on growth and timber quality of Eucalyptus grandis in Zululand. S. A. Forestry Journal, n.144,p.29-34, 1980.

BROWNING, B. L. The chemistry of wood. New York: Interscience, 1963. 689p.

BURGER, L.M.; RICHTER, H. G. Anatomia da Madeira. São Paulo: Nobel, 1991. 154p

BUSNARDO, C.A.; GONZAGA, J.V., FOELKEL, C.E.B. et al. Em busca da qualidade ideal da madeira do eucalipto para produção de celulose: II. Inter-relações entre propriedades das árvores e de suas madeiras. In:CONGRESSO LATINOAMERICANO DE CELULOSE E PAPEL, 3. São Paulo, 1983. Anais. São Paulo: ABCP, 1983. v.1, p.31-47.

CAMPINHOS JUNIOR, E. A importância da produção de madeira de Eucalyptus, geneticamente melhorado, para os setores moveleiro e de construção civil: perspectivas e desafios. In: SEMINÁRIO MADEIRA DE EUCALIPTO: TENDÊNCIAS E USOS. Curitiba, 2001. Anais. Curitiba: FUPEF, 2001. p.53-58,

CHAFE, S. C. Growth stress in trees. Australian Forest Research, v.9,n.3,p.203-223, 1979. 
CARVALHO, A. M. Valorização da madeira do híbrido Eucalyptus grandis x Eucalyptus urophylla através da produção conjunta de madeira serrada em pequenas dimensões, celulose e lenha. Piracicaba, 2000. 129p. Dissertação (Mestrado) Escola superior de Agricultura "Luiz de Queiroz", Universidade de São Paulo.

CHAFE, S. C. Variation in longitudinal growth stress basic density and modulus of elasticity with height in the tree. Australian Forest Research, n.11,p. 79-82, 1981.

CHAFE, S. C. Variation in longitudinal growth stress with height in trees of Eucalyptus nitens Maiden. Australian Forest Research, v.15,n.51-55, 1985.

COSTA, E. M. A madeira de eucalipto na indústria moveleira. In: SEMINÁRIO SOBRE PROCESSAMENTO E UTILIZAÇÃO DA MADEIRA DE REFLORESTAMENTO, 4. Curitiba, 1996. Anais. Curitiba: ABPM/ SBS, 1996. p. 75- 89.

COUTO, H.T.Z. Manejo de florestas e suas utilizações em serraria. In: SEMINÁRIO INTERNACIONAL E UTILIZAÇÃO DA MADEIRA DE EUCALIPTO PARA SERRARIA, São Paulo, 1985. Anais. Piracicaba: IPEF;IPT;IUFRO;ESALQ, 1995. p. 20-30,

COUTO, L., BRANDI, R.M., CONDE, A.R. et al. Influência do espaçamento no crescimento do Eucalyptus urophylla, de origem híbrida, cultivado na região de Coronel Fabriciano, MG. Revista Árvore, v.1,n.2,p.57-71, 1977.

CRÊSPO, E. A. Tensão de crescimento e suas conseqüências, controláveis e não acontroláveis, no desdobro e secagem do Eucalyptus grandis e E. saligna. Muell. Piracicaba, 2000. 119p. Dissertação (Mestrado) - Escola superior de Agricultura "Luiz de Queiroz", Universidade de São Paulo.

CRUZ, C. R., LIMA, J.T., MUNIZ, G. I. B. Variações dentro das árvores e entre clones das propriedades físicas e mecânicas de híbridos de Eucalyptus. Scientia Forestalis, n.64,p.33-47,2003.

DANIEL, T.W., HELMS, J.A., BACKER, F.S. Principles of silviculture. New York: McGraw-Hill, 1979. 492 p.

DEL MENEZZI, C. H. Utilização de um método combinado de desdobro e secagem para a produção de madeira serrada de Eucalyptus grandis Hill ex-Maiden E E. cloeziana F. Muell. Piracicaba, 1999. 77p. Dissertação (Mestrado) - Escola superior de Agricultura "Luiz de Queiroz", Universidade de São Paulo.

DINWOODIE, J. M. Growth stresses in timber - a review of literature. Forestry, v.39,n.2,p.162-170, 1966. 
DONALD, D. G. M.; SCHUTZ, D. J. The response of Eucalyptus to fertilizer application at planting: the Louw's Creek trial. South Áfrican Forestry Journal, n.102,p.23-28, 1977.

DUNISCH, O.; BAUCH, J.; MULLER, M. et al. Subcellular quantitative determination of $\mathrm{K}$ and $\mathrm{Ca}$ in phloem, cambium, and xylem cells of spruce (Picea abies [L.] Karst.) during arlywood and latewood formation. Holzforschung, v.52,n.6,p.582-588, 1998.

FERNANDES, P. S. Variações de densidade da madeira e suas relações com as tensões de crescimento em progênies de Eucalyptus urophylla S. T. Blake. Piracicaba, 1982. 85p. Dissertação (Mestrado) - Escola superior de Agricultura "Luiz de Queiroz", Universidade de São Paulo.

FERNANDES, P. S.; FLORSHEIM, S. M. B.; ROCHA, F. T. et al. Tensões de crescimento em procedências de Eucalyptus grandis Hill Ex Maiden e suas relações com as características das fibras e densidade básica. Revista do Instituto Florestal, v.1,n.1,p.215-234,1989.

FERRAND, J. CH. Growth stresses and silviculture of eucalypts, Australian Forest Research, v.13,n.1,p.75-81,1983.

FERREIRA, M. Escolha de espécies de eucalipto. Circular Técnica - IPEF, n.47, p.29, 1979,

FERREIRA, M. ; KAGEYAMA, P. Y. Melhoramento genético da densidade da madeira de eucalipto. Silvicultura, n.14,p.148-152, 1978.

FOELKEL, C.E.B., MORA, E., MENOCHELLI, S. Densidade básica: sua verdadeira utilidade como índice de qualidade da madeira de eucalipto para produção de celulose. O papel, v.53,n.5,p.35-40, 1992.

FREITAS, A. R.; BRITO NETO, O. Os avanços tecnológicos no processamento e uso de produtos florestais: produção de madeira serrada de eucalipto. In: CONGRESSO FLORESTAL BRASILEIRO, 7. Curitiba, 1993. Anais. Curitiba: SBS;SBEF, 1993, v.3, p. 293-295.

GAIOTTO, M. R. Avaliação da madeira de Eucalyptus saligna e Eucalyptus urophylla para produção de lâmina. Piracicaba, 1993. 119 p. Dissertação (Mestrado) - Escola Superior de Agricultura "Luiz de Queiroz", Universidade de São Paulo.

GARCIA, J.N. Estado de tensão em árvores e de deformação em peças de madeira serrada. São Paulo, 1992. 243p. Tese (Doutorado) - Escola Politécnica, Universidade de São Paulo. 
GARCIA, J.N. Técnicas de Desdobro de Eucalipto. In: SEMINÁRIO INTERNACIONAL E UTILIZAÇÃO DA MADEIRA DE EUCALIPTO PARA SERRARIA, São Paulo, 1995. Anais. Piracicaba: IPEF;IPT;IUFRO;ESALQ, 1995. p. 59-67.

GARCIA, J.N. Gains end losses an sawn wood yield and quality thorough forest improvement, management and sawing strategies. In: INTERNATIONAL SYMPOSIUM EUCALYPTUS PLANTATIONS, Guangzhou, 2002. Proceedings. Guangzhou: WORLD SCIENTIFIC, 2002 p. 292-403.

GARCIA, J.N.; LIMA, I.L. DE. Log end splitting and improvement in sawing Eucalyptus grandis. In: THE FUTURE OF EUCALYPTS FOR WOOD PRODUCTS, Launceston, 2000. Proceedings. Launceston: IUFRO, 2000 p. 113-24.

GARCIA, S.L.R. Importância de características de crescimento, de qualidade da madeira e da polpa na diversidade genética de clones de eucalipto. Viçosa, 1998. 103 p. Dissertação (Mestrado) - Universidade Federal de Viçosa.

HANS, A. S.; BURLEY, J.; WILLIAMSON, P. Wood quality in Eucalyptus grandis (Hill) Maiden grown in Zambia. Holzforschung, v.26,n.4,p.138-141, 1972.

HASELEIN, C. R.; BERGER, R.; GOULART, M.; et al. Propriedades de flexão estática da madeira e umidade e a $12 \%$ de umidade de um clone de Eucalyptus saligna Smith sob efeito do espaçamento e da adubação. Ciência Florestal, v.12,n.2,p.147-152, 2002.

HARRIS, J. M. Effect of rapid growth on wood processing. In: WORD CONGRESS, 17., Japan, 1981. Proceedings., Japan: IUFRO, 1981. p. 117-125.

HIGGS, M.L.; RUDMAN, P. The effects of fertilizing and thinning on wood properties of E. regnans. Appita, v.27,n.1,p.51-55,1973.

HILLIS W. H.; BROWN, A. G. Eucaliptos for wood production. Melbourne: CSIRO. 1984. 434p.

INSTITUTO BRASILEIRO DE DESENVOLVIMENTO FLORESTAL - Norma para medição e classificação de toras de madeira de folhosas. Brasília, 1984. 50 p.

INSTITUTO DE PESQUISA E ESTUDOS FLORESTAIS. Influência da espécie, do espaçamento e da adubação na produção de madeira de eucalipto. Piracicaba: IPEF, 1976. 4 p. (Circular Técnica, 12)

JACOB, W.S., BALLONI, E.A. Efeitos da fertilização na qualidade da madeira. Boletim Informativo IPEF, v.6,n.20, p.1-12, 1978. 
JACOBS, M. R. The growth of woody stems. Bulletin Commonwealth Forests Bureau, n., 28,p. 67, 1945.

JANKOWSKY, I. P. Madeira juvenil, formação e aproveitamento industrial. IPEF. Circular técnica, n. 81, p. 18, 1979.

JANKOWSKY, I. P. Equipamentos e processos para secagem de madeiras. In: SEMINÁRIO INTERNACIONAL E UTILIZAÇÃO DA MADEIRA DE EUCALIPTO PARA SERRARIA, São Paulo, 1995. Anais. Piracicaba: IPEF;IPT;IUFRO;ESALQ, 1995. p. 109-118.

JORGE, F; PEREIRA, M. Influência da silvicultura na qualidade da madeira. Revista Florestal, v.12,n.2,p.27-31,1998.

KELLISON, R.C., RUSS, L., FREDERICK, D.J. Effect of silvicultural practices on wood quality of southern hardwoods. Tappi Journal, v.66,n.1,p. 67-69, 1983.

KIKUTI, P., NAMIKAWA, I.S. Estudo da interação clone $x$ níveis da adubação em Eucalyptus saligna. O papel, n.3,p. 37-44, 1990.

KLEM, G. S. Quality of wood form fertilized forests, Tappi, n.51,p.99-103, 1968.

KOGA, M. E. T. Matérias-primas fibrosas. In: D' ALMEIDA, M. L. O. Celulose e papel: tecnologia da fabricação do papel. São Paulo: IPT, 2 ed. 1988, v. 1 p. 15-44.

KUBLER, H. Growth stresses in trees and related wood properties. Forestry Abstracts v.48,n.3,p.131-189. 1987.

KUCERA, B. A hypothesis relating current annual height increment to juvenile wood formation in Normay spruce. Wood and Fiber Science, v.26,n.1,p.152-167, 1994.

LAMPRECHT, H. Silvicultura nos trópicos, Berlim: GTZ, 1990. 343p

LAND, S.B.; DICKE, S.G.; TUSKAN, G.A. et al. Genetic, site, and within-tree variation in specific gravity and moisture content of young sycamore trees. Tappi Journal, v.66,n.3,p.149-153, 1983.

LARSON, P. R. Silvicultural control of the characteristics of wood used for furnish. In: Forest Biology Conference, 4. Quebec, 1967.Proceedings. Quebec: Tappi,1967, p. 143-151.

LARSON, P. R. Wood Formation and the concept of wood quality. New Haven: Bulletin Yale University: School of Forestry, n.74, p.54, 1969. 
LEWARK. S. Anatomical and physical differences between juvenile and adult wood. In: IUFRO WORD CONGRESS,18. , Iugoslavia, 1986. Proceedings. Iugoslávia: IUFRO, 1986, p. 272-281.

LIMA, I.L DE ; GARCIA, J.N.; NOGUEIRA, M. C. S. - Influência do desbaste nas tensões de crescimento de $E$. grandis Hill ex-Maiden. Scientia Forestalis, n.58,p.111-125, 2000.(a)

LIMA, I.L DE; GARCIA, J.N.; PIEDADE, S. M. DE S. - Rachadura de extremidade de tora e suas implicações nas rachaduras da madeira serrada. Scientia Forestalis, n.61,p.13-24, 2002.

LIMA, J. T; BREESE, M. C.; CAHALAN, C. M. - Variation in wood density and mechanical properties in Eucalyptus clones. In: THE FUTURE OF EUCALYPTS FOR WOOD PRODUCTS, Launceston, 2000. Proceedings. Launceston: IUFRO, 2000, p. 282-290. (b)

LISBOA, C. D. J. Estudo das tensões de crescimento em toras de Eucalyptus grandis Hill, ex Maidan, Floresta, v.23,n.1/2,p.82-3, 1993.

LUCKHOFF H. A. Pruning of E.grandis. Forestry in South Africa, n.8,p.75-85,1967.

MALAN, F. S. The control of end splitting in sawlogs: A short literature review. South African Forestry Journal, n.109,p.14-79, 1979.

MALAN,F.S. Studies on the phenotypic variation in growth stress intensity and its association with tree and wood properties of South African grown Eucalyptus grandis (Hill ex Maiden). Stellenbosch, 1984, 258 Thesis (Ph.D.) - University of Stellenbosch.

MALAN, F. S. Relationships between Growth Stress and Some Tree Characteristics in South African Grown Eucalyptus grandis. South African Forestry Journal, n.144,p. 43-46, 1988.

MALAN, F. S. Variation, association and inheritance of juvenile wood properties of Eucalyptus grandis Hill ex Maiden with special reference to the effect of rate of growth. South African Forestry Journal,n.157, p.16-23, 1991.

MALAN, F. S. Eucalipts improvement for lumber production. In: SEMINÁRIO INTERNACIONAL E UTILIZAÇÃO DA MADEIRA DE EUCALIPTO PARA SERRARIA, São Paulo, 1995. Anais. Piracicaba: IPEF;IPT;IUFRO;ESALQ, 1995. p. 1-19.

MALAN, F. S. The wood properties and sawn board quality of the Eucalyptus grandis $\mathrm{x}$ E. urophylla hybrid. South African Forestry Journal,n.188,p. 29-35, 2000. 
MALAN, F. S.; HOON, M. Effect of initial spacing and thinning on some wood properties of Eucalyptus grandis. South African Forestry Journal, n.163,p.13-20, 1992.

MALAVOLTA, E. Elementos da nutrição mineral de plantas. São Paulo: Agronômica Ceres, 1980. 251p.

MARCH, E. K. ; BURGER, T. F. The relation between silvicultural treatment and timber quality in Eucalyptus grandis (Hill) ex-maiden Forestry in South África, n.8,p.63$74,1967$.

MATTHECK, C.; WALTHER,F. A new felling technique to avoid end-splitting of deciduos trees. Karisruhe, Germany: Karisruhe Nuclear Research Centre, Institute for Materials Research II, 1991. p. 110-113.

MEGRAW, R. A. Wood quality factores in Loblolly pine. Atlanta: Tappi Press, 1985. $102 p$.

MELLO, H.A. Efeitos da adubação mineral sobre as qualidades da madeira. Piracicaba: IPEF/ESALQ, 1968. 15p. (Relatório Técnico)

MELLO, H.A.; MASCARENHAS SOBRINHO, J., SIMÕES, J.W. et al. Resultados da aplicação de fertilizantes minerais na produção de madeira de Eucalyptus saligna Sm. Em solos de cerrado do Estado de S. Paulo. IPEF, n.1,p.7-26, 1970.

MESSINA, M. G. Response of Eucalyptus regnans F. Muell. to thinning and urea fertilization in New Zealand. Forest Ecology and Management ,v,51,n.4,p.:269-83, 1992

MIGLIORINI, A.J. Variação da densidade básica da madeira de Eucalyptus grandis W. Hill ex Maiden em função de diferentes níveis de produtividade da floresta. Piracicaba, 1986, 100p. Dissertação (Mestrado) - Escola superior de Agricultura "Luiz de Queiroz", Universidade de São Paulo.

MIRANDA, M. J. A. C. Estudo da influência do espaçamento de plantio de Eucalyptus saligna Smith no rendimento em madeira serrada, nas condições verde e seca. Piracicaba, 1997. 177p. Dissertação (Mestrado) - Escola superior de Agricultura "Luiz de Queiroz", Universidade de São Paulo.

MIRANDA, M. J. A. C.; NAHUZ, M. A. R. Estudo da influência do espaçamento de plantio de Eucalyptus saligna Smith nos índices de rachamento após o desdobro e após a secagem. Scientia Forestalis, n.55,p.107-116, 1999. 
NICHOLSON, J. E. Growth stress differences in Eucalypts. Forest Science, v.19,n.3,p.169-174. 1973.

OKUYAMA, T. Assessment of growth stresses and peripheral strains in standing trees. In: CONFERÊNCIA IUFRO SOBRE SILVICULTURA E MELHORAMENTO DE EUCALIPTOS, Salvador, 1997, v.3, p.1-14.

OLIVEIRA, J. T. S. Problemas e oportunidades com a utilização da madeira de eucalipto. In: WORKSHOP SOBRE TÉCNICAS DE ABATE, PROCESSAMENTO E UTILIZAÇÃO DA MADEIRA DE EUCALIPTO, Viçosa, 1999. Anais. Viçosa: UFV;DEF;SIF;IEF, 1999. p.39-52.

OLIVEIRA, J. T. S. Caracterização da madeira de eucalipto para a construção civil. São Paulo, 1997, 426p. Tese (Doutorado)- Escola Politécnica, Universidade de São Paulo.

OPIE, J. E.; CURTIN, R. A.; INCOLL, W. D. Stand management. In: HILLIS, W.; BROWN, A. G. Eucaliptos for wood production. Melborne: CSIRO, 1984. 434p.

PANSHIN, A.J.; ZEEUW, C. Textbook of wood technology. New York: McGraw-Hill, 1964. v.1. 705 p.

PONCE, R. H Perspectivas do eucalipto na substituição de madeiras nativas. In: SEMADER - SEMINÁRIO SOBRE PROCESSAMENTO E UTILIZAÇÃO DE MADEIRAS DE REFLORESTAMENTO, 4. Curitiba, 1996. Anais, Curitiba: ABPM,1996. p. 41-46. .

PURNELL, R. C. Variation in wood properties of Eucalyptus nites in a Provenance Trial on the Eastern Transvaal Highveld in South Africa. South African Forestry Journal n.144,p.10-22, 1988.

RAYMOND C. A.; MUNERI A. Effect of fertilizer on wood properties of Eucalyptus globulus. Canadian Journal of Forest Research. v. 30, n. 1;p. 136-144,2000.

REVISTA DA MADEIRA. Exportações batem recorde de US\$ 5,6 bilhões. Revista da madeira, Edição especial, p. 6-14, jun.,2004.

REZENDE, M.A.; SAGLIETTI, J.R.C., CHAVES, R. Variação da massa específica da madeira de Eucalyptus grandis aos 8 anos de idade em função de diferentes níveis de produtividade. Scientia Forestalis, n.53,p.71-78, 1998. 
ROCHA, M .P. Eucalyptus grandis Hill ex Maiden e Eucalyptus dunnii Maiden como fontes de matéria prima para serrarias. Curitiba, 2000. 185p. Tese (Doutorado). Universidade Federal do Paraná.

SANTOS, P. E. T. dos. Avaliação de características tecnológicas de madeira para serraria em progênies de polinização aberta de eucalipto e implicações para o melhoramento genético. Piracicaba, 2002. 153p. Tese (Doutorado) - Escola Superior de Agricultura "Luiz de Queiroz", Universidade de São Paulo.

SCANAVACA JUNIOR, L. Caracterização silvicultural, botânica e tecnológica do Eucalyptus urophylla S. T. Blake e de seu potencial para utilização em serraria. Piracicaba, 2001. 108p. Dissertação (Mestrado) - Escola Superior de Agricultura "Luiz de Queiroz" Universidade de São Paulo.

SCANAVACA JUNIOR L.; GARCIA, J. N. Rendimento em madeira serrada de Eucalyptus urophylla, Scientia Forestalis, n.63,p.33-43, 2003.

SCHACHT, L.; GARCIA , J. N. Variação entre e intra clones nas rachaduras de topo em Eucalyptus urophylla. In: IUFRO CONFERENCE ON SILVICULTURE AND IMPROVEMENT OF EUCALYPTUS, Salvador, 1997. Proceedings. Colombo: EMBRAPA;IPEF;SIF;SEAGRI-DDF, 1997. p.401-404.

SCHACHT, L.; GARCIA, J. N.; VENCOVSKY, R. Variação genética de indicadores de tensão de crescimento em clones de Eucalyptus urophylla. Scientia Forestalis, n.54,p.55-68, 1998.

SCHÖNAU, A.P.G. The effect of planting espacement and pruning on growth, yield and timber density of Eucalyptus grandis. South African Forestry Journal, n.88,p.1623, 1974.

SCHÖNAU, A. P. G.; COETZEE, J. Initial spacing, stand density and thinning in eucalypt plantations. Forest Ecology and Management, n.29,p.245-266, 1989.

SELLA, R. L. Técnicas silviculturais e de exploração para a obtenção de madeira de qualidade para a laminação e serraria In: Seminário madeira de eucalipto: tendências e usos. Curitiba, 2001. Anais, Curitiba: FUPEF, 2001, p.19-24.

SGARBI, F.; BRITO, J.O.; SILVEIRA, R.L.V.A. Características químicas e físicas e dimensões das fibras da madeira juvenil do híbrido de Eucalyptus grandis $\mathrm{x}$ Eucalyptus urophylla, cultivado na omissão de macronutrientes e boro em solução. Revista Árvore, v.24,n.3,p.323-331,2000. 
SHIELD, E. D. Plantation grown eucalypts: Utilization for lumber and rotary veneers primary conversion. In: SEMINÁRIO INTERNACIONAL E UTILIZAÇÃO DA MADEIRA DE EUCALIPTO PARA SERRARIA, São Paulo, 1995. Anais. Piracicaba: IPEF;IPT;IUFRO;ESALQ, 1995. p. 133-39.

SILVA, J. C. Características da madeira de eucalipto. Revista da Madeira, n.52,p. 30-8, 2000.

SILVA,J.C. Caracterização da madeira de Eucalyptus grandis Hill ex. Maiden, de diferentes idades, visando a sua utilização na indústria moveleira. Curitiba, 2002, 160p. Tese (Doutorado) - Universidade Federal do Paraná.

SILVEIRA R. L. V. de A. Efeito do potássio no crescimento, nas concentrações dos nutrientes e nas características da madeira juvenil de progênies de Eucalyptus grandis w. hill ex maiden cultivadas em solução nutritiva. Piracicaba, 2000. 169p. Tese (Doutorado) - Escola Superior de Agricultura "Luiz de Queiroz", Universidade de São Paulo.

STAPE, J. L. Manejo de Eucalyptus spp para desdobro frente aos avanços silviculturais de produção. In: SEMADER - SEMINÁRIO SOBRE PROCESSAMENTO E UTILIZAÇÃO DE MADEIRAS DE REFLORESTAMENTO, 4. Curitiba, 1996. Anais, Curitiba: ABPM,1996. p. 17-28.

STAPE, J. L.; MARTINI, E. L. Desbaste de Eucalyptus: Opção de manejo para áreas com limitações ambientais ao corte raso. In: ENCONTRO TÉCNICO FLORESTAL, 5, Belo Horizonte, 1991. Anais. Belo Horizonte: ABRACAVE, 1991, p. 30-50.

TEIXEIRA, M.L.; SOUZA, A. N.; SOUZA, M. A. M.; et al. Avaliação da qualidade da madeira de seringueira Hevea sp para produção de celulose e carvão vegetal. In: CONGRESSO FLORESTAL PANAMERICANO, 1. Curitiba, 1993. Anais. São Paulo: SBS/SBEF, V.2,1993, p. 588-90.

TRUGILHO, P.F.; LIMA, T. J.; SILVA, S. C. da S; et al. Relação entre as rachaduras de toras e tábuas com a tenção de crescimento. In: Congresso Florestal Brasileiro, 8. São Paulo: SBS, 2003. (COMPACT DISC)

TRUGILHO, P.F.; MENDES, L. M.; SILVA, J. R. M. da; et al. Influência da idade nas características físicas, químicas e anatômicas da madeira de Eucalyptus grandis. In: IUFRO CONFERENCE ON SILVICULTURE AND IMPROVEMENT OF EUCALYPTUS, Salvador, $1997 . \quad$ Proceedings. Colombo: EMBRAPA;IPEF;SIF;SEAGRI-DDF, 1997. p.269-275. 
TRUGILHO,P.F.; LIMA,J.T.; ROSADO,S.C.S.; MENDES,L.M.; et al. Avaliação da tensão de crescimento em clones de Eucalyptus. Floresta e Ambiente, v.9,n.1,p.38-44, 2002.

VALERI, S.V., AGUIAR, I.B., BANZATTO, D.A. et al. Variação da densidade básica da madeira de Eucalyptus grandis Hill ex Maiden com a altura do caule e aplicação de fósforo e calcário dolomítico. In: CONGRESSO FLORESTAL BRASILEIRO, 6. Campos do Jordão, SP, 1990. Anais. São Paulo: SBS/SBEF, 1990. p.746-750.

VAN WYK , J. L. Hardwood sawmilling can have a bright future in South Africa South African Forestry Journal, n.107,p. 47-53. 1978.

VIANA, L. O. Experiência do SENAI/CETMAN com Secagem de Eucalipto. In: SEMADER - SEMINÁRIO SOBRE PROCESSAMENTO E UTILIZAÇÃO DE MADEIRAS DE REFLORESTAMENTO, 4. Curitiba, 1996. Anais, Curitiba: ABPM,1996. p. 119-130.

VIGNERON,P.; GERARD,J.; BOUVET,J.M. Relationship between basic density and growth in a fertilization trial with clones of Eucalyptus hybrids in Congo. In: POTTS,B.M.; BORRALHO,N.M.G.; REID,J.B.; et al. EUCALYPT PLANTATIONS: IMPROVING FIBRE YIELD AND QUALITY. Hobart, 1995. Proceedings, Sandy Bay: CRCTHF/IUFRO, 1995. v.1, p.68-72.

VILLIERS, A. M. de. Utilization problems with some Eucalypts in South Africa. In: IUFRO-5. South África, 1973. Meeting, South África: IUFRO, 1973. v.2,p.238-255.

VITAL , B.R. Métodos de determinação da densidade da madeira. Boletim Técnico SIF, n.1,p.1-21, 1984.

VITAL, B.R. Reflexos da fertilização mineral na qualidade e na utilização da madeira. In: BARROS, N.F.; NOVAIS, R.F. Relação solo-eucalipto. Viçosa: Folha de Viçosa, 1990. p.323-330.

WATANABE, H. A. A study of the origin of longitudinal growth stress in tree stems. In: INTEERNATIONAL UNION OF FORESTRY RESEARCH ORGANIZATIONS IUFRO MEETING SECTION 41. Melboune, 1965. Proceedings. Melbourne: IUFRO;CSIRO, 1965. v., 17p.

WAUGH, G. Sawing of Young fast growing eucalypts. In: Seminário internacional sobre produtos sólidos de Madeira de alta tecnologia. In:Encontro sobre tecnologias apropriadas de desdobro, secagem e utilização da madeira de eucalipto, 1. Belo Horizonte, 1998. Anais. Viçosa:SIF/UFV/DEF, 1998, p. 69-81. 
WIKINS, A. P. Nature and origin of growth stresses in trees. Australian Forestry, v.49,n.1, p. 56-62,1986.

WILHELMY, V.; KUBLER, H. Stresses and checks in log ends from relieved growth stresses, Wood Science, v. 6,n.2,p.136-42, 1973.

WILKES, J. The influence of rate of growth on the density and heartwood extractives content in eucalypt species. Wood Science and Technology, v.18,n.2,p. 113-20, 1984.

WILKES, J.; ABBOTT, D. Influence of the rate of tree growth on the anatomy of eucalypt species, Appita, v.37,n.3,p.36-37, 1983.

WILKINS, A. P. KITAHARA R. Silvicultural treatments and associated growth rates, growth strains and wood properties in 12.5-year-old Eucalyptus grandis, Australian Forestry, v.54,n.1/ 2,p.99-104, 1991.

WILKINS, A. P.; HORNE, R. Wood-density variation of young plantation grown Eucalyptus grandis in response to silvicultural treatments, Forest Ecology and Management, v.40,n.1/2,p.39-50,1991.

WILSON, P. J. Splitting studies on logs of Eucalyptus macarthurii, E. elata, and E. radiata. INSTITUTE FOR COMMERCIAL FORESTRY RESERCH, Pietermaritzburg, 1985. Annual Report, Pietermaritzburg: University of Natal, 1985, p. 135-142.

YAO, J. Relations between height and growth stresses within and among white ash, water oak, and shagbark hickory. Wood Science, v.11,n.4,p.:246-51, 1979.

ZOBEL, B. Wood quality from fast-grown plantations. Tappi, v.64,n.1,p.17-74, 1981.

ZOBEL, B. Silvicultural effects on wood properties. IPEF International, n.2,p.31-38, 1992.

ZOBEL , B.J., JETT, J.B. Genetics of wood production. Berlin: Springer-Verlag, 1995. $337 \mathrm{p}$. 